\title{
Science Teaching Efficacy Beliefs and the Lived Experience of Preservice Elementary Teachers
}

Karen A. Kettler

West Virginia University

Follow this and additional works at: https://researchrepository.wvu.edu/etd

\section{Recommended Citation}

Kettler, Karen A., "Science Teaching Efficacy Beliefs and the Lived Experience of Preservice Elementary Teachers" (2013). Graduate Theses, Dissertations, and Problem Reports. 358.

https://researchrepository.wvu.edu/etd/358

This Dissertation is protected by copyright and/or related rights. It has been brought to you by the The Research Repository @ WVU with permission from the rights-holder(s). You are free to use this Dissertation in any way that is permitted by the copyright and related rights legislation that applies to your use. For other uses you must obtain permission from the rights-holder(s) directly, unless additional rights are indicated by a Creative Commons license in the record and/ or on the work itself. This Dissertation has been accepted for inclusion in WVU Graduate Theses, Dissertations, and Problem Reports collection by an authorized administrator of The Research Repository @ WVU.

For more information, please contact researchrepository@mail.wvu.edu. 
Science Teaching Efficacy Beliefs and the Lived Experience of Preservice Elementary Teachers

\author{
Karen A. Kettler
}

Dissertation submitted to the College of Human Resources and Education at West Virginia University in partial fulfillment of the requirements for the degree of

Doctor of Education

in

Curriculum and Instruction

Patricia Obenauf, Ed. D., Chair

Jeffrey S. Carver, Ed. D.

Sharon Hayes, Ph. D.

James Rye, Ph. D.

Keely Camden, Ed. D.

Department of Curriculum and Instruction/Literacy Studies

Morgantown, WV 2013

Key Words: Science Efficacy; Phenomenology; Science Education

Copyright 2013 Karen A. Kettler 


\section{ABSTRACT \\ Science Teaching Efficacy Beliefs and the Lived Experience of Preservice Elementary}

\section{Teachers}

\section{Karen A. Kettler}

The current study utilized a mixed methods approach to examine the science teaching efficacy beliefs (STEB) of preservice elementary teachers as they participated in a Science Methods course. The following questions were addressed using quantitative survey data and qualitative interviews: What are the STEB of preservice elementary teachers as they progress through a Science Methods course?; How do the STEB of preservice elementary teachers with higher and lower personal science teaching efficacy (PSTE) beliefs change as they progress through a Science Methods course?; What is the nature of the lived experiences of preservice elementary teachers with higher and lower PSTE beliefs as they progress through a Science Methods course?; and How does the meaning developed during the lived experience of preservice elementary teachers with higher and lower PSTE beliefs influence their STEB? The participants $(\mathrm{n}=21)$ included preservice elementary teachers registered for a Science Methods course as part of the "Block" semester, during their final year of teacher preparation prior to the student teaching experience. Quantitative data was obtained via Science Teaching Efficacy Belief Instrument- form B (STEBI-B) surveys taken at the beginning and end of the Science Methods course. This data was utilized to categorize participants into low, medium, and high efficacy groups, depending on how they scored in relation to one another. Qualitative data was obtained concurrently, through in-depth interviews with four "lower" efficacy participants and four "higher" efficacy participants, and was conducted after the "pre" survey and before the "post" survey, utilizing transcendental phenomenological methodology. Results showed a significant difference between pre- and post- survey data, indicating that the participants, as a whole, experienced an increase in PSTE during the Science Methods course $(\mathrm{p}<0.001)$. An examination of the specific subgroups (low, medium, and high efficacy) show a significant difference between the pre- and post- PSTE scores for individuals with low $(\mathrm{p}=0.005)$ and medium $(\mathrm{p}=$ $0.004)$ efficacy, but not those with high efficacy $(p=0.184)$. The phenomenological interview data revealed five themes with regard to the experience of those with lower and higher efficacy: The power of realistic learning experiences, informal field experiences; The power of authentic teaching experiences; Modeling, the second-hand experience; The necessity of forming relationships; and Assessments and feedback as meaningful work. The composite textural descriptions of interview data revealed that while low efficacy participants found the course "boring" and "repetitive," and they found the assessments and feedback ineffectual, they enjoyed specific aspects of the course, including the field and teaching experiences, as they were more receptive to these experiences. The structural descriptions of the low efficacy participants revealed that their previous negative experiences with science educators impacted their perceptions of their experiences in the course and their beliefs about science education. The high efficacy participants found the activities in the course to be "frustrating," "random," and "pointless," as these individuals had experienced similar activities during previous science courses. Because the high efficacy participants had had generally positive previous experiences with science education and had high expectations for both the Science Methods course and the 
teacher, they were extremely critical of the course and were less receptive to learning during course activities. The overall essence of the experience for both efficacy groups was a need for connectedness with the science content, the assessments, the elementary students, and the teacher of the course. 


\section{TABLE OF CONTENTS}

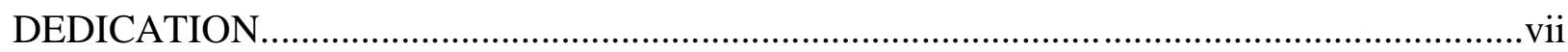

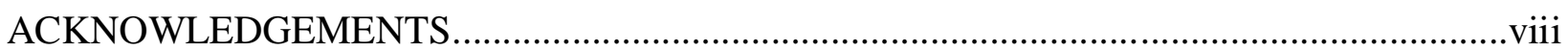

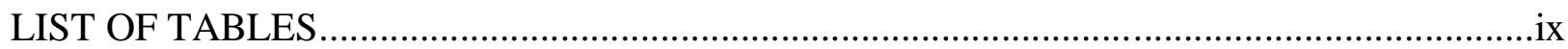

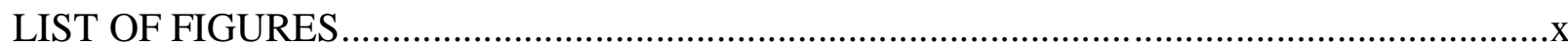

\section{CHAPTER}

1. INTRODUCTION TO THE RESEARCH

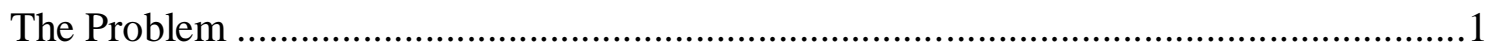

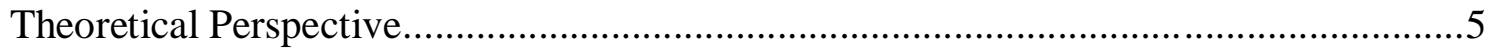

Preservice Teacher Preparation...................................................................

Purpose

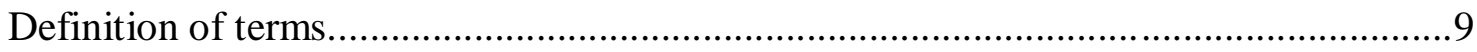

2. REVIEW OF LITERATURE

Social cognitive theory and the Construct of Self-Efficacy....................................11

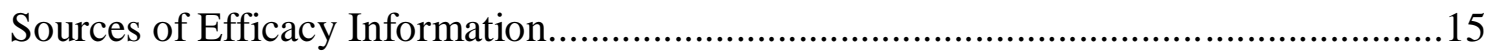

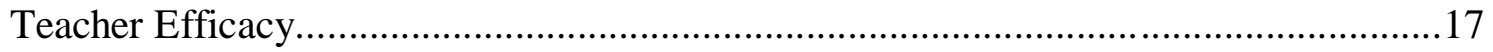

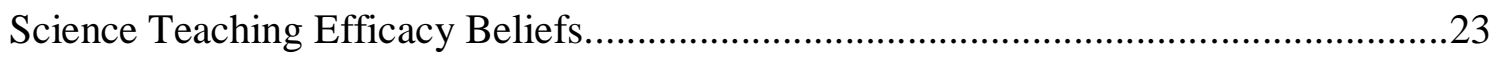

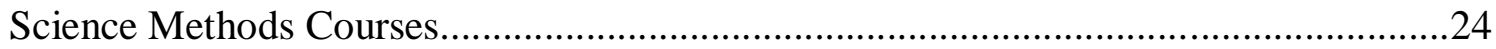

Preservice Teacher Education after the Science Methods Course: Student Teaching

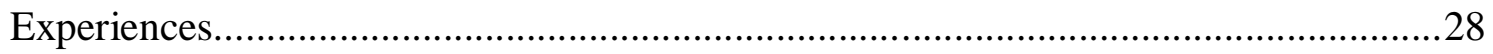

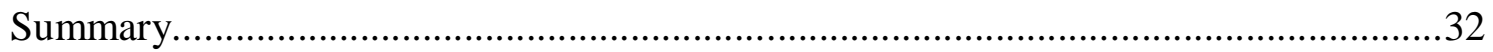

\section{METHODOLOGY}

Study Overview 


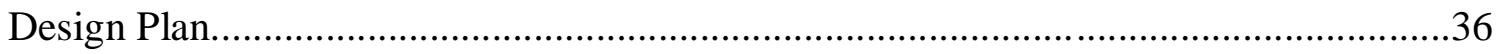

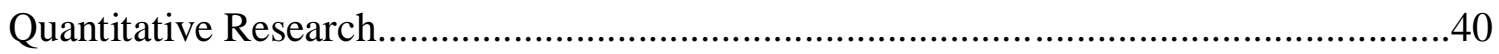



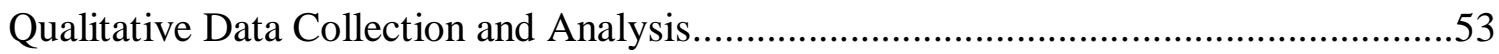

Mixed Methods Analysis and Data Integration...........................................................59

\section{RESULTS}

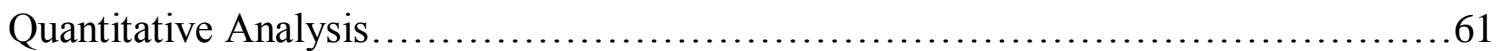

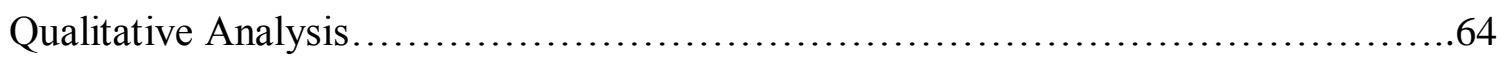

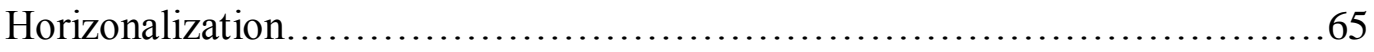

Themes or Meaning Units................................................66

Textual and Structural Descriptions....................................... 80

The Experience for Low Efficacy Participants..........................81

The Experience for High Efficacy Participants.........................92

Composite Textual Descriptions: What did Low Efficacy Participants Experience

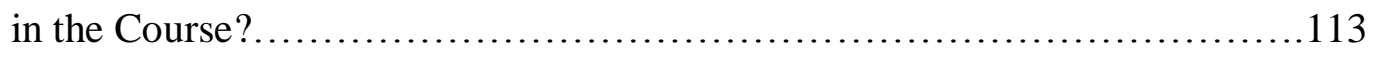

Composite Structural Descriptions: How did Low Efficacy Participants

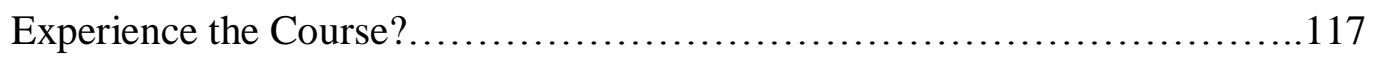

Composite Textual Descriptions: What did High Efficacy Participants Experience

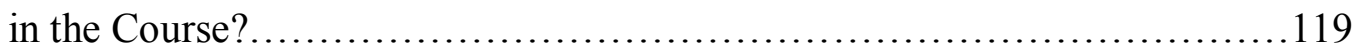

Composite Structural Descriptions: How did High Efficacy Participants

Experience the Course?............................................... 123

\section{DISCUSSION}

The Essence of the Experience. 
Sources of Efficacy in the Science Methods Course..............................129

Expectations and Learning.............................................. 134

Previous Experiences and the Conscious Mind..............................135

Contributions of the Current Study to Teacher Preparation Programs.................137

Creating Connectedness in Teacher Preparation Programs.......................... 142

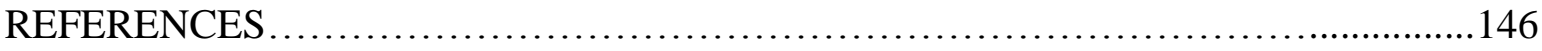

APPENDICES

Appendix A: Participant Cover Letter..........................................153

Appendix B: Demographic Survey.......................................... 155

Appendix C: STEBI-B Survey........................................... 156

Appendix D: Focused Life History Interview Questions...........................158

Appendix E: Post Science Methods Course Interview Questions........................159

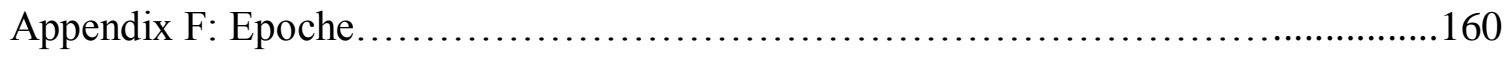

Appendix G: Significant Statement Tables....................................... 163 


\section{DEDICATION}

To my husband, Kevin, the one who calms my crazy. 


\section{ACKNOWLEDGEMENTS}

Completing my doctorate has been a dream of mine since I was a child, and there are many people whom have helped me along the way. Specifically, I was extremely appreciative to Dr. Jeffrey Carver for sharing his wisdom about the complexities of higher education when it was needed, and for providing effective feedback and encouragement throughout this process. I want to thank Dr. Sharon Hayes for helping me to better understand transcendental phenomenology, which was not an easy task. In addition, I want to thank Dr. Pat Obenauf, Dr. Jim Rye, and Dr. Keely Camden for their helpful comments and support.

I am forever grateful to West Liberty University’s “Joe of all trades,” Mr. E. Joseph Nolan IV, for his computer and statistical expertise. His help in creating my survey and educating me in new ways to analyze the data were invaluable.

I would also like to thank Dr. Zachary Loughman for giving me the "friendly" shove I needed to finish my doctorate and for listening to me complain (occasionally...).

Most importantly, I am grateful to my husband, Kevin, for tolerating my stress and listening to me say the words "transcendental phenomenology" while pretending to be interested. I love you so much (and I didn't mind the glazed look in your eyes when I would talk about my research). Lastly, Sebastian and Violet, my little treasures, thank you for putting up with Mommy's busy schedule! 


\section{LIST OF TABLES}

Table 1: One Way Repeated Measures Analysis of Variance Between STEBI-B Time

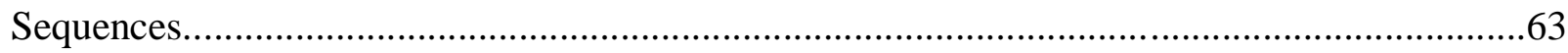

Table 2: Demographic Data for Interview Participants..................................................65

Table 3: Themes or Meaning Units and Evidence............................................................66

Table 4: Similarities and Differences between Textural and Structural Descriptions for Low and

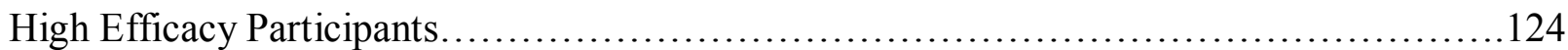




\section{LIST OF FIGURES}

Figure 1: Concurrent Nest Design with prominent qualitative data collection....................37

Figure 2: Changes in PSTE for whole group........................................................62

Figure 3: Changes in PSTE scores for efficacy subgroups ...........................................64 


\section{Chapter 1}

As a professor of Life Sciences for Preservice Elementary Teachers courses, I have noticed that many of my students struggle with both science content and pedagogy. This science content-rich course is a requirement for preservice elementary teachers and is taken prior to the Science Methods course and student teaching experience. Aside from this course, I have found that my students have had limited exposure to science content and teaching strategies as part of their higher education curriculum. Each semester, I take an informal poll as to how many students actually like science, and I have been dismayed at the lack of raised hands. Recently, I assigned a teaching project in which the students worked in groups to teach science content to their peers. Each group was randomly assigned a topic relevant to the course, and I required that the lesson should include active learning strategies. Observations of their interactions within their teaching groups and the implementation of their science lessons revealed a high level of anxiety in many students. Several students lacked preparation skills, and others lacked confidence in themselves to carry out the assignment. This caused me to wonder about the origins of confidence in preservice teachers. Specifically, I questioned what experiences can increase or decrease their beliefs in their abilities to complete a task and perform the task well, and what do these experiences mean to individuals who struggle with or exude confidence in their abilities to teach?

\section{The Problem}

Current state of science education. There have been concerns in past decades over the state of science education in elementary schools, particularly with regard to the quality and time spent on science content (Gee, 1996; Tilgner, 1990). The United States is lagging behind other countries in terms of science knowledge, as is evident in the low science scores form the Trends 
in International Mathematics and Science Study (Bursal, 2012). These findings reinforce previous concerns about the quality of elementary science education (Jang, 2004), as well as the quality of preservice science teacher education. Previous studies have found that many teacher programs are deficient in the preparation of preservice teachers in the area of science (Levitt, 2001; McDonnough \& Matkins, 2010; Plourde, 2002; Wenner, 1993). This deficiency in preparation for science teaching has led to poor teacher attitudes toward science and less time dedicated to science education in elementary schools (Brand \& Wilkins, 2007; Levitt, 2001; Palmer, 2001; Wenner, 1993). One of the causes of this deficit is that many teacher education programs have focused mostly on science curriculum and less concern has been given to learning and pedagogy (Hurd, 1986; Kelly \& Ponder, 1997). In addition, science anxiety may be a contributing factor, as compared to other majors, education majors have shown much higher levels of science anxiety (Udo, Ramsey, \& Mallow, 2004), which may lead to limited time spent on science content in elementary classrooms (Bursal, 2012).

Science reform efforts. There have been several studies concerning science education reform which have emphasized the significance of teacher learning in promoting reform (Anderson, 1994, 1995, 1996). According to Abell, Park Rogers, Hanuscin, Lee, and Gagnon (2009), content knowledge alone is not sufficient for effective science education, as "science teachers must also have knowledge about science learners, curriculum, instructional strategies, and assessment through which they transform their science knowledge into effective teaching and learning" (p. 79). In order for curriculum reform to occur, teachers must be educated in science content pedagogy and gain an understanding of student learning as part of their teacher preparation program (Anderson \& Smith, 1987; Stepans, McClung, \& Beiswenger, 1995; Tobin, Tippins, \& Gallard, 1994). 
The American Association for the Advancement of Science (AAAS) (1993), the National Science Teachers Association (NSTA) (1992), and the National Research Council (NRC) (1996, 2011) are science education organizations that have aided in science education reform by constucting goals and a framework for primary and secondary classrooms, as well as benchmarks for teacher preparation. For example, the NRC's (2007) Taking Science to School report summarizes research findings on science learning and provides recommendations about effective science teaching in grades K-8. The goals of such organizations are to help students conduct scientific inquiries and gain an understanding of the nature of science, and to aide teachers in developing and implementing these types of educational experiences (AAAS, 1993; NRC, 1996; NSTA, 1992). Studies of preservice and inservice teacher experiences with science have found that many individuals struggle with science content, do not feel prepared to teach science at the elementary level, and have difficulty implementing reform techniques in the classroom (Kelly, 2000; Yilmaz \& Huyuguzel Cavas, 2008). However, in terms of science education reform, Gunning and Mensah (2011) believe that "elementary school teachers are the key to reform" (p. 171).

Preservice teacher preparation. Preservice elementary teacher perparation programs vary with regard to state certification requirements (Blank \& Dalkilic, 1992); however, most institutions require six to nine hours of science courses for content preparation (Kelly, 2000), and tend to be teacher-centered, lecture-oriented, fact-driven courses accompanied by cook-book laboratory exercises (NRC, 1996; Stepans et al., 1995). Preservice teachers also take a number of education courses, including foundations of education, educational psychology, language, and literacy courses (Kelly, 2000). The final years of teacher preparation include methods courses, which focus on educating preservice teachers on how to teach particular content areas, such as 
social studies, mathematics, and science, and aim to integrate content and pedagogy. The term used to describe knowledge of content and pedagogy is pedagogical content knowledge (Shulman, 1986), and with regard to science, it is "working knowledge of science that enbles the teacher to re-cast science in a way that effectively communicates understanding of the learner whether the negotiated experiences involve discussion, inquiry-based investigations, or reflective exploration and explanation" (Kelly, 2000, p. 756). The methods block of couses are followed by a culminating educational experience of student teaching in an elementary school (Kelly, 2000). As part of these courses, perservice teachers will engage in field oberservations of inservice teachers and have practicum experiences.

Instructional behavior of elementary teachers is shaped by attitudes, beliefs, and pedagogical content knowledge obtained through classroom and field experiences (Plourde, 2002; Thompson,1992; Tobin et al., 1994). It is generally believed that preservice teachers must obtain a "sufficient knowledge base coupled with pedagogical expertise" (Kelly, 2000, p. 756); however, as this study will explore, there are other factors that may effect preservice teachers' abilities to provide effective educational experiences.

Science education for preservice teachers. There are several factors that have shown to affect the quality of elementary science education and teachers' effectiveness in teaching science at the elementary level, including science content knowledge (Ramey-Gassert \& Shroyer, 1992), attitudes (Wenner, 1993), and science teaching self-efficacy beliefs (Cantrell, Young, \& Moore, 2003; Wenner, 1993). Numerous studies have found that teachers lack confidence, and possess low self-efficacy with regard to their beliefs in their capability to teach science (Appleton, 2003; Enochs \& Riggs, 1990; Riggs, 1991; Schoeneberger, 1986). This lack of confidence to effectively teach science has resulted in a lessened likelihood to teach this 
subject (Ramey-Gassert \& Shroyer, 1992). Science teaching self-efficacy beliefs of preservice teachers are the focus of the current study. In order to explore the concept of self-efficacy, I delved into Albert Bandura's Social cognitive theory and the construct of self-efficacy.

\section{Theoretical Perspective}

In an examination of literature concerning preservice elementary teacher preparation and confidence in science teaching, I came across many studies that examined the construct of selfefficacy beliefs in teaching, which are grounded in Albert Bandura's Social cognitive theory. Essentially, Bandura $(1977,1986,1997)$ posited that there is a shared relationship between environmental forces and behavioral outcomes, and that behavior is a result of environmental (external) and internal thoughts, beliefs, and feelings. He stated that "what people think, believe and feel affects how they behave" (Bandura, 1986, p. 25). Bandura (1986) believed that knowledge and skills are not enough to predict performance ability, but an individual's beliefs about their ability to perform a task and what they expect the outcome of their performance to be will dictate behavior. Self-efficacy or perceived self-efficacy is a construct of Bandura's Social cognitive theory (Bandura, 1977, 1986, 1997). Bandura (1986, 1997) suggested that beliefs will influence an individuals' strategies in pursuing a particular endeavor, the amount of effort they will exert while performing the endeavor, their effort at persevering and resilience in the face of difficulties during the endeavor, their positive or negative thought patterns, the amount of stress they experience during difficulties, and their ability to recognize their accomplishments. People will avoid activities if they do not believe they will be successful, and perform, with assuredness, endeavors that they believe they can successfully complete (Bandura, 1986). Bandura asserted that those with high perceived self-efficacy will engage more fully in an endeavor, as they will be more persistent and energetic, and they will put all of their attention and effort into a 
challenging task (Bandura, 1986). Those with poor self-efficacy may be motivated to learn, but their self-doubt will hinder their successful employment of a skill they were previously adept at utilizing (Bandura, 1986). Ultimately, Bandura $(1977,1986)$ found that perceived self-efficacy will contribute to how much a person is motivated and how much they can accomplish. The Social cognitive theory and the construct of self-efficacy have been utilized as the theoretical framework for examining science teaching efficacy in preservice teacher preparation programs (Bleicher, 2004).

Self-efficacy subcategories. The construct of self-efficacy can be divided into two dimensions: personal self-efficacy (efficacy expectation) and outcome expectancy (Bandura, 1997). An efficacy expectation, as described by Bandura (1977) is:

The conviction that one can successfully execute the behavior required to produce the outcomes... Individuals can believe that a particular course of action will produce certain outcomes, but if they entertain serious doubts about whether they can perform the necessary activities such information does not influence their behavior. (p. 193) Bandura (1997) further defined perceived (personal) self-efficacy as the "beliefs in one's capabilities to organize and execute the courses of action required to produce given attainments" (p. 3). Bandura (1977) described an outcome expectancy as "a person's estimate that a given behavior will lead to certain outcomes," (p. 193) and a "judgment of the likely consequence such performances will produce" (Bandura, 1986, p. 391).

Teaching efficacy. Self-efficacy beliefs can be applied to those in the teaching profession, and is generally termed General Teaching Efficacy (Cantrell et al., 2003). Cantrell et al. (2003) describe personal teaching efficacy as a "future-oriented belief" about the level of competence a person (the teacher) expects to display in a given situation (teaching), whereas 
outcome expectancy is more general (teachers in general) and describes how the intention to go through with an action (teaching) depends on the expected success of that action (student success or failure). Teacher Efficacy is linked to student achievement, attitude, and affective growth variables that may positively affect efficacy (Cantrell et al., 2003).

Self-efficacy beliefs are considered to be "context and subject matter dependent," and these beliefs can be applied to the science content area (Bursal, 2012, p. 41). There are two types of efficacy beliefs with regard to science teaching: Personal science teaching efficacy (PSTE), which is an individual's belief in their capabilities to teach science, and science teaching outcome expectancy (STOE), which is a general belief that a positive outcome will result from effective science teaching (Bleicher, 2004; Enochs \& Riggs, 1990). According to Cantrell et al. (2003), PSTE and STOE function independently and will not influence one another; i.e. a preservice teacher may believe that they are incapable of teaching elementary science effectively, but have a more general belief that science can be taught effectively to elementary students.

\section{Preservice Teacher Preparation}

The final year of preservice elementary teacher preparation is one of intense concentration in which preservice teachers focus on pedagogy and they are immersed in the practical aspects of teaching. Generally, in this final year, students will participate in both their Science Methods course and student teaching experience. Anderson (1997) has described a Science Methods course as the only place where content can be addressed seriously and the holistic act of teaching is prominent. A Science Methods course functions in "bridging the gap between theory and practice, between course work and student teaching" (Anderson, 1997, p. 270). According to Cantrell et al. (2003), Science Methods courses and practicum courses may 
cause changes in efficacy beliefs of preservice teachers and help preservice teachers continue to develop science teaching efficacy beliefs as they progress through this final year of teacher preparation. Anderson (1997) posits that Science Methods courses and the student teaching experience should not be the "end-all" of becoming an effective and proficient science teacher, but the beginning of a life long process of learning in order to ultimately become an expert. Since these courses function in establishing the pedagogical foundations for science teaching, the experiences of preservice teachers should be positive and foster a love of science and science teaching. However, little is known about the "lived experience" of preservice teachers as they progress through the first part of this practical science teaching experience, the Science Methods course; therefore, the current study will address this gap in knowledge by both determining the changes in science teaching efficacy beliefs as individuals progress through a Science Methods course and the context through which these changes in efficacy occur. Because a previous study by Plourde (2002) found that student teaching did not affect PSTE beliefs, the current study will focus only on determining how PSTE beliefs of preservice elementary teachers change as they progress through a Science Methods course, rather than examining both the Science Methods course and student teaching experience.

\section{Purpose}

The purpose of this study is to determine how STEB, specifically PSTE beliefs, change as students' progress through a Science Methods course, as well as to understand the essence of the lived experience of individuals with varying degrees of personal science teaching efficacy (PSTE). The following four research questions will guide this study:

1a. What are the STEB of preservice elementary teachers as they progress through a Science Methods course? 
1b. How do the STEB of preservice elementary teachers with higher and lower PSTE beliefs change as they progress through a Science Methods course?

1c. What is the nature of the lived experiences of preservice elementary teachers with higher and lower PSTE beliefs as they progress through a Science Methods course?

1d. How does the meaning developed during the lived experience of preservice elementary teachers with higher and lower PSTE beliefs influence their STEB?

Understanding how PSTE beliefs change due to the experiences of a Science Methods course and the meaning of these experiences for preservice teachers, can help educators in teacher preparation programs better understand the basis for student beliefs in order to develop interventions for improving efficacy.

\section{Definition of Terms}

The following terms will be used to help describe the theory and design plan behind this study:

Self-efficacy: Bandura (1986) proposed the construct of self-efficacy as an individual's futureoriented belief in their ability to perform a task and what they expect the outcome of their performance to be. These beliefs will dictate behavior (Bandura, 1986).

Science Teaching Efficacy Beliefs (STEB): Because self-efficacy beliefs can be subject specific, science teaching efficacy beliefs are self-efficacy beliefs as they apply to the field of science teaching (Bleicher, 2004; Enochs \& Riggs, 1990).

Personal Science Teaching Efficacy (PSTE): An individual's belief in their capabilities to teach science (Bleicher, 2004; Enochs \& Riggs, 1990).

Science Teaching Outcome Expectancy (STOE): A general belief that a positive outcome will result from effective science teaching (Bleicher, 2004; Enochs \& Riggs, 1990). 
Transcendental Phenomenology: Transcendental phenomenology takes a systematic approach to avoiding bias and preconceptions in the researcher, through the formation of the epoche, a selfreflection process performed by the researcher, in order to achieve a state of being completely “open, receptive, and naïve” during interviews with participants (Moustakas, 1994, p. 22). This form of phenomenological research emphasizes "intuition, imagination, and universal structures" in the telling of the story of an experience, which will further elicit understandings of "perceptions, feelings, thoughts, and sensual awareness in consciousness with reference to a specific experience" (Moustakas, 1994, p. 22). 


\section{Chapter 2: Review of the Literature}

The following will provide a review of the theoretical perspective that grounds studies in self-efficacy, Bandura's Social cognitive theory, as well as a review of factors that affect selfefficacy beliefs, teaching efficacy, and the more specific construct of science teaching efficacy. I will also provide an overview of studies examining the science teaching efficacy beliefs of preservice teachers as they progress through various experiences of preservice teacher preparation, including Science Methods courses and student teaching. The theoretical perspective that guides my explorations of the "lived experiences" of preservice elementary teachers, and a more detailed discussion of the quantitative tool for measuring STEB will be discussed in Chapter 3, the Methodology section.

\section{Social Cognitive Theory and the Construct of Self-Efficacy}

"Of the many cues that influence behavior, at any point in time, none is more common than the actions of others" (Bandura, 1986, p. 206).

Self-efficacy is a construct of Albert Bandura's social cognitive theory of learning, which "examines the transformation mechanism in terms of conception-matching processes whereby symbolic representations are translated into appropriate courses of actions" (Bandura, 1986, p. 390). Bandura posits that knowledge of how to perform a task, possession of appropriate skills, and the "transformational operations" for performing a task do not necessarily lead to successful completion of that task, as "self-referent thought" has an important role in linking knowledge and behavior (Bandura, 1986, p. 390). The Social Cognitive Theory suggests that an individual will function as a result of the interaction of multiple factors, including cognitive processes, environmental factors, and behavior (Bandura, 1977, 1986, 1997). Essentially, Bandura (1986) 
suggests that the beliefs an individual possesses can exert a certain amount of control over feelings, thoughts, and behaviors or actions.

The nature of an individual is defined in terms of symbolic, forethought, vicarious, selfregulatory, and self-reflective capabilities, along with environmental/external stimuli (Bandura, 1986). Bandura (1986) suggests that these factors are "interacting determinants of one another" (p.18). Symbols enable an individual to "process and transform transient experiences into internal models that serve as guides for future action," and give "meaning, form, and continuance" to their experiences (Bandura, 1986, p. 18). Forethought regulates behavior, in that an individual will "anticipate the likely consequences of their prospective actions," which will "motivate" and "guide their actions" (Bandura, 1986, p. 19). Vicarious capabilities involve "observing other people's behavior and its consequences for them," which enables an individual to "acquire rules for generating and regulating behaviors without having to form them gradually by tedious trial and error" (Bandura, 1986, p. 19). Self-regulatory capabilities allow an individual to change their own behavior by observing, judging, and reacting to their own actions and choices (Bandura, 1986). Self-reflective capabilities allow an individual to reflect on and perform self-evaluations of their experiences and cognitive processes, which can ultimately affect future behaviors and thoughts (Bandura, 1986).

Self-efficacy beliefs refer to a combination of "cognitive, social, and behavioral subskills" that are "organized into integrated courses of action;" however, simply possessing these sub-skills does not dictate the ability to use them in varying circumstances (Bandura, 1986, p. 391). Depending on the circumstance, individuals' capabilities to perform a particular task may vary, depending on their perception of their capabilities at that time (Bandura, 1986). Bandura (1986) believes that competency depends on both skills and self-efficacy beliefs. 
Perceived self-efficacy is defined as an individual's "judgments of their capabilities to organize and execute courses of action required to attain designated types of performances" (Bandura, 1986, p. 391). In essence, how an individual perceives their abilities and the actual skills they possess will affect their performance at a particular task (Bandura, 1986).

Perceptions, behavior and performance. Recent research regarding elementary science teacher preparation has focused on studies of self-efficacy, specifically with regard to science teaching self-efficacy beliefs (STEB). The basis for this research is Bandura's studies on mechanisms of human behavior. Bandura (1977) has stated,

On the one hand, the mechanisms by which human behavior is acquired and regulated are increasingly formulated in terms of cognitive processes. On the other hand, it is performance-based procedures that are proving to be the most powerful for effecting psychological changes. As a consequence, successful performance is replacing symbolically based experiences as the principle vehicle of change. (p. 191) Bandura (1977) posits that, “...cognitive events are induced and altered most readily by experience of mastery arising from effective performance" (p. 191). In other words, successful completion of a task, rather than just cognitive processes concerning that task, is a powerful effector of behavior and psychological change. In terms of teacher preparation, experiences with effective teaching of science content will influence thoughts and future behaviors regarding science education. Essentially, a person's thoughts of their capabilities to perform a particular task have profound influence on their ability complete a task (Bandura, 1977). Experiences with successful completion of that task will strengthen their belief in their abilities and, therefore, improve their likelihood of success in future attempts (Bandura, 1977). Individuals' perceptions of their capabilities have a significant influence on the actual completion of a given task 
(Bandura, 1981). These perceptions include, "thought patterns and emotional reactions during anticipatory and actual transactions with their environment" (Bandura, 1981, p. 201). With regard to preservice teacher preparation for science education, an individual will not engage in science teaching if they believe they will not be successful, and their thoughts and emotions prior to and during a particular task will influence their ability to be successful.

Self-efficacy beliefs are related to future-oriented behaviors, as knowledge of selfefficacy can be used to predict behavioral changes in a given situation (Bandura, 1977). Bandura (1977) proposed a theory of self-efficacy in order to attempt to analyze "changes achieved in fearful and avoidant behavior" (p. 193). According to Bandura (1981), the construct of selfefficacy is "concerned with judgments about how well one can organize and execute courses of action required to deal with prospective situations that may contain ambiguous, unpredictable, and often stressful elements" (p. 201). Perceived efficacy is associated with "behavior, thought patterns, and affective arousal" (Bandura, 1981, p. 201). Individuals who personally assess themselves to be incapable to deal with a particular situation tend to continually judge themselves to be inadequate, and they tend to over-dramatize difficult situations (Bandura, 1981, p. 201). Essentially, those with lower perceived self-efficacy tend to make a "mountain out of a mole-hill" when confronted with a challenging task for which the outcome is ambiguous. Those with higher perceived self-efficacy utilize the appropriate skills necessary for a given situation and put greater effort into overcoming obstacles (Bandura, 1981). Properly assessing one's capabilities is essential for success (Bandura, 1981). Those who possess an over-inflated view of their capabilities may be setting themselves up for failure, as they lack the necessary skills for success; whereas, those who under-inflate their capabilities may limit their attempts at successful completion of a task (Bandura, 1981). Individuals who lack confidences in their abilities tend to 
dwell on their perceived inadequacies, which will cause further hindrances and avoidance behaviors (Bandura, 1981).

\section{Sources of Efficacy Information}

Bandura $(1977,1981,1997)$ has determined that there are four sources of efficacy information, including: enactive mastery experiences (performance accomplishments), vicarious experiences, verbal persuasion and social influences, and emotional arousal/physiological responses.

Mastery experiences. Bandura $(1981,1997)$ posits that mastery experiences have the most influence on efficicacy beliefs, because they provide the individual with knoweledge of the necessary components for success. Successes positively impact efficacy beliefs, whereas, failures negatively impact efficacy, particularly if the individuals' efficacy beliefs are not yet cemented (Bandura, 1981, 1997). However, if an individual achieves success without much effort, they may become discouraged in the face of challenges (Bandura, 1997). Bandura (1997) believes that setbacks and challenges can be beneficial in developing strong efficacy beliefs; that a "resilient sense of efficacy requires experience in overcoming obstacles through perseverant effort" (p. 80). Success after challenges help individuals believe that they possess the skills necessary to complete a task, and it promotes an understanding that perseverence is necessary for achieving success (Bandura, 1997). Essentially, success in the face of adversity will promote a stronger sense of efficacy, because an individual gains the knowledge that if they can succeed under difficult circumstances, than they can also succeed under similar or less challenging circumstances (Bandura, 1981, 1997). In addition, once a strong self-efficacy is established after continuous successes, occassional failures are less likely undermine efficacy (Bandura, 1981, 
1997). With regard to teaching, field and practicum experiences in an elementary classroom are considered mastery experiences which will influence efficacy beliefs.

Vicarious experiences. Bandura (1997) posits that modeling can influence efficacy behaviors. Vicarious experiences refer to those situations in which an activity is modeled to allow another individual to "appraise their capabilities in relation to the attainments of others" (Tschannen-Moran \& Woolfolk Hoy, 2007; Bandura, 1997, p. 86). People tend to compare themselves to others in similar situations whom they judge to be of similar competence, and if those individuals perform successfully, perceived efficacy may be raised; whereas, if they perform poorly, perceived efficacy may be lowered (Bandura, 1981). According to Bandura (1997), "the greater the similiarity, the more persuasive are the models' successes and failures" (p. 87). Those with little knowledge of their capabilites are more likely to have their efficacy beliefs influenced by vicarious experiences (Bandura, 1997). With regard to teaching, preservice teachers' observing others teaching would be considered a vicarious experiences.

Verbal or social persuasion. In this source of efficacy, individuals are "led, through suggestion, into believing that they possess certain capabilities and that they can surmount difficulties" (Bandura, 1981, p. 204). Verbal persuasion is not as powerful in its effect on efficacy as mastery experiences; however, it is a contributer to either promoting or demoting efficacy beliefs (Bandura, 1981). Bandura (1981) posits that it may be easier to persuade someone that they are incapable, than to persuade someone of their capability, suggesting that “illusory boosts in efficacy are readily disconfirmed by the results of one's actions," whereas, "people who are persuaded of their inefficacy tend to avoid challenging activities and give up readily in the face of difficulties" (p. 204). According to Cantrell et al. (2003), social persuasion can "provide information about the nature of teaching, give encouragement and strategies for 
overcoming obstacles, and provide feedback on a teacher's performance” (p. 179). In addition, evaluations which stress the positive aspects of teacher performance tend to raise self-efficacy beliefs, whereas, evaluations that stress the negative aspects of performance tend to decrease self-efficacy beliefs (Cantrell et al., 2003).

Emotional arousal/ physiological responses. Bandura (1981) suggests that individuals tend to determine their cabability of performing a task by relying on their emotional arousal. Highly emotional states tend to interfere with the ability to perform and tend to result in increased fear (Bandura, 1981). Bandura (1981) believes that thoughts of an inability to perform will lead to the inability to perform, and, conversely, individuals who are more relaxed tend to expect a successful outcome. With regard to teaching, if an individual is highly anxious about their ability to complete a task, they may experience an inablity to teach effectively.

\section{Teacher Efficacy}

A study by Harker, Gibbs, Ryan, Weir, and Adams (2000) found that $60 \%$ of teachers felt unprepared to teach, and showed that many teachers led stressful lives and would potentially leave the teaching profession. This statistic may be a result of ineffective preservice teacher preparation. Gibbs (2002) posits three key characteristics of effective teachers, including: the ability to survive the demands of the profession, the ability to be persistant and resiliant, and the ability to be innovative. Gibbs (2002) believes that these qualitites are driven by teachers' beliefs in their self-efficacy as educators, and that effective teachers can "exercise this efficacy, and ...exercise thought control over their actions" (p. 2). A study by Davis, Petish, and Smithey (2006) examined the relationship between teaching practice and self-efficacy of teachers and found that teachers who held higher efficacy beliefs had positive beliefs about student learning 
capabilities through the use of cooperation and various experiences, implemented studentcentered lessons, and exhibited more professional development.

Teacher efficacy has been described as a measurement of the "extent to which teachers believe their efforts will have a positive effect on student achievement" (Ross, 1994, p. 3), and "the extent to which the teacher believes he or she has the capacity to affect student performance" (Berman, McLaughlin, Bass, Pauly, \& Zellman, 1977, p. 139). Studies of teacher efficacy originated from two sources: Rotter's (1966) locus of control theory and Bandura's theory of self-efficacy $(1977,1981,1997)$. Rotter's $(1966)$ theory posits that there are internal control mechanisms (individual efforts) and external control mechanisms (efforts beyond an individuals control) that impact success or failure, which further impact expectancies of control. However, most studies of teacher efficacy have originated from Bandura's (1977) self-efficacy theory, which posits that judgements of incapabilities influence behavior. Bandura (1977) believes that judgments are based on past behaviors and experiences, but that expectations can be altered with new information (Bandura, 1986). As was previously stated, the construct of selfefficacy can be divided into two dimensions: personal self-efficacy (efficacy expectation) and outcome expectancy (Bandura, 1977). According to Gibson and Dembo (1984), if Bandura's theory of self-efficacy is applied to teaching, (personal) self-efficacy beliefs would represent "teachers' evaluation of their abilities to bring about positive student change;" whereas outcome expectancy would "reflect the degree to which teachers believed the environment could be controlled, that is, the extent to which students can be taught given such factors as family background, IQ, and school conditions" (p. 570). Gibbs (2002) further describes teacher outcome expectations as "beliefs that acting in certain ways are likely to lead to certain outcomes" (p. 2). Gibbs (2002) notes that there is a incongruency between expectations placed on teachers in 
teacher preparation programs, particularly regarding the production of artifacts and "exemplars of action and consequenses" (p. 2). Essentially, Gibbs (2002) is suggesting that preservice teachers understand that if they perform in a certain manner, they know what to expect of the outcome. Gibbs (2002) believes that outcome expectancies of teachers can be limited, due to the unpredictability of the teaching profession, particularly with respect to expectations of novice teachers. Because outcome expectancies of preservice teachers only indicate general expectations of outcomes of certain behaviors in teaching, this information is not sufficient for determining if a teacher believes in his or her own capabilties as an educator (Gibbs, 2002). Therefore, it is important to examine personal self-efficacy beliefs when examining teacher efficacy (Gibbs, 2002). Gibbs (2002) believes that self-efficacy in teaching, is a "powerful predictor of how and whether a teacher will act" (p. 2). Ultimately, a teacher's belief in their capabilties will dictate whether they will be effective educators (Gibbs, 2002).

Gibson and Dembo (1984) examined the dimensions of self efficacy in teaching, including personal teaching efficacy (beliefs in ones' capabilities to impact student learning) and general teaching efficacy (beliefs that factors outside of the classroom, such as home environment, background, and family, limit teacher effectiveness as a teacher), as well as the behaviors of teachers with high and low efficacy beliefs. This study revealed that teacher efficacy is best examined using a "multidimensional approach" of looking at both personal teaching efficacy and general teaching efficacy (Gibson \& Dembo, 1984). They found that those with high efficacy tend to be more persistant in the classroom, would lead students to correct answers with questioning, tended to be less critical when students provided incorrect answers, were more flexible and less stressed if there was a disruption in routine, and attempted innovative teaching strategies (Gibson \& Dembo, 1984). Studies performed over the last several 
decades have found associations between teacher efficacy and student motivation, teacher use of innovative instructional strategies, management teachniques, and time spent on subjects (Bandura, 1977; Berman et al., 1977; Tschannen-Moran, Woolfolk Hoy, \& Hoy, 1998). Sources of efficacy and preservice teacher preparation. Teacher efficacy can be influenced by mastery experiences (experiences of actual teaching), vicarious experiences (watching others teach), verbal persuasion (verbal exhortions of competance as a teacher), and emotional arousal/physiological responses (physical symptoms indicating success or failure while teaching) (Bandura, 1986; Ross, 1994). Tschannen-Moran et al. (1998) have suggested that preservice teachers require "more opportunities for actual experiences with instructing and managing children in a variety of contexts with increasing levels of complexity and challenges to provide mastery experiences and specific feedback" (p. 24). Mastery experiences, for teachers or preservice teachers, are obtained through accomplishments in teaching (Bandura, 1997). If an individual is successful in their teaching task, self-efficacy increases, which will then raise expectations for future successful endeavors at a similar teaching task (Bandura, 1997; Tschannen-Moran \& Woolfolk Hoy, 2007). However, a lack of success at teaching will decrease efficacy and lower expectations for future success at teaching (Tschannen-Moran \& Woolfolk Hoy, 2007). Verbal persuasion, such as the encouragement of effort and persistance and the emphasis of positive accomplishments early in the learning process, will positively influence efficacy beliefs (Tschannen-Moran et al., 1998). This source of efficacy beliefs with regard to teaching may include "verbal interactions that a teacher receives about his or her performance and prospects for success from important others in the teaching context, such as administrators, colleagues, parents, and members of the community at large" (Tschannen-Moran \& Woolfolk Hoy, 2007, p. 945). Vicarious experiences for teachers include observations of those modeling 
teaching tasks; however, the degree to which vicarious experiences will impact teacher efficacy is related to the degree to which the observer relates to the individual modeling the task (Tschannen-Moran \& Woolfolk Hoy, 2007). Factors such as gender, experience level, training and race will effect the level of influence of the vicarious experience (Tschannen-Moran \& Woolfolk Hoy, 2007). Psychological and emotional arousal will also affect teacher efficacy, in that feelings of joy or fear will promote or demote an increased or decreased sense of efficacy (Tschnnen-Moran \& Woolfolk Hoy, 2007). Another factor that has shown to impact efficacy is knowledge of content. A study by Ramirez Sangueza (2010) of preservice teachers in a Science Methods course and student teaching experience showed that the depth of understanding science content can affect teaching efficacy, as individuals with lower efficacy expressed a weaker understanding of science and experienced challenges while learning science, and struggled while attempting to teach science content. However, those with higher efficacy exhibited more of a connection to science content and generally had more positive experiences with science (Ramirez Sangueza, 2010).

Tschannen-Moran et al. (2007) suggest that teachers make two judgements with regard to their capability to teach: the requirements of the task, and how competent they will be with regard to the identified requirements. Self efficacy has an important influence on the capability of teachers, in that the "self perception of competence" needs to be considered in addition to the “actual level of competence” (Tschannen-Moran \& Woolfolk Hoy, 2007, p. 946). They also suggest during the first year of teaching, efficacy beliefs can be enhanced by creating an environment that will promote success, such as having a smaller class size with proficient students (Tschannen-Moran et al., 1998). 
Why is developing a strong sense of efficacy during preservice teacher preparation important? Firmly established efficacy beliefs can be difficult to change (Tschannen-Moran et al., 1998), because these beliefs have been strengthened by repeated successes or failures (Bandura, 1997). Bandura (1997) suggests that each time an individual has an experience that is similar to that in which the individual has achieved success, that experience will act as a "redundant indicator" and will be "given significance, and remembered," which will further strengthen efficacy beliefs (Bandura, 1997, p. 82). However, Bandura (1997) suggests that experiences which are dissimilar to perviously established self-efficacy beliefs are often "minimized, discounted, or forgotten in reconstructed memory" (p. 82). This is significant in terms of promoting the development of strong self-efficacy in teacher preparation programs, because novice teachers with higher efficacy may be less likely to be deterred by occasional challenges faced while teaching (Tschannen-Moran et al., 1998).

In addition, studies have shown that there is a relationship between teaching commitment (Coladarci, 1992) and teacher burnout (Skaalvik and Skaalvik, S., 2007) and teacher efficacy. Teacher burnout can include both emotional (Maslach, Jackson, \& Leiter, 1996) and physical exhaustion (Pines \& Aronson, 1988). Teachers who are "burned-out" may develop a poor attitude toward both their students and fellow teachers, and they possess "a general feeling that they are no longer doing a meaningful and important job.” (Skaalvik and Skaalvik, S., 2010, p. 1060). Studies have show that teachers with lower self-efficacy are more likely to experience the negative and cynical feelings representative of burnout (Bandura, 1997; Slaavik and Slaavik, S., 2007) and, reciprically, feelings of burnout can affect self-efficacy (Skaalvik and Skaalvik, S., 2007, 2010). Therefore, helping preservice teachers to develop a strong sense of efficacy in a teacher preparation program may prevent teacher burnout. Furthermore, research has shown that 
developing strong efficacy beliefs during teacher preparation can help novice teachers have a more satisfying, positive, and less stressful teaching experience, they experience less difficulties while teaching, and are more optimistic about their persistance in the teaching field (Burley, Hall, Villeme, \& Brockmeier, 1991; Hall, Burley, Villeme, \& Brockmeier, 1992; TschannenMoran et al., 1998).

\section{Science Teaching Efficacy Beliefs.}

There are many studies that have examined science teaching efficacy beliefs (STEB), including the variables associated with STEB at different stages of teacher preparation, changes in efficacy beliefs during different courses of teacher preparation (Cantrell et al., 2003), and STEB and field experiences of preservice teachers (Cannon \& Scharmann, 1995).

Measuring science teaching efficacy beliefs. STEB have been measured using Gibson and Dembo's (1984) teacher efficacy scale to measure two components of teacher efficacy: personal and general teaching efficacy. Other studies have utilized Gibson and Dembo's (1984) scale, but with variations (Enochs and Riggs, 1990; Hoy \& Woolfolk, 1993; Woolfolk \& Hoy, 1990). Enochs and Riggs (1990) utilized this scale to develop the Science Teaching Efficacy Beliefs Instrument for measuring efficacy beliefs of inservice teachers (STEBI-A) and preservice teachers (STEBI-B). The STEBI measures two dimensions of science teaching self-efficacy: Personal Science Teaching Efficacy (PSTE) and Science Teaching Outcome Expectancy (STOE) (Enochs and Riggs, 1990). Since the early 1990's, there have been many studies that have utilized the STEBI-B to determine the effects of interventions in preservice teacher preparation programs, such as Science Methods courses and student teaching, on STEB (Mulholland, Dorman, \& Odgers, 2004; Palmer, 2006; Tosun, 2000). Measurements of STEB utilizing the STEBI have indicated that PSTE is positively related to prior school experiences with science 
(Hechter, 2011), early field experiences (Cantrell et al., 2003), and discipline-integrated Science Methods courses (Joet, Usher, \& Bressoux, 2011).

\section{Science Methods Courses}

There have been numerous studies over the past two decades involving Science Methods courses, which provided useful background information for the current study. Researchers have examined the role of Science Methods courses in preservice teacher preparation programs utilizing a variety of data collection techniques, including surveys, questionnaires, observations, and interviews to examine different aspects of preservice teacher development. These studies addressed the role of science education reform in Science Methods courses (Anderson, 1997), examined preservice teachers' attitudes and efficacy beliefs toward science (Bayraktar, 2009), determined the effects of incorporating constructivist teaching practices into Science Methods courses (Kelly, 2000), and examined the influences of field experiences on science efficacy beliefs (Cannon \& Scharmann, 1996; McDonnough \& Matkins, 2010; Swars \& McMunn Dooley, 2010).

Science Methods courses and educational reform. The Science Methods course has been described by Anderson (1997) as a "holistic" course where teaching is "front and center, rather than submerged within a focus that is mainly on contextual and background aspects of learning to teach," and it is "the only place in the typical teacher education program where the subject matter perspective can be addressed seriously” (p. 269). Science Methods courses are part of the final preparations in preservice teacher education. This course "connects theory and practice" and helps students become more autonomous in their development as a teacher (Anderson, 1997, p. 270). With the goal of putting science educational reform in action, research by Anderson (1997) suggested that Science Methods courses should be the "foundation of a 
science teacher's professional development, both individually and programmatically" (p. 270), should allow students to "take responsibility for directing their own learning" (p. 273), and should allow opportunities for students to "reflect upon and reassess the values and beliefs they should hold with respect to science learning and teaching” (p. 273). In addition, a Science Methods course should allow for opportunities to conduct work within real-world science classrooms, to collaborate with other students, to connect science to the classroom, and promote critical thinking by challenging their current beliefs and values (Anderson, 1997).

Another study by Kelly (2000) examined the development and implementation of a reform-based Science Methods course for preservice teachers. This study followed a constructivist perspective and was informed by the construct that preservice teachers are likely to learn about science content and science pedagogy through a variety of different venues, which will cause them to reflect on their role as a learner of science and as a science educator. The Science Methods course in the study was also designed and implemented from the constructivist perspective. The author utilized open-ended questionaires, which gathered information concerning science background, personal interest and attitudes toward science, confidence in teaching ability, knowledge of science pedagogy, and feelings toward informal and formal learning environments. Results indicated that effective constructivist teaching practices in a Science Methods course will allow preservice teachers to experience teaching in formal and informal learning environments, and provide them with the opportunity to observe and reflect upon the various learning styles of elementary students (Kelly, 2000).

Science Methods courses with field experiences. Science Methods courses often incorporate field experiences which involve preservice teachers visiting elementary schools for observations or practicum experiences. A study by Swars and McMunn Dooley (2010) focused 
on a field-based Science Methods course which was integrated within an elementary school that follows a professional development school (PDS) model. Specifically, this study examined whether a field-based methods course, within the context of a PDS, caused an increase in teaching efficacy, and if preservice teachers would classify the PDS-model as being the cause or contributer to changes in their teaching efficacy beliefs (Swars \& McMunn Dooley, 2010). Researchers utilized the Science Teaching Efficacy Beliefs Survey, Form B (STEBI-B), developed by Enochs \& Riggs (1990), in order to measure personal science teaching efficacy (PSTE) and science teaching outcome expectancies (STOE), and they utilized qualitative openended questionnaires. Ultimately, they determined that preservice teachers' beliefs in their skills and their ability to teach science effectively (their PSTE) became significantly stronger during the PDS-based Science Methods courses; however, their general belief that effective teaching of science (outcome expectancies) can influence student learning did not change significantly (Swars \& McMunn Dooley, 2010).

Another study by McDonnough and Matkins (2010) also examined the effects of field experiences on science teaching efficacy beliefs and, specifically, determined the extent to which various field experiences and instructor involvement influenced efficacy and students' abilities to connect educational theory to teaching practice. In this study, the practicum field experiences were concurrent or not concurrent with a Science Methods course. After gathering data from STEBI- B surveys (Enochs \& Riggs, 1990) and interviews, it was determined that STEB increased as a result of the concurrent methods course and field experience, and preservice teachers showed a greater understanding of science teaching strategies $($ McDonnough \& Matkins, 2010). 
Science Methods courses, STEB, and attiudes. A study by Bayraktar (2009) examined effects of a Science Methods course on STEB and attitudes toward science. The Science Methods course in this study educated students on science content, science process skills, assessment techniques, misconceptions with regard to science content, safety issues, modeling, and science teaching strategies; however, this course did not include a practicum component in which preservice teachers taught in an elementary classroom. The author utilized the STEBI-B (Enochs \& Riggs, 1990) for measuring PSTE and STOE, as well as an attitude survey. Results of the study indicated that attitudes toward science increased during the Science Methods course, particularly with regard to enjoyment of science, and poor attitudes at the beginning of the course were most likely due to previous negative experiences with science (Bayraktar, 2009). Also, results showed an increased PSTE over the course of the semester, indicating positive effects of the course on preservice teacher confidence in science teaching skills (Bayraktar, 2009), which are similar results to those found by Cantrell et al. (2003). However, STOE scores did not increase during the Science Methods course, indicating the need for a practicum component to increase this general belief in the effectiveness of science teaching (Bayraktar, 2009). These results indicated that a course which focuses on content, process skills, misconceptions, assessment, and teaching strategies, will increase PSTE, but not the general beliefs of positive outcomes of science teaching (Bayraktar, 2009). The author recommends adding a practicum component to the Science Methods course, and incorporating learning approaches such as inquiry and activity-based learning (Bayraktar, 2009). In addition, the author found that it is important to better prepare students prior to entering methods courses by increasing competency in science content and pedagogical content knowledge using constructivist teaching strategies (Bayraktar, 2009). 
Science Methods courses, field experiences, and cooperative learning. A study by Cannon and Scharmann (1996) examined three factors associated with effective science teacher preparation: self-efficacy, cooperative learning processes, and the influence of early field experiences. Specifically, they explored the influence of a cooperative early field experience in a Science Methods course on preservice elementary teachers' science self-efficacy. Utilizing the STEBI- B survey (Enochs \& Riggs, 1990) and personal interviews, they obtained results which indicate that early field experiences appear to have a positive influence on STEB, and that cooperative learning in the field is beneficial and enjoyable. Cannon and Scharmann (1996) suggest that it is important for preservice teachers to experience a sense of community as part of their education in order to avoid feelings of isolation when they begin teaching. The perception of isolation can result from a combination of childhood experiences in elementary schools, or isolating experiences in preservice teacher preparation programs (Cannon \& Scharmann, 1996). The authors believe that teacher preparation courses which incorporate field experiences should consider moving toward a model that encourages preservice teachers to work in cooperative groups, both in classrooms and in public schools (Cannon \& Scharmann, 1996).

\section{Preservice Teacher Education after the Science Methods Course: The Student Teaching}

\section{Experience}

The preservice teacher's final challenge in undergraduate education is the student teaching experience. Studies have shown that students enter into this experience with content and pedagogical knowledge, but also with experiences that will influence their cognitive perceptions of learning and teaching (Ball, 1988; Lortie, 1975). Specifically, their beliefs about science and science teaching will influence their behavior and teaching philosophies (Plourde, 2002; Thompson, 1992; Tobin, Tippins, \& Gallard, 1994). Research has shown that efficacy beliefs 
impact behavior during student teaching experiences. According to Saklofske, Michaluk, and Randhawa (1988), student teachers with higher student teaching efficacy were better able to manage students in the classroom, presented lessons better, and exhibited more effective questioning behavior. In addition, there have been links between preservice teacher efficacy beliefs and attitudes toward student motivation and the ability to control a classroom environment (Woolfolk \& Hoy, 1990). A study by Woolfolk and Hoy (1990) showed that preservice teachers with low efficacy beliefs were more pessimistic in their attitudes regarding student motivation, were more controlling in the classroom, and utilized rewards and punishment to influence student behaviors. Therefore, it can be reasoned that the efficacy beliefs developed during the Science Methods course, taken prior to the student teaching experience, would effect teaching behaviors during this experience.

PSTE, STOE, and student teaching. According to Riggs (1991), regardless of the amount of previous science content courses, students enter their student teaching experience with limited knowledge of concepts, which can lead to anxiety about their abilities and effectiveness as a teacher (Plourde, 2002). In a study examining the influence of the student teaching experience on science self-efficacy and outcome expectancy beliefs of preservice teachers, Plourde (2002) found that while student teaching did not affect PSTE beliefs, the experience did negatively influence STOE. While these results were unexpected, the author postulated that the prior experiences with science cemented preservice teacher beliefs and attitudes about science teaching prior to entering into the experience; therefore, their PSTE beliefs did not change during student teaching (Plourde, 2002). Plourde (2002) believed that changes to outcome expectances were due to the broad context of student teaching experience in its entirety, including interactions with students, teachers, parents, administrators, as well as experiences with the 
limited availability of materials, limited time, and concerns about the curriculum. Experiences with a lack of time, materials, supplies, and support, as well as an ineffective curriculum, negatively influenced STOE (Plourde, 2002). Ultimately, the preservice teachers in this study believed that teachers, in general, do not positively influence children in science education (Plourde, 2002). Ginns and Watters (1990) found that student teachers with concerns about their abilities in science education may prove ineffective in the classroom, providing inadequate learning experiences that lack effort and time consideration. Another study, however, showed that student-centered teaching strategies during student teaching can positively affect STEB, as preservice teachers experienced an increase in their STEB as a result of participating in inquirybased learning (Bhattacharyya, Volk, \& Lumpe, 2009).

STEB measurements in practicum-oriented courses. A study by Cantrell et al. (2003) examined the variables that affect the development of positive efficacy beliefs of preservice teachers and how these beliefs change over time. The authors utilized the STEBI-B survey to measure STEB (Enochs \& Riggs, 1990), specifically examining the constructs of PSTE and STOE; as well as a demographic questionaire concerning students' current coursework and past science experiences. They followed 268 students through three semesters, including a science seminar, advanced Science Methods, and student teaching experience; however, only 12 students were followed in all three groups. The results indicated that the amount of time actually spent teaching elementary science to children in a classroom influenced PSTE. They found that there was no significant difference in STEB between participants'participation in the Science Methods course and student teaching experience. In addition, the results indicated that the more science courses an individual took beyond the assigned science courses within the curriculum, the better their STOE. The authors suggest that early field experiences which include lesson plan 
development and teaching experiences provide opportunities for mastery experiences in teaching science to small groups, develop a community of learning with ample opportunity for vicarious experiences, promote positive physiological and emotional arousal, and provide social persuasion relative to successful science teaching experiences (Cantrell et al., 2003).

\section{Contributers to STEB during Science Methods courses and student teaching. A}

study by Ramirez Sangueza (2010) examined contributers to STEB of six preservice elementary teachers during a Science Methods course and student teaching experience. Specifically, the author examined the following research questions, "1]. What science experiences influence science teaching self-efficacy in pre-service elementary teachers? and 2.] How are science teaching practices depicted across different levels of efficacy during student teaching?" (Ramirez Sanguez, 2010, p. 3). The author utilized the STEBI-B to determine the PSTE values of preservice students in two Science Methods courses in order to select two individuals with low PSTE, two with mid-level PSTE, and two individuals with high PSTE (Ramirez Sangueza, 2010). These individuals became the "cases" for the qualitative case studies. STEBI-B results showed that each of the partipants exhibited an increase in efficacy beliefs during the two semesters of the Science Methods course and student teaching experience (Ramirez Sangueza, 2010). The results indicated several contributers to self-efficacy beliefs, including content knowledge, prior experiences with science, and the degree of personal enjoyment or interest in the content (Ramirez Sangueza, 2010). With regard to content knowledge, Ramirez Sanguez (2010) found that those with lower efficacy felt that they only needed to know slightly more than their elementary students in order to effectively teach science, whereas, those with higher efficacy believed the the purpose of having high content knowledge was to create rigorous and challenging science education experiences. Those with lower efficacy tended to teach less 
science and expressed doubts about their abilities to teach science content (Ramirez Sangueza, 2010). Those with higher efficacy viewed a lack of sufficient content knowledge as an area for improvement, rather than an insurmountable challenge (Ramirez Sangueza, 2010). With regard to prior science experiences, those with lower efficacy reported poor experiences with science in teacher-centered learning environments; whereas, those with higher efficacy generally had positive experiences with science (Ramirez Sangueza, 2010). Personal enjoyment was also cited as a contributer to efficacy for those with lower efficacy, in that they felt that if they had an interest in the content, they would be able to teach that content, regardless of any negative prior experiences (Ramirez Sangueza, 2010). Regarding teaching practice, those with lower efficacy exhibited a larger increase in efficacy in their Science Methods course, compared to their student teaching experience, due to the struggles and challenges faced during these experiences. In addition, those with low efficacy blamed their struggles on external factors, such as insufficient science teaching experience and a lack of content knowledge (Ramirez Sangueza, 2010). Those with higher efficacy exhibited better classroom management skills and were not intimidated by challenges (Ramirez Sangueza, 2010). The author also noted the influence of disposition and reflections on progression and development in teaching practice (Ramirez Sangueza, 2010).

\section{Summary}

Overall, the literature regarding the science teaching efficacy beliefs of preservice teachers indicate that in order to increase STEB, Science Methods courses should incorporate contructiviest strategies, reform techniques such as inquiry-based field experiences, field observations and practicum experiences, cooperative group work, experiences with assessment strategies, and they should allow for opportunities to increase pedagogical content knowledge. 
While there have been studies that have examined the combined interventions of the Science Methods course and the student teaching experience of preservice teachers with regard to views of inquiry and research experience (Windschitl, 2003), and with regard to STEB and teaching practice (Ramirez Sangueza, 2010), the literature did not reveal any studies which examined the changes in STEB and the lived experience of preservice elemenary teachers with varying levels of efficacy beliefs during their final year of teacher preparation; specifically with regard to the Science Methods course. Therefore, the current study will address this phenomenon. Understanding the context of the experiences of the Science Methods course would help those in teacher prepreparation programs to better understand the perceptions of students with differing levels of efficacy. Tschannen-Moran et al. (1998), posit that the reason there is much research concerning self-efficacy beliefs and preservice teachers is due to the persistent nature of such beliefs once they have been established within the individual. Gaining an understanding of these beliefs and how they form in preservice teachers, prior to the firm establishment of such beliefs, may enable teachers to intervene by providing experiences which will increase efficacy beliefs. 


\section{Chapter 3: Methodology}

\section{Study Overview}

The current study was conducted using mixed methods research, as I used qualitative and quantitative methodologies to both develop and obtain answers to my research questions within a single study. Mixed methods studies consist of both qualitative and quantitative research and, therefore, contain elements of positivist (quantitative) and interpretive-constructivist (qualitative) philosophies (Sale, Lohfeld, \& Brazil, 2008). In order to "resolve the anomalies" inherent in the combining of two paradigms, an alternative "pragmatist approach" has been posited from mixed methods studies (Morgan, 2008, p. 62). Pragmatism utilizes abductive reasoning (reasoning that will move between inductive and deductive reasoning), follows an intersubjective approach, where the researcher works back and forth between differing frames of reference (between objectivity and subjectivity), and utilizes transferability, where researchers will "investigate the factors that affect whether the knowledge we gain can be transferred to other settings" and examine "what people can do with the knowledge they produce" (Morgan, 2008, pp. 58-60). According to Morgan (2008), the strength of a pragmatic approach to research is the "emphasis on the connection between epistemological concerns about the nature of the knowledge that we produce and technical concerns about the methods that we use to generate that knowledge" (p. 62).

One of the concerns about conducting mixed methods research is the debate over the epistemological and ontological issues of qualitative and quantitative paradigms (Sale et al., 2008). Phillips (1988) described the epistemological and ontological issues of quantitative researchers as those in which the perception of truth is "something which describes an objective reality, separate from the observer and waiting to be discovered;" whereas, qualitative 
researchers concerns regard "the changing nature of reality created through people's experiences - an evolving reality in which the subject and researcher are mutually interactive and inseparable" (as cited in Sale et al., 2008, p. 371). The current study, while it is a single study, utilized methodologies that examined different phenomena. The quantitative portion of this study examined the changes in self-efficacy during a Science Methods course. The qualitative portion of the study examined the essence of the lived experiences of individuals with differing levels of self-efficacy. The "objective reality" of the quantitative self-efficacy survey results were “independent of human perception,"from an outside source, and the empirical data were "indicators that represent truth" (Sale et al., 2008, p. 365); as I, the researcher, did not influence the phenomena under examination - in this portion of the study. However, I did influence and was influenced by my interactions with the case participants chosen for the qualitative interviews. The participants and I were "interactively linked so that findings are mutually created within the context of the situation," (Denzin \& Lincoln, 1994, as cited in Plano Clark \& Creswell, 2008, p. 365). The findings represented the multiple realities of the participants, as individuals with differing levels of self-efficacy, based on how they constructed their reality during the Science Methods course (Berger \& Luckmann, 1966, as cited in Plano Clark \& Creswell, 2008, p. 365). While two paradigms were represented in this study, the positivist (quantitative) and the interpretive-constructivist (qualitative), the complementary nature of the qualitative and quantitative research allowed for a mixed design, as they utilize different lenses to examine phenomena within the same study (Sale et al., 2008).

In the following section, I will discuss my design plan and provide a detailed description of the quantitative and qualitative data collection and analysis methods. I will discuss my sampling techniques for the study, as well as how I performed data integration. I will explain 
how the quantitative data was gathered via science teaching efficacy surveys at the beginning of the Science Methods course and after the Science Methods course. I will also discuss how the qualitative data was gathered after analyzing the pre-survey data, in which individuals were classified as higher or lower efficacy based on how they scored in relation to one another. I selected four individuals from each efficacy group and performed qualitative research on these individuals. The qualitative study was phenomenological in nature; specifically, I utilized transcendental phenomenological methodology to determine the essence of the experiences during the participant's final year of teacher preparation, examining the meanings created by those with high or low efficacy as they participated in a Science Methods course.

\section{Design Plan}

The most appropriate design for answering my research questions was a Concurrent Nested Design, in which the qualitative research was nested within the quantitative research. This design involved the simultaneous collection of qualitative and quantitative data, with a predominant method that guided the project (Creswell, Plano Clark, Gutmann, \& Hanson, 2008). The concurrent nested design allowed for a comparison of quantitative and qualitative data for congruent findings (Creswell et al., 2008). Specifically, this design allowed me to identify changes in the quantitative survey data throughout the semester and determine if such changes were also reflected in the qualitative responses to interview questions. In addition, a deeper examination of the qualitative interview responses allowed me to understand the context with which these changes occurred. The qualitative research was nested within the quantitative research, because this method of data collection answered different, more context-rich questions and the data was used to inform the quantitative research questions (Creswell et al., 2008). I struggled with determining which method was dominant, as I felt that both components were 
essential to the main research questions; but ultimately, the research revolved around the lived experiences of those with varying levels of efficacy, which was measured via qualitative means. Therefore, the qualitative methodology was predominant in this study. The qualitative and quantitative data was integrated in the analysis phase of the study (Creswell et al., 2008) (Figure $1)$.



Analysis of findings

Figure 1: Concurrent Nested Design with prominent qualitative data collection (Creswell et al., 2008). This is a simplified visual representation of the study design.

Design purpose. The purpose of my study was complementarity and expansion. Through my research, I used the results of one method to elaborate on another (complementarity) and I used different methods to "increase the scope of the inquiry" (expansion) (Greene, Caracelli, \& Graham, 2008). This study was conducted during the final year of a preservice elementary teacher preparation program, as students participated in a Science Methods course.

Sampling technique. This study followed a mixed methods design, so I utilized different sampling strategies for the quantitative and qualitative portions of the study. For the quantitative portion, I selected participants based on their participation in a Science Methods course for 
elementary education majors during the Fall of 2012. This course was taken as part of the Methods and Materials Block semester (17 semester credit hours) for elementary education students, which included science, mathematics, social studies, and language arts methods and materials courses, as well as an instructional design and assessment course, and a course concerning collaborative techniques for elementary students with exceptionalities ("Student teaching and certification," n.d.). These courses were taken the semester prior to the student teaching experience.

The Methods and Materials Science Block course, which will be referred to as the "Science Methods" course in this study, required students to drive approximately 10 miles from the University to a private elementary institution. The course ran from 2:00 pm until 5:00 pm on Thursday afternoons during the Fall of 2012. This private institution is accredited by the Independent School Association of the Central States (ISACS), has an enrollment of 150 students, and has multiple programs for children of varying ages, including an early childhood (ages 2-4 years), primary (kindergarten - second grade), and upper elementary (grades 3-5) program, with class sizes of 15 students or less ("Fact Sheet," n.d.). The teacher of the Science Methods course was also the designated science instructor for the private school, having taught at the institution for over twenty years. At the start of the Science Methods course, students were required to first observe the teacher as she instructed elementary students in a science lesson, then, after the completion of the lesson, the University students would critique the lesson and discuss a science education topic. As the semester progressed, the students were split into groups and conducted a group lesson with elementary students. Individuals who were not teaching were required to observe their peers as they were conducting a lesson and provide feedback concerning the success of the lesson. Due to the time constraints of the Science Methods course, 
the University students were only able to observe the teacher as she instructed the fifth grade class; however, the group lessons were conducted with different grades, depending on the group. Therefore, while each individual was able to observe various grades being taught a lesson, he/she was only able to teach a lesson to one grade. Evaluation of each of the group lessons by the teacher of the Science Methods course was limited, because of the simultaneous lessons conducted by University students in different grades. The course also required University students to participate in two field experiences, including a visit to a local environmental center and a visit to a local University with a "space program" for elementary and middle school students.

All of the students enrolled in the Methods and Materials Science block (there were 27 students) were asked to participate in three STEBI-form B surveys regarding their science teacher self-efficacy beliefs over the course of the Science Methods course; however, only 21 agreed to participate in the study (20 females and one male). This type of sampling procedure was considered convenience sampling, or specifically, volunteer sampling (Teddlie \& Yu, 2008). For the qualitative portion of this mixed methods study, I selected participants based upon the purposeful sampling technique, typical case sampling, to achieve "representativeness or comparability" (Teddlie \& Yu, 2008, p. 204).

The qualitative portion of the study involved purposive sampling techniques, as this form of sampling involved selecting "units (individuals, or groups of individuals, or institutions) based on specific purposes associated with answering a research study's questions" (Teddlie \& Yu, 2008, p. 200). Specifically, I was "sampling to achieve representativeness or comparability" in the use of case sampling, as I selected small groups of individuals with low and high efficacy based on their PSTE scores from the "pre" STEBI-B surveys, and I conducted a 
phenomenological study of individuals within that group to determine the essence of their lived experience (Teddlie \& Yu, 2008, p. 204). This type of study, as I will discuss further in the sections below, enabled me to gain an understanding of the meaning of the experience of the Science Methods course for those with low and high efficacy, but with regard to the context under which the experience occurred. As a result of the case samplings from each efficacy group, the meaning the of experiences of a Science Methods course could be transferred to others classified as having low or high efficacy, as they go through similar experiences (Teddlie \& Yu, 2008).

As the researcher and not the teacher of this course, I had limited interactions with the students registered for the course, aside from the time spent giving the surveys or conducting interviews. Participation in this study was not mandatory, and did not affect the students' grades or evaluations. In addition, there were no incentives-based recruitment procedures utilized for this study. This study was evaluated as an "expedited" study and was approved by the Institutional Review Board from both affiliated institutions in August of 2012. Prior to the beginning of the study, each potential participant received a copy of the "Participant Cover Letter" describing the details of the study (Appendix A).

\section{Quantitative Research}

I measured STEB using the Science Teaching Efficacy Beliefs Instrument, form B, which was initially developed by (Enochs \& Riggs, 1990), and later revised by Bleicher (2004). The STEBI-B was designed to measure Bandura's two components of self-efficacy: outcome expectation or Science Teaching Outcome Expectancy (STOE - an individual is motivated to perform an action if they believe there will be a positive outcome), and self-efficacy expectation or Personal Science Teaching Efficacy (PSTE - an individual is confident they can perform a 
particular action successfully) (Bleicher, 2004). The STEBI-B included a mixture of questions on outcome expectations of teaching science and personal efficacy beliefs (Bleicher, 2004; Enochs \& Riggs, 1990). Specifically, 13 questions addressed PSTE and 10 questions addressed STOE, and each consisted of a 5-point Likert scale of strongly agree (SA), agree (A), uncertain (UN), disagree (D), and strongly disagree (SD) (Enochs \& Riggs, 1990). The survey consisted of a mixture of positive and negative questions concerning the two subscales, with positive questions having the scale: $\mathrm{SA}=5$ points, $\mathrm{A}=4$ points, $\mathrm{UN}=3$ points, $\mathrm{D}=2$ points, $\mathrm{SD}=1$ point, and negative questions having a reverse score: $\mathrm{SA}=1, \mathrm{~A}=2, \mathrm{UN}=3, \mathrm{D}=4, \mathrm{SD}=5$ (Enochs \& Riggs, 1990). Given this scoring system, PSTE scores ranged from 13-65, and STOE scores ranged from 10-50 (Enochs \& Riggs, 1990). I used Bleicher's (2004) revised STEBI-B, as the revised version included two changes to two original STOE questions, as these questions showed cross-loading in the factor-analysis, and they showed "low item-total correlations" (p. 386). Essentially, the wording of item numbers 10 and 13 in the survey was confounding student responses; therefore, Bleicher (2004) modified those two questions to make them clearer to students. In addition, in the revised Bleicher (2004) survey, question 19 read, "I wonder if I will have the necessary skills to teacher science" (p. 391). The word "teacher" in question 19 was not present in Enochs and Riggs (1990) original STEBI-B survey, rather, the original survey read, "I wonder if I will have the necessary skills to teach science" (emphasis added to indicate correction) (p. 26). Therefore, number 19 in the current STEBI-B survey used in this study reflected the intentions of the original.

Preceding the STEBI-B survey questions, I added several questions that were considered background variables which may have influenced PSTE and STOE scores. These variables included: gender, ethnicity, age range, the number of previous science courses taken, the number 
of previous teaching experiences, and prior experience with science (Bleicher, 2004). Initially, I planned to determine the association between the background variables and the PSTE and STOE subscales using Bleicher's (2004) method of analysis, in which the variables would be divided into separate categories and then an independent t-test or ANOVA (depending on the number groups or levels) would be performed to determine any "significant differences between group means" (Bleicher, 2004, p. 386). However, given that all of the Science Methods students were Caucasian, approximately the same age, and only three students were male, I did not conduct this analysis. Refer to Appendix B to view the demographic survey and Appendix $C$ to view the modified STEBI-B survey as it has been designed for this study (Enochs \& Riggs, 1990; Bleicher, 2004).

For this study, I measured the changes in science teaching efficacy beliefs (STEB) over time for the 21 individuals $(n=21)$ as they progressed through a Science Methods course. The dependent variable was the measure of STEB, specifically the PSTE, and the independent variable was the intervention of the Science Methods course. I collected data at three time periods: one time point at the beginning of the Science Methods course (pre) and two time points at the end of the Science Methods course (post and retrospective pre). The retrospective pre-test (r-pre) was performed after the post-test at the end of the Science Methods course, and was utilized in this study to enhance the internal validity and statistical power of the pre/post-test method of data collection (Cantrell, 2003).

The reason for utilizing the retrospective pre-test in addition to the traditional pre-test, was due to concerns regarding the "change effects of a training intervention," such as that of a Science Methods course, as there could have been a "response shift bias" occurring in the pre/post-test which would potentially threaten the interval validity of the test (Cantrell, 2003, p. 
177). According to Cronbach and Furby (1970), the internal validity of the pre/post-test relies upon the idea that the "underlying metric a respondent employs when completing both the pretest and the post-test remains the same for both points in time" (as cited in Cantrell, 2003, p. 177). A previous study by Cantrell (2003) regarding the use of the retrospective pre-test (along with a pre- and post-test) with the STEBI-B survey for preservice teachers indicates that when individuals take a pre-test, they have an incomplete "conceptualization of the concept to be measured," which, during their progression through the Science Methdods course, changes due to the intervention of the course (Cantrell, 2003, p. 177). Because of the changes in "views, beliefs, and behaviors relative to the construct," a "response shift bias" must occur, which means the metric for measuring these changes must be recalibrated (Cantrell, 2003, p. 177). The response shift bias has been classified as a "shifting in the respondents perception of themselves," and it is this change in preception that is the threat to internal validity (Cantrell, 2003, p. 177). In order to account for this shift in perception and allow participants to provide a more accurate representation of their perceptions prior to the intevention, a retrospective pre-test was given after the post-test, so that the participant could "reflect back on her beliefs and retrospectively determine where she would rate herself on the first day of the course" (Cantrell, 2003, p. 178) .

As was previously mentioned, the STEBI-form B measured two constructs of STEB: personal science teaching beliefs (PSTE) and science teaching outcome expectancies (STOE). In this study, I focused exclusively on the PSTE data, as this was more relevant to the overall objectives of the quantitative portion of my study, which were to examine the PSTE of individuals in the study and changes in PSTE for these individuals due to the course, rather than expectations of science teaching. The PSTE and STOE scores can be evaluated separately, as per 
the literature, because they do not correlate (Bleicher, 2004). Using the PSTE scores from the "pre-" data, I placed the participants into subgroups of higher, middle, and lower efficacy. A previous study, which examined preservice teachers' varying levels of efficacy with regard to teaching practice in a Science Methods course and student teaching experience, divided individuals into groups of higher efficacy, middle efficacy, and lower efficacy depending on how they scored in relation to their peers (Ramirez Sangueza, 2010); thereby eliminating the arbitrary placement of individuals into groups. This technique for grouping individuals was also utilized in the current study, and the categories were determined by dividing the range of PSTE scores by the number of categories $(n=3)$ (Ramirez Sangueza, 2010). Once individuals were placed into a subgroup, a One-Way Repeated Measures Analysis of Variance (ANOVA) was performed to determine significance of the variance ratio $(\mathrm{F})$ between the three mean PSTE scores for each of the three groups $(\alpha=.05)$. In addition, a post-hoc Holm-Sidak test was performed to determine a significant difference in mean values between the "pre," "post," and "rpre" data. Ultimately, there was one mean score for each of the 3 subgroups across the three time periods. Analysis in this regard focused on the sample means between time periods, rather than variance ratios. The subgroups of low, middle, and high efficacy were treated as individual entities in order to evaluate progress (or lack of progress) over time. The reliability coefficient for the PSTE is .87 (Bleicher, 2004). The quantitative methods addressed research questions 1a (What are the Science Teaching Efficacy Beliefs (STEB) of pre-service elementary teachers as they progress through a Science Methods course?), and 1b ( How do the STEB of pre-service elementary teachers with high and low efficacy beliefs change as they progress through a Science Methods course?). 
I administered the STEBI-B at the beginning (pre) and end of the Science Methods course (post and r-pre). My reasoning for gathering STEB data in this manner is because I needed to establish a baseline score for STEB at the beginning of the final year of teacher preparation, then again after the Science Methods course to determine if there were changes in STEB due to the experiences in this course. I utilized the results of the "pre" STEBI-B survey to select individuals with varying levels of self-efficacy (higher efficacy and lower efficacy), to participate in the qualitative portion of the study.

\section{Qualitative Research}

The qualitative data collection involved a phenomenological study of eight individuals participating in the Science Methods course. These individuals were chosen based on their PSTE scores, as I chose four individuals with the highest PSTE score and four individuals with the lowest PSTE score. There were few participants who scored in the "low efficacy" category (only one individual); therefore, this I chose to interview the three lowest "middle efficacy" individuals and the one individual in the "low efficacy" category. I considered these four individuals those with "lower efficacy," and the four who scored the highest the "higher efficacy" category.

I utilized a transcendental phenomenological approach to the eight case studies in order answer questions 1c (What is the nature of the lived experiences of preservice elementary teachers with higher and lower PSTE beliefs as they progress through a Science Methods course?), and 1d (How does the meaning developed during the lived experience of preservice elementary teachers with higher and lower PSTE beliefs influence their STEB?). Through this data, I hoped to gain an understanding of how experiences affect STEB and how differing levels of PSTE affect the lived experiences of those participating in the Science Methods course. 
Given that I utilized transcendental phenomenological methodology to conduct the qualitative portion of this study, I conducted in-depth, semi-structured interviews with each of the case study participants at two time points during the Science Methods course; one "pre" interview at the beginning of the course (after the "pre" STEBI-B survey) and one "post" interview after the course (prior to the "post" STEBI - B survey). The following section will provide background into phenomenological studies, specifically focusing on transcendental phenomenology, and it will provide a more detailed explanation as to why I chose this is type of methodology and how I conducted this portion of the study.

Phenomenology. As previously mentioned, I chose to perform a phenomenological study for the qualitative portion of this research. This type of study focuses on "descriptions of what people experience and how it is that they experience what they experience" in order to ultimately determine the "essence of shared experiences" of individuals involved in the phenomenon of interest (Patton, 2002, p. 107). Phenomenology shares several commonalities with other forms of human science research, including Ethnography, Grounded Theory, Hermeneutics, and Heuristics (Moustakas, 1994). These commonalities, according to Moustakas (1994), include:

1. An acceptance and recognition of the value of qualitative research, including design and methodologies, and the understanding that quantitative research is not appropriate for the study of human experiences.

2. A holistic approach to research, rather than the parts that make up the whole.

3. Gaining an understanding of the meaning of the experience

4. Gaining a description of the experience through interviews with those who experienced the phenomenon. 
5. Viewing the qualitative data as essential to the understanding of behavior and as a valuable resource for further inquiry.

6. An understanding of the role of the researcher in developing research questions.

7. Understanding that the behaviors and experience are linked as parts of a whole. (p. 21)

Transcendental phenomenology. Transcendental phenomenology differs from the above commonalities in the philosophical underpinnings of the transcendental perspective (described below), as well as in the methods of data collection and analysis (Moustakas, 1994).

Transcendental phenomenology takes a systematic approach to avoiding bias and preconceptions in the researcher, through the formation of the epoche, a self-reflection process performed by the researcher, in order to achieve a state of being completely "open, receptive, and naïve" during interviews with participants (Moustakas, 1994, p. 22). In addition, this form of phenomenological research emphasizes "intuition, imagination, and universal structures" in the telling of the story of an experience, which will further elicit understandings of "perceptions, feelings, thoughts, and sensual awareness in consciousness with reference to a specific experience" (Moustakas, 1994, p. 22). The other forms of human science research do not take this approach to examining the human experience, as there is less concern over the impact of researcher bias on potential findings. In transcendental phenomenology, the formation of the epoche and the systematic approach to gathering data help to eliminate this bias and focus on the individuals experience and the meaning generated by the individual during the experience. A detailed description of the generation of the epoche can be found in the Qualitative Data Collection and Analysis section.

The following section includes a general description of the conceptual framework surrounding phenomenology. This precedes a deeper description of transcendental 
phenomenology, with an emphasis on data collection and analysis procedures and how they are informed by this methodology

Conceptual Framework. Phenomenology has its roots as a philosophical tradition developed by Edmund Husserl, as well as those of Heidegger, Sartre, Merleau-Ponty, Kant, Hegel, and Descartes (Moustakas, 1994; Patton, 2002; Spiegelberg, 1982). Although there are different forms of phenomenology, hermeneutic phenomenology (van Manen, 1990) and empirical transcendental or psychological phenomenology (Moustakas, 1994), the basic philosophical assumptions of this form of research concern the lived experiences of people, the idea that these experiences are conscious (van Manen, 1990) and the assumption that examination of these experiences result in a description of the essence or meaning of the phenomenon (Moustakas, 1994). The German philosopher, George Wilhelm Friedrich, refers to phenomenology as "knowledge as it appears to consciousness, the science of describing what one perceives, senses and knows in one's immediate awareness and experiences" (as cited in Moustakas, 1994, p. 26). Stewart and Mickunas (1990) discuss four philosophical perspectives of phenomenology, which include the "return to the traditional task of philosophy" as the "search for wisdom;" the suspension of presupposition" with the formation of the epoche; the intentionality of consciousness," which assumes that "consciousness is always directed at an object;" and "the refusal of the subject-object dichotomy" and the "reality of an object is only perceived within the meaning of the experience of an individual" (as cited in Creswell, 2007, pp. 58-59). The consciousness of the individual is significant in phenomenology, as "what appears in the consciousness is the phenomenon" of interest, and the phenomena are the building blocks of human science and the basis for all knowledge (Moustakas, 1994, p. 26). The object that appears in the conscious mind has a direct relationship to the how it exists in the natural world, because 
this object in the conscious is the "absolute reality," and what is in the real world is a "product of learning" (Moustakas, 1994, p. 27). Phenomenology involves "returning to the self to discover the nature and meaning of things as they appear and in their essence" (Moustakas, 1994, p. 26).

Transcendental phenomenology. I have decided to use Moustakas' approach to transcendental phenomenological data collection and analysis for this study, as it focuses on a “description of the experiences of participants" (Creswell, 2007), rather than interpretations of the experience by the researcher, as is the case with hermeneutical phenomenology (van Manen 1990). This form of research also differs from Heuristics, which focuses on finding the nature and meaning of life experiences with an autobiographical perspective, in which the "self" of the researcher is present within the research process (Moustakas, 1990, p. 9). The term "transcendental" has been described by Moustakas (1994) as that "in which everything is perceived freshly, as if for the first time" (p. 34). This state of "fresh" perception can be achieved through the development of an epoche, as developed by Husserl, in which the researcher sets aside personal experiences and preconceived notions in order to view the experience under study with a fresh perspective (Creswell, 2007). Moustakas (1994) claims that Transcendental Phenomenology is:

...the first method of knowledge because it begins with "things themselves"; it is also the final court of appeal. Phenomenology, step by step, attempts to eliminate everything that represents a prejudgment, setting aside presuppositions, and reaching a transcendental state of freshness and openness. A readiness to see in an unfettered way, not threatened by the customs, beliefs, and prejudices of normal science, by the habits of the natural world or by knowledge based on unreflected everyday experience. (p. 41) 
Moustakas (1994) has identified several steps necessary for examining the essence of the lived experience of a phenomenon, including the identification of the phenomenon, the development of an epoche by the researcher, and the collection of data from several individuals who have experienced the phenomena. Analysis of the data includes the identification of significant quotes and then the formation of themes (Creswell, 2007). Following this analysis, the researcher will develop a textural and structural description of the experiences in order to determine the essence of the phenomena (Creswell, 2007). A more detailed description of this process can be found below.

Transcendental phenomenology or empirical psychological phenomenological research is the most frequently applied human inquiry research, and draws from the Duquesne Studies in Phenomenological Psychology (Moustakas, 1994; Creswell 2007), as well as from methods of data analysis from van Kaam (1966), who “operationalized empirical phenomenological research in psychology" (Moustakas, 1994). Van Kaam (1966) performed studies which examined high school and college students' feelings of being understood, and he felt that a preconceived methodology utilizing statistical analysis would "distort rather than disclose a given behavior through an imposition of restricted theoretical constructs on the full meaning and richness of human behavior" (p. 14) (as cited in Moustakas, 1994, p. 12). According to Moustakas (1994), this approach to phenomenological research requires a "return to experience in order to obtain comprehensive descriptions that provide the basis for a reflective structural analysis that portrays the essences of the experiences" (p. 13). It is the task of the researcher or "human scientist" to determine the "underlying structures of an experience by interpreting the originally given descriptions of the situation in which the experience occurs" (Moustakas, 1994, p. 13). This will lead to a description of the experience, an understanding of the meaning of the phenomenon by 
those who experience it, as well as provide an understanding of a universal essence of the phenomenon (Moustakas, 1994).

Intentionality and transcendental phenomenology. The concept of intentionality, as posited by Husserl (1931), is connected to transcendental phenomenology, in that intentionality "refers to consciousness" (Moustakas, 1994, p. 28). When an individual is conscious of an object, there is a relationship between the object in the conscious and the "act of consciousness," which is intentional (Moustakas, 1994, p.28)." Husserl (1931) noted factors that are connected to understanding consciousness, such as feelings, judgments, and desires. According to Kockelmans (1967), the term "intention" refers to the "orientation of the mind to its object; the object exists in the mind in an intentional way" (p. 32). Intentionality is linked to meaning, as it necessitates the need to "be present to ourselves and to things in the world" and the recognition that the self and the world are connected to meaning (Moustakas, 1994, p. 28). According to Moustakas (1994), "intentional acts are objectifying while feeling acts are non-objectifying," (p. 29). An example from education that would illustrate this meaning would be that of a preservice teacher intentionally observing an in-service teacher during a field experience as this individual models a particular teaching strategy. The preservice teacher may experience feelings of intrigue while viewing the teacher. Smith (1981) would describe the viewed object (the in-service teacher as he/she models a teaching strategy) as the intentional act (the perception of the object in the consciousness), and the feeling of intrigue would be the non-object (as cited in Moustakas, 1994, p. 29). Essentially, the perception of the experience allows it to exist in the consciousness, where the actual experience is the "objectifying quality," and the feeling evoked from the experience is the "non-objectifying quality" (Moustakas, 1994, p. 29). 
The concept of objectifying qualities and non-objectifying qualities lead to a discussion of the concepts of nomea and noesis, which are the components of intentionality. Moustakas (1994) describes the nomea is the phenomenon of an object, not the object itself, and the perception of how this object appears can be affected by viewpoint, experiences, and judgments of the individual perceiving the object. In the above example, the noema would be the perception of the intentional experience of watching the in-service teacher, and this perception is influenced by the experiences of the preservice teacher. It is this perception that is in the consciousness. The noetic (noesis) is described as the "explication of the intentional processes themselves," or how the previous experiences of the preservice teacher influence their perceptions as they observe the in-service teacher (Moustakas, 1994, p. 32). Ultimately, to address the challenges associated with determining intentionality, the researcher must consider:

...explicating the sense in which our experiences are directed, discerning the features of consciousness that are essential for the individuation of objects (real or imaginary) that are before us in consciousness (Noema), explicating how beliefs about such objects (real or imaginary) may be acquired, how it is that we are experiencing what we are experiencing, integrating the noematic and noetic correlates of intentionality into meanings and essences of experiences. (Moustakas, 1994, p. 31-32)

According to Husserl (1977), on the noematic side of an experience, there is an "uncovering and explication... of what is actually presented in consciousness," which is "continually changing in perception;" (p. 46) whereas, on the noetic side, there is an "explication of the intentional processes themselves" (as cited in Moustakas, 1994, p. 30). Essentially, a researcher can try to determine what noetic factors of an experience account for an individual's noematic meanings (Moustakas, 1994). In the current student, I will try to determine what noetic factors account for 
the noematic meanings made by preservice teachers with varying levels of science teaching selfefficacy beliefs as they experience a Science Methods course. In order to determine the relationship between these two entities (noema/noesis), the "textural (noematic) and structural (noetic) dimensions of phenomena, and the derivation of meanings is an essential function of intentionality" (Moustakas, 1994, p. 31). A detailed description of how I gathered the textural and structural dimensions in this study are included in the Qualitative Data Collection and Analysis section.

Intuition and transcendental phenomenology. Transcendental phenomenology is also bound to the concept of intuition (Moustakas, 1994). According to Descartes (1977), intuition is an "inborn talent" that will produce "solid and true judgments concerning everything that presents itself" (as cited in Moustakas, 1994, p. 32). Intuition is the place from which knowledge stems, and it is void of impressions and attitude (Moustakas, 1994). Philosophers such as Husserl and Descartes consider the self as an "intuitive-thinking being," who thinks, senses, and feels, which become evident with clarity through an intuitive reflective process (Moustakas, 1994). Intuition is "essential in describing whatever presents itself, whatever is actually given" (Moustakas, 1994, p. 33). Therefore, intuition is necessary for data collection and analysis during transcendental phenomenological research. I relied heavily on intuition when determining which statements made by participants were significant and in the organization of these statements into meaningful clusters of data for the determination of themes.

\section{Qualitative Data Collection and Analysis}

Data collection techniques. As previously mentioned, I utilized phenomenological interviewing techniques for my qualitative data collection. The phenomenological interviewing process is open-ended, informal and interactive (Moustakas, 1994), and I conducted two 
interviews with each participant during the experience of the Science Methods course. The interview questions were designed to determine the noetic factors (previous experiences with science education and science teachers) and how these factors account for the noematic meanings generated by the participants (the experiences of the Science Methods course and the feelings and thoughts associated with these experiences).

I first conducted a semi-structured, in-depth "focused life history" interview with each case participant at the beginning of the Science Methods course, after the "pre-" STEBI-B survey. As was previously mentioned, the case participants chosen for the interviews were those with the four highest and four lowest PSTE scores from the "pre-" STEBI-B survey. The focused life history interview helped to create a context for the study, as I had each participant provide a detailed description of their experiences with science education and preservice teacher preparation (Seidman, 1998). During this interview, I asked participants to reconstruct their experiences with family, peers, and teachers (specifically science teachers), focusing on past experiences in school and in any other extracurricular science events, such as tutoring and participation in science fairs. The interview included several open-ended "how" questions designed to "reconstruct a range of constitutive events in their past family, school, and work experiences," which were then followed by prompts for further clarification. The interviews were conducted in my office and generally lasted up to 40 minutes per participant. A list of Focused Life History interview questions can be found in Appendix D.

At the end of the Science Methods course, before the "post-" STEBI-B survey, I interviewed participants again to arouse a "comprehensive account of the person's experience of the phenomenon" (Moustakas, 1994, p. 114). During this final interview, I attempted to create a trusting and relaxed environment by beginning with some social conversation, followed by a 
suggestion to the participant to "take a moment to focus on the experience ....then to describe the experience fully" (Moustakas, 1994, p. 114). This interview concentrated on the specific details of the experience with the Science Methods course. I asked participants about their experiences within the course, specifically focusing on the activities they participated in throughout the semester and the feelings and thoughts associated with these experiences. These details led to the building of their opinion of the experience (Seidman, 1998). I asked students to talk about their relationships with their peers within the course, their teacher, and the students they worked with (during the field experiences). These types of questions were designed to place the experience "within the context of the social setting" (Seidman, 1998, p. 12). I also asked them to construct a typical day from beginning to end to further elicit details of the experience (Seidman, 1998). Refer to Appendix E for a list of the questions I utilized for the semi-structured "Post-Science Methods course" interview.

Qualitative data analysis. Phenomenological analysis has been described by Patton (2002) as a form of analysis that "seeks to grasp and elucidate the meaning, structure, and essence of the lived experience of a phenomenon for a person or group of people" (p. 482). Moustakas (1994) developed an approach for determining the meaning or essence of the lived experience using transcendental phenomenological methodology. The three processes that are used in transcendental phenomenology to "facilitate the derivation of knowledge," include the generation of the Epoche, Transcendental Reduction, and Imaginative Variation (Moustakas, 1994, p. 33).

The generation of an Epoche requires the researcher to become aware of their role in the study and identify any involvement with the participants or subject matter, as well as develop an awareness of any personal bias and preconceptions the researcher possesses prior to beginning 
the study (Patton, 2002). Moustakas (1994) stated that an epoche "requires a new way of looking at things, a way that requires that we learn to see what stands before our eyes, what we can distinguish and describe" (p. 33). The formation of an epoche is an on-going process of analysis throughout a study to help the researcher discard these preconceptions and biases (Patton, 2002). I began developing an epoche prior to conducting my first Focused Life History interview. This process involved a period of meditation in which I examined my feelings and thoughts regarding the interview participants and the more general concept of science education. I continued to develop the epoche after transcribing the Life History interviews and prior to conducting the post-Science Methods course interviews. The generation of the epoche allowed me to enter into my study with an open mind, devoid of judgment, so that the experiences of my participants were free of my preconceptions. This "phenomenological attitude shift" produced by the epoche helped establish rigor in my study (Patton, 2002). Refer to Appendix F to view the epoche generated for the current study.

After the generation of the epoch, I performed a Transcendental Reduction in which I "consider[ed] each experience in its singularity," and where the phenomenon of the Science Methods course and the experiences of individuals with varying levels of PSTE within the course were "perceived and described in [their] totality" (Moustakas, 1994, p. 34). Through this process, a "textural description of the meaning and essences of a phenomenon" was generated (Moustakas, 1994, p. 34). Essentially, this step required that the phenomenon be described, complete with details of "perceptions, thoughts, feelings, sounds, colors, shapes" of the experience (Moustakas, 1994, p. 34). Transcendental Reduction has been described as a form of analysis in which the researcher "holds the phenomenon up for serious inspection" where it is 
taken apart and inspected (Denzin, 1989, as cited in Patton, 2002, p. 485). To accomplish this, Denzin (1989) suggests "bracketing" the data using the following five steps:

1. Locate within the personal experience, self -story, key phrases and statements that speak directly to the phenomenon in question.

2. Interpret the meanings of these phrases and statements that speak directly to the phenomenon in question

3. Obtain the subject's interpretations of these phrases, if possible.

4. Inspect these meanings for what they reveal about the essential, recurring features of the phenomenon being studied.

5. Offer a tentative statement, or definition of the phenomenon in terms of the essential recurring features identified in step 4. (as cited in Patton, 2002, pp. 485-486)

During the process Transcendental Reduction, I bracketed the data by first placing all of the interview transcripts before me so that the data was "horizonalized" or "spread out" (Patton, 2002, p. 486). This allowed the data to be examined "with all elements and perspectives having equal weight" (Patton, 2002, p. 486), in order to create a "meaning or meaning unit" list from the horizonalized statements (Moustakas, 1994, p. 118). The horizonalization process involved an examination of each of the post-Science Methods course interviews for significant statements in order to obtain information about the experience directly from the participants themselves, providing perspective as to how the participants described the various aspects of the course (Moustakas, 1994). All significant statements were recorded verbatim and were not arranged in any particular order (Moerer-Urdahl \& Creswell, 2004; Moustakas, 1994), other than being labeled as statements made by those with low or high efficacy. Due to the quantity of significant statements made by the eight interview participants and the varying topics discussed during the 
interviews, I grouped statements into the following categories for both high and low efficacy groups: Field experiences, relationships, the teaching experience, teaching models, taught by teacher, assessments, and perceptions of efficacy.

Based on this examination of the significant statements, invariant themes or meaning units emerged from the data. Creating the themes of the experience of the Science Methods course involved an examination of the "non-repetitive and non-overlapping" significant statements for meanings (Moerer-Urdahl \& Creswell, 2004, p. 9), and then grouping these meanings into "meaningful clusters," and, finally, themes (Patton, 2002, p. 486). After determining the themes, I texturized the data for each interview participant and then created a composite textural description for both the high and low efficacy groups. Texturizing involved first looking at the descriptions of the experience made by the individual participants (reviewing interview questions such as, "Describe the experience... What did you do?"), followed by a deeper examination of the feelings or thoughts generated by the experience (reviewing questions such as "How did that experience make you feel? What thoughts come to mind when you reflect on that experience?"). Patton (2002) describes this in-depth examination of the themes as "an abstraction of the experience that provides content and illustration, but not yet essence," which helps the researcher to understand the experience through the feelings associated with the experience, rather than just a description of the experience itself (p. 486).

The invariant themes were then expanded upon using Imaginative Variation, which involved looking at the themes from many different angles (Moustakas, 1994; Patton, 2002). During the process of Imaginative Variation, I carefully examined the context of the experience, so that I was able to formulate the "structural essence of the experience," and "present a picture of the conditions that precipitate[d] [the] experience" (Moustakas, 1994, p 35). This part of the 
analysis required an in-depth examination of the experience that looked beyond the feelings generated by the experience, but looked at how previous experiences could have precipitated these feelings (Patton, 2002). Through an examination of participants' feelings and thoughts concerning science content and science education based on previous educational experiences, I was able to determine the why of the experience (why did they feel/think what they did during the experience). The process of creating the structural descriptions was intuitive and ultimately helped to determine the deeper meaning of the experience for individuals with high and low efficacy (Moustakas, 1994, Patton, 2002).

After the composite textural and structural essences were determined for both the high and low efficacy groups, they were integrated with one another to "arrive at a textural-structural synthesis of meanings and essences" of the Science Methods experience (Moustakas, 1994, p. 36).

Trustworthiness of data. I determined the trustworthiness of my findings by emailing each participant a copy of the textural-structural description I created from their experience. I requested that the participant examine the description for errors, for which I made revisions accordingly (Humphrey, 1991, as cited in Moustakas, 1994). I received only one minor correction (the age of a participant) during this process, indicating that the textural and structural descriptions of each participant's experience were accurate and considered trustworthy data.

\section{Mixed Method Analysis and Data Integration}

My strategy for analysis was typology development, as "the analysis of one method considers the homogeneity within and the heterogeneity between subgroupings of data on some dimension of interest, yielding a set of substantive categories" (Plano Clark \& Creswell, 2008, p. 236). For my study, the quantitative "pre" results informed the qualitative cases, as subgroups 
were formed and analyzed for similarities and differences among efficacy scores (Plano Clark \& Creswell, 2008, p. 236). To achieve integration, the typology of the individuals in the Science Methods course were determined using the survey, as individuals were classified as high or low efficacy. Analysis of qualitative data within each of these groups indicated commonalities and differences within the group and between the groups (Plano Clark \& Creswell, 2008, p. 237). There were certain commonalities among individuals in the high efficacy group, as well as among those in the low efficacy group (Plano Clark \& Creswell, 2008, p. 237). This type of analysis was appropriate, because the typology was "created from one data type and applied to an analysis of the other data type"(Plano Clark \& Creswell, 2008, p. 238).

Within the literature, there were little data available as to how to integrate phenomenological data and quantitative survey data. Essentially, I used the quantitative data to tell the story of the qualitative data, and visa-versa. Any changes in self-efficacy data that occurred during the semester as a result of experiences within the Science Methods course was illuminated in the qualitative interview data. The meanings and essences of the experiences that were derived during the qualitative studies shed light on the changes in the self-efficacy survey results. After preforming an initial analysis of both the qualitative and quantitative data separately, I re-examined each data set in light of the other and attempted to find trends. Using this methodology, I was able to tell the story of the experiences of individuals with varying degrees of self-efficacy as they experience a Science Methods course. In telling this story, I illuminated the essence of these experiences, while also describing how the experiences changed self-efficacy. 


\section{Chapter 4: Results}

\section{Quantitative Analysis}

The quantitative portion of this study explored changes in Personal Science Teaching Efficacy (PSTE) beliefs of preservice elementary students participating in their Science Methods block course. This group of individuals was analyzed as a whole $(n=21)$ to help answer research question 1a (What are the Science Teaching Efficacy Beliefs (STEB) of pre-service elementary teachers as they progress through a Science Methods course?), and grouped into one of three subgroups of low, medium and high efficacy, depending on how they scored in the pretest to help answer research question $1 \mathrm{~b}$ (How do the STEB of preservice elementary teachers with higher and lower efficacy beliefs change as they progress through a Science Methods course?). Specifically, I examined changes in PSTE over the course of the semester of the Science Methods course. The range of PSTE scores run from 13-65, with 13 PSTE questions, and individuals were able to score from 1-5 points per question. For analytical purposes, and in order to conduct the qualitative portion of this study, the data were divided into tertiles using the range of PSTE scores achieved by this group of individuals. The tertiles represented low, middle, and high PSTE groups. Tertile range was calculated by dividing the overall range of participants' PSTE pre-test scores by 3 to yield a (rounded) value of 9 as the span per tertile. This was performed in order integrate the quantitative scale of PSTE scores into categorical ranks of low, middle, and high. PSTE scores ranged from a value of 30 to 58, and given this range of values, there were 12 high efficacy participants $(n=12), 11$ middle efficacy participants $(n=11)$, and one low efficacy participant $(\mathrm{n}=1)$.

Initially, an analysis of the whole group's PSTE scores was performed using a One-Way Repeated Measures Analysis of Variance (ANOVA). The results indicated a significant 
difference in the mean values $(\mathrm{p}=0.002)$ of the PSTE scores (Figure 2).

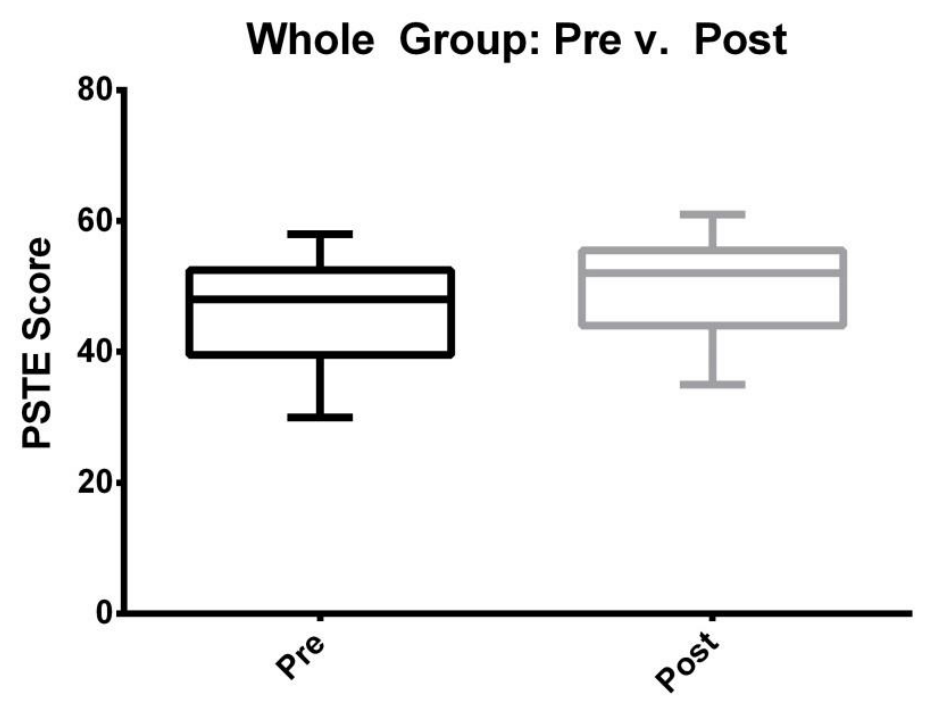

\section{STEBI-B Time Sequence}

Figure 2. Changes in PSTE for whole group. This figure illustrates the changes in the mean PSTE scores for all participants in the study between the pre- and post-STEBI-B surveys.

A subsequent post-hoc Holm-Sidak test was performed to determine between which events significant difference is present, while accounting for Bonferroni inequality. A comparison of the pre- and post-tests indicated a significant difference in mean values $(\mathrm{p}=$ 0.001). A comparison of the post-test and retrospective pre-test also indicated a significant difference in mean values $(\mathrm{p}=0.048)$. There was no significant difference in the mean values of the pre and retrospective pre-test scores $(\mathrm{p}=0.139)$. The specific subgroups of low, medium and high PSTE scoring individuals were also analyzed using the one way repeated measures ANOVA with the pre-, post- and retrospective pre-test data. Results indicated that the retrospective pre-test data were confounding the overall trends between the pre- and post-test when analyzed by ANOVA, due to the wide range of values in this group and the loss of appropriate degrees of freedom. Since the initial findings in the whole group analysis indicated 
that there was no significant difference between the pre- and retrospective pre-test data, even though homoscedastic, the retrospective pre-test data were removed from all subsequent analyses, in order to more accurately focus only on pre- and post-test data. The whole group PSTE scores were reanalyzed without this retrospective pre-test data and again indicated a significant difference in mean values of the pre- and post-tests, but the significance was greater $(\mathrm{p}<0.001)($ Table 1).

Table 1

One-Way Repeated Measures Analysis of Variance Between STEBI-B Time Sequences

\begin{tabular}{|c|c|c|c|c|c|}
\hline ANOVA Components & $\underline{\mathbf{S S}}$ & $\underline{\mathrm{DF}}$ & $\underline{\text { MS }}$ & F (DFn, DFd) & $\underline{P \text { value }}$ \\
\hline STEBI-B Time Sequence & 227.5 & 2 & 113.8 & $F(1.490,29.81)=7.528$ & $P=0.0046$ \\
\hline Participants & 2905 & 20 & 145.2 & $F(20,40)=9.611$ & $P<0.0001$ \\
\hline Residual (random) & 604.5 & 40 & 15.11 & & \\
\hline Total & 3737 & 62 & & & \\
\hline
\end{tabular}

The specific subgroups were reanalyzed with just the pre and post-test data using a paired t-test. The low efficacy subgroup showed a significant difference in the mean values $(p=0.005)$ of the pre and post-test scores. The medium efficacy group also showed a significant difference in the mean values $(\mathrm{p}=0.004)$ of the pre- and post-test scores. However, the high efficacy group did not show a significant difference in the mean values of the pre- and post-test scores $(\mathrm{p}=$ 0.184). Trends in the data show that there was a significant increase in PSTE scores for both low and medium efficacy groups, whereas the PSTE scores of the high efficacy groups do not change significantly and seem to plateau (Figure 3). These findings indicate that while the Science Methods course did not increase or decrease the PSTE beliefs of those whom already had high 
efficacy, it did have a positive impact in the PSTE beliefs of those with lower efficacy.

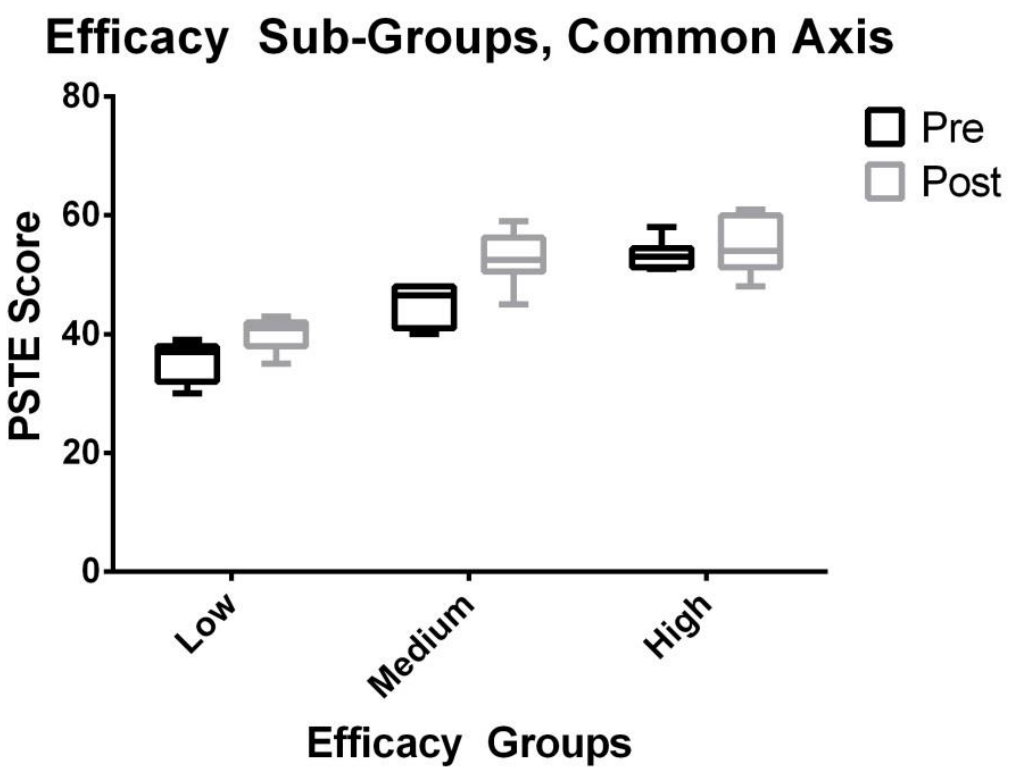

Figure 3. Changes in PSTE scores for efficacy subgroups. This figure illustrates the changes in PSTE scores before and after a Science Methods course for individuals with low, medium, and high efficacy.

\section{Qualitative Analysis}

The qualitative portion of this study utilized transcendental phenomenological methodology, which involved conducting in-depth interviews before and after the experience of a Science Methods course, and was followed by the development of themes, and ultimately, a determination of the essence of this experience for participants with lower and higher efficacy. As it was previously mentioned in Chapter 3, interview participants were chosen based on their PSTE scores from the pre-STEBI survey taken at the beginning of the semester. It should be noted that all interview participants were female; however, this was to be expected, because $96 \%$ of the participants in the entire study were female. In addition, the one male participant could not be considered for the qualitative interviews, as his PSTE score placed him in the upper- medium efficacy group, which fell outside of the scope of interest for the qualitative portion of the study. 
Pseudonyms were used in order to assure anonymity. With the exception of Sara, who was 24

years old, all participants were between 18-22 years of age. Most of the participants reported the same number of previous science courses, which was expected due to similar curricular requirements for all elementary education majors (refer to Table 2 for the demographic data). I suspect that the inconsistency seen in the data for Jamie was due to her incorrect recollection of the science courses she has taken.

Table 2

Demographic Data for Interview Participants

\begin{tabular}{|c|c|c|c|c|c|c|c|}
\hline Participant & $\begin{array}{l}\text { PSTE } \\
\text { Score }\end{array}$ & $\frac{\text { Low/High }}{\text { Efficacy }}$ & Ethnicity & Age & $\frac{\frac{\text { Previous }}{\text { Science }}}{\frac{\text { Courses }}{\text { Taken }}}$ & $\frac{\underline{\text { Previous }}}{\underline{\text { Experience }}}$ & $\begin{array}{c}\begin{array}{c}\text { Prior } \\
\text { Experience }\end{array} \\
\underline{\text { with Science }}\end{array}$ \\
\hline Amy & 30 & Low & $\begin{array}{c}\text { Causasion } \\
\text { (non- } \\
\text { hispanic) }\end{array}$ & $\begin{array}{l}18- \\
21\end{array}$ & $4-7$ & None & Negative \\
\hline Sara & 34 & Low & $\begin{array}{c}\text { Causasion } \\
\text { (non- } \\
\text { hispanic) }\end{array}$ & $\begin{array}{l}22- \\
30\end{array}$ & $4-7$ & None & Negative \\
\hline Jane & 37 & Low & $\begin{array}{c}\text { Causasion } \\
\text { (non- } \\
\text { hispanic) }\end{array}$ & $\begin{array}{l}18- \\
21\end{array}$ & $4-7$ & None & Negative \\
\hline Cara & 37 & Low & $\begin{array}{c}\text { Causasion } \\
\text { (non- } \\
\text { hispanic) }\end{array}$ & $\begin{array}{l}18- \\
21\end{array}$ & $4-7$ & None & Negative \\
\hline Kate & 52 & High & $\begin{array}{c}\text { Causasion } \\
\text { (non- } \\
\text { hispanic) }\end{array}$ & $\begin{array}{l}18- \\
21\end{array}$ & $4-7$ & $\begin{array}{c}\text { Substitute / } \\
\text { Volunteer }\end{array}$ & Positive \\
\hline Beth & 53 & High & $\begin{array}{c}\text { Causasion } \\
\text { (non- } \\
\text { hispanic) }\end{array}$ & $\begin{array}{l}18- \\
21\end{array}$ & $4-7$ & $\begin{array}{l}\text { Substitute / } \\
\text { Volunteer }\end{array}$ & Positive \\
\hline Jamie & 53 & High & $\begin{array}{c}\text { Causasion } \\
\text { (non- } \\
\text { hispanic) }\end{array}$ & $\begin{array}{l}22- \\
30\end{array}$ & $0-3$ & $\begin{array}{l}\text { Substitute / } \\
\text { Volunteer }\end{array}$ & Positive \\
\hline Jenn & 53 & High & $\begin{array}{c}\text { Causasion } \\
\text { (non- } \\
\text { hispanic) }\end{array}$ & $\begin{array}{l}18- \\
21\end{array}$ & $4-7$ & $\begin{array}{c}\text { Substitute / } \\
\text { Volunteer }\end{array}$ & Positive \\
\hline
\end{tabular}

\section{Horizonalization: An Examination of Significant Statements}

While the qualitative portion of this research endeavored to glean the overall essence of the lived experience of this course from the perspective of those with low and high science 
teaching efficacy beliefs, due to the expansive nature of the experience and the variety of activities involved, it was necessary to examine the different aspects of the experience separately with regard to the significant statements. Based on the research questions of this study, specifically questions 1.c. (What is the nature of the lived experiences of pre-service elementary teachers with higher and lower efficacy beliefs as they progress through a Science Methods course?), and $1 \mathrm{~d}$. (How does the meaning developed during the lived experience of pre-service elementary teachers with higher and lower efficacy beliefs influence their science teaching efficacy beliefs?), and based on the nature of the interview questions asked of participants in order to determine this information, it was determined that the significant statements could be examined from seven perspectives: the field experiences; relationships developed within the course; descriptions of the teaching experience; the experience of watching the teacher and peers perform lessons (teaching models); the experience of being taught by the teacher of the course; the nature of the assessments used in the course; and participants' perceptions of their own science teaching efficacy. Refer to Appendix G to view the Significant Statement Tables 1-7.

\section{Themes or Meaning Units}

Based on an examination of the significant statements, themes or meaning units emerged regarding how those with low and high science teaching efficacy experienced the Science Methods course. The overall themes of the experience, regardless of efficacy classification, included: the power of realistic learning experiences; the power of authentic teaching experiences; modeling, the second-hand experience; the necessity of forming relationships, peer bonding and dependency; and assessments and feedback as meaningful work (Table 3).

Table 3

Themes or Meaning Units and Evidence

Themes/Meaning Units

The power of realistic learning experiences:

\section{Evidence in Participants' Statements}

- I think it is good to see that teaching doesn't have to take place in a classroom. I think that is one of the biggest things that you see. 


\section{Informal field experiences}

The power of authentic teaching experiences

Modeling, the second-hand experience

The necessity of forming relationships

Assessments and feedback as meaningful work
- When we went to the [Environmental] Center we actually did what he would do with the students.

- These [field] experiences were more...I would say...I don't know, more realistic, because you are actually out there in nature. ...So, it was more realistic and I think they could get a better understanding.

- $\quad$ [Preferred field experiences] to be more taught from the educators perspective and how that would be worked into my classes.

- I thought it [the lesson] went really well. I was really nervous about it...

- Overall it went better than I thought, like we were concerned about time, because we had 60 minutes to do it and we've never really taught a lesson that long before. I've never really had experience above second grade, so I was nervous about that, but it did go well.

- I think if there was a way to maybe do instead of the group teaching like that...because sometimes there was like five and six people in a group and I feel like that was hard to let everyone voice certain...I think maybe an individual teach... I think I would benefit from that and plus it would help me too, because I always get nervous teaching in front of my peers, but I feel like that would have helped me better.

- Maybe a little better [confidence in teaching science], just because I got that experience to teach science that one time.

- About the same [confidence in teaching science]... It is not how well I think I would teach it, but now I know that I've actually done a lesson and it is not like super stressful for me to have to find material or help or resources, or things like that.

- When we would watch our other classmates teach, I feel like we got a lot from it, because you learn...the way I would teach something and the way someone else would teach something is so different.

But, with other classmates, it was a great opportunity to learn how to work with others that have different teaching styles from yourself because not everyone is going to teach things the same way, so it was a really good collaborative effort on how do we work with each of our personalities, yet teach one activity to a group of students, so that was really nice.

$\underline{\text { Relationships with teacher }}$

- $\quad$ The class was too big and she [teacher] was too all over the place.

- $\quad$ She [teacher] was like a separate entity. Relationships with elementary students

- We never really interacted with them [students] too much.

- We really didn't have time to develop relationships with the students. Relationships with peers

- $\quad$...when one of us has a weakness...we work well together, the four of us...I guess we...in ways that she has weaknesses, I have the strengths and in ways that I have the weaknesses she has the strengths.

- The class has had discussions on that as a whole...We will sit there and even during class...it is just those looks that you exchange... why are we even here?

- I don't think it was as meaningful work

- It [assignment to read book] didn't capture my attention in any way, shape or form.

- She [teacher] grades them and she'll give us not much feedback. She just says good job, your paper was great and that is it.

- If I am doing something wrong I want to know, so I can improve and that didn't happen so...

- I am just depending on my student teacher that I am placed with to help me with my science... that is where I am going to get most of my help from.

- $\quad$...just this feeling of like not being satisfied by what I got from that [course] and just the boredom.

- She [teacher] might talk about one or two things that we have already heard of, so it was just like...it seemed really repetitive, it wasn't a lot of new information. 
Description of themes. As previously mentioned in the review of literature, Bandura's Social cognitive theory suggests that an individual will function as a result of the interaction of multiple factors, including cognitive processes, environmental factors, and behavior, and that the nature of an individual is defined in terms of symbolic, forethought, vicarious, self-regulatory, and self-reflective capabilities, along with environmental/external stimuli (Bandura, 1986). This concept was evident in the descriptions of experiences of those participating in this Science Methods course. Participants' perceptions of the various experiences within this course were shaped by a number of factors, including their previous experiences with science education, particularly with science teachers, their feelings about science in general, how they viewed their ability to teach science, their thoughts concerning the teacher of the Science Methods course, and relationships developed within the course. These factors also ultimately shaped what students felt they needed in order to feel confident while teaching science. There were common themes that arose during the interview process; however, both high and low efficacy participants held distinctively different perceptions of the nature of the experiences within this course, as was evident in their descriptions.

The power of realistic learning experiences. During the Science Methods course, participants engaged in two informal field experiences. It has been determined that alternative means of education for preservice teachers, such as informal learning experiences, are necessary for effective teacher preparation (Kelly, 2000; Stepans et al., 1995). Informal learning environments provide a place for explorations of content in a non-traditional context (Martin and Reynolds, 1996). According to Tuchman and Isaacs (2011), informal pre-service learning experiences have positively linked efficacy beliefs and student engagement in learning. In the current study, some low efficacy participants' comments regarding the informal field experiences 
included positive statements about the realistic nature of such experiences and the benefits of learning content during investigations, while others found this an engaging form of learning, both for themselves and for their future students. Regarding the informal field experience at an environmental center, in which participants investigated the distribution of trees and examined stream fauna, Sara (low efficacy) stated, "Yeah, I loved it. I mean, I didn’t know there was so much stuff in the creeks, like animals." The experience also helped Sara to explore other models of teaching, as was evident in her statement, "I think it is good to see that teaching doesn't have to take place in a classroom. I think that is one of the biggest things that you see." Other low efficacy participants also enjoyed the non-traditional learning environment. Cara said, "I like doing that kind of stuff instead of just sitting in the classroom. I liked it. It was pretty beneficial I thought." Jane realized the benefits of experiencing these informal learning environments as part of the course when she stated, "Realizing that there're things out there to go to as well, outside the classroom; that was beneficial." Other participants enjoyed the realistic nature of these learning experiences, where participants could experience what elementary students would learn in the same informal environment. Jane (low efficacy) felt that the informal experiences were ...like a real situation...Those were the best experiences in the whole class... When we went to the [environmental] center, we actually did what he would do with the students. Us getting to actually do it, instead of just talking about it and experiencing what the kids would experience, that kind of thing. We were like kids doing it, it was so much fun. Kate and Jamie (high efficacy) also enjoyed the realistic nature of these experiences. Kate explained, “

These [field] experiences were more...I would say...I don't know, more realistic, because you are actually out there in nature. I mean you could do that at school, but you 
couldn't really walk in the woods, you know? So, it was more realistic and I think they

[students] could get a better understanding.

Regarding the informal field experience at the "Challenger Center," Jamie commented, “... It was really neat...it was this big simulation thing, but it really felt real... they really made it seem so real and kids would love that. If we loved it, you know they will." However, two of the other high efficacy participants, Beth and Jenn would have preferred to experience the informal learning environments from the perspective of a teacher. Beth thought that "[In the field experiences] we were being students, instead of taking the teacher role, which I thought would have been more beneficial since that's what we are going to do." Similarly, Jenn said that she would have preferred field experiences 'to be more taught from the educators' perspective and how that would be worked into [her] classes."

The power of authentic teaching experiences. "Practice" teaching experiences have become a part of many preservice teacher preparation programs, and such experiences have allowed preservice teachers to "assess and interpret their content knowledge and pedagogical expertise" (Kelly, 2000). According to Bandura (1997), mastery or enactive experiences, such as the teaching experience of participants in this study, help preservice teachers gain an understanding of the difficulties involved in teaching and enables them to gain insight into their own teaching abilities. In the current study, several of the low efficacy participants discussed their concerns with what they perceived as difficulties. Sara stated, "I thought it went really well. I was really nervous about it... I was like "Oh my gosh, that's like the most boring topic ever." While Sara thought her teaching experience was successful, her nervousness had to do with her concern that the topic was "boring." Cara and Amy, both low efficacy participants, commented on the fact that the lesson was conducted with peers as a group. While Amy was happy about the 
opportunity to work in a group, "because you didn't have to teach the whole time," Cara felt that the large teaching group impeded each individuals teaching experience. She stated,

I think if there was a way to maybe do... instead of the group teaching like that...because sometimes there was like five and six people in a group and I feel like that was hard to let everyone voice certain...I think maybe an individual teach... I think I would benefit from that, and plus it would help me too, because I always get nervous teaching in front of my peers, but I feel like that would have helped me better.

While Jane (low efficacy), like Amy, was apprehensive about the idea of teaching for a much longer time period than she had ever experienced, she also had concerns about her lack of experience teaching to upper elementary students. Jane stated,

Overall it went better than I thought, like we were concerned about time, because we had 60 minutes to do it and we've never really taught a lesson that long before. I've never really had experience above second grade, so I was nervous about that, but it did go well. The high efficacy participants had more positive comments about their experiences teaching a lesson with elementary students. Kate and Beth felt that their lessons were successful; however Beth felt that there "was a little bit of confusion about what we were actually supposed to be teaching the students." Jaime also commented on her lack of preparation for the teaching experience when she stated,

I think it was good for me to actually teach children strictly a science lesson. Yeah, I'm glad that we had to do it; I just wish that we would've been better prepared. I think it was helpful to do it for that experience.

While Jamie was able to see the positive nature of the teaching experience, her serious concerns about not knowing what was expected of her from the teacher were evident when she stated, 
My group went the second class we had ever had of the semester, so we were very...we felt very unprepared...We felt really rushed into it and everything...It was the second week of classes that we had to do that, so we had the first class...ever...and the next week she told us that we were teaching. So, we had one week to get everything ready. We had absolutely no experience with those kids and really none with our professor either. We didn't really know what she expected and everything. And, I don't know ...that made it so difficult.

Jenn and Kate (both high efficacy) were also impressed by the level of knowledge of their students. Jenn said, "I was really surprised by a lot of the things. The way that they had answered questions was shocking to me, because they knew a lot...they had all kinds of good answers." Kate said she was "surprised by how much the kids knew already" when she conducted her lesson.

Modeling, the second-hand experience. According to Bandura, vicarious experiences, such as those experienced by the participants in this study as they watched their teacher and their peers teach lessons, can be powerful sources of self-efficacy (Bandura, 1997). During these vicarious experiences, participants would compare themselves and their capabilities to those who were modeling the teaching behavior (Bandura, 1997; Tschannen-Moran \& Woolfolk Hoy, 2007). While watching others teach, or having a "second-hand" teaching experience was positive for some participants, it was not for others.

Peer modeling. Low and high efficacy participants responded differently to the experience of watching their peers teach; several of the low efficacy participants discussed the positive aspects of peer modeling, whereas, the high efficacy participants either did not discuss peer modeling at all, or expressed a more negative out-look. Cara (low efficacy) stated how it 
was beneficial for the class "to see their [peers] ideas and what they come up with." Beth (low efficacy) was enthusiastic about learning different teaching styles when she stated, "When we would watch our other classmates teach, I feel like we got a lot from it, because you learn...the way I would teach something and the way someone else would teach something is so different." When Beth worked with her peers in the group lesson, she noted how she benefited from observing how different teaching styles can be utilized in the same lesson when she stated, It was a great opportunity to learn how to work with others that have different teaching styles from yourself, because not everyone is going to teach things the same way, so it was a really good collaborative effort on how do we work with each of our personalities, yet teach one activity to a group of students... so that was really nice.

Those with higher efficacy were less enthusiastic about watching others teach. Jamie stated, “...the class itself, just going and sitting and watching her teach or watching my fellow students teach, I didn't think that was helpful." Jenn, the participant who used the term "secondhand" to describe the passive learning experience of watching either her teacher or peers teach, stated,

When we were in that [Science Methods] classroom, it was more like, still seeing...I'm taking what someone else is doing, more observing, more second-hand, more than like actually doing, like experiencing that stuff... it made me feel like we were not as involved.

Teacher modeling. The experience of either observing their Science Methods teacher conduct a lesson with elementary students or observing her conduct a lesson with the participants of this course brought forth a variety of comments from both low and high efficacy participants. Beth (low efficacy) thought some of the teachers' activities conducted with the elementary 
students were "really cool," but she expressed more concerns about the teacher's ability to manage the students, as she stated, "I think the lesson would have went a lot better if she had had more classroom management." Other participants also commented on the teachers' skills with classroom management, both with the elementary students and the Science Methods students. Jamie (high efficacy) stated,

I don't think that the teacher that we had even really had control over the classes that we saw her teaching, because we would actually watch her teach classes too, with her students, mainly the fourth and fifth graders. They just kind of were wild the whole time. I mean, I felt like, why is this person telling us how to teach? I didn't really get much from it.

Similarly, Beth (high efficacy) felt that, "We just don't listen because she never gets our attention and there is no management involved."

Participants had more positive comments about watching the teacher conduct lessons with her fourth and fifth grade students, rather than with their Science Methods class. Jen (high efficacy) stated,

I don't think that teacher is a bad teacher or that she didn't try or didn't care, I just feel like she is one of those people that is better with younger students...For me, I feel like it was harder for her to take what she does and what she knows and show us how to do that rather than show us her doing it.

Amy held a similar view on this experience, as she stated,

As far as her teaching the kids, that was better for me than her teaching us...Some of the things that she did with the kids was good... When she was interacting with the students it was ok, but afterwards [conducting a lesson with their class] it was not good. 
Jamie (high efficacy) voiced her concerns about how the teacher's capabilities as a teacher would impact her own capabilities when she stated,

I feel like in a way it made me nervous about teaching science because I feel like if she can't even tell us how to teach science, and she has been doing this for I don't know how many years, she said like 30 years or something she has been teaching.

The necessity of forming relationships. During this Science Methods course, participants interacted with their peers, their teacher, and the elementary students in the class; however, the extent of the relationships developed with these individuals varied.

Relationships with the teacher. The comments from most participants regarding the relationship formed with the teacher of the course were generally not positive. Sara (low efficacy) felt that the teacher was "like a separate entity," and Beth (high efficacy) said that she "felt that no relationships were getting formed with the professor." Amy (low efficacy) commented on the class size and the teacher's ability to focus when she stated, "The class was too big and she [the teacher] was too all over the place." This lack of relationship with the methods teacher was evident in Kate's (high efficacy) statement, ...she forgot our names every week and it would get really frustrating, because apparently she gives you bonus points if you have a comment about something. So everybody would be raising their hand and she would call on you and I don't even think she would listen half of the time, because she was trying to look for our names and try to remember and then she was just like 'a-huh, a-huh' and then when we were done she would go 'what's your name again?'

While Jenn (high efficacy) expressed a more positive opinion about the teacher's ability to teach the elementary students, she felt the "disconnection" with the teacher, stating, 
The kids liked her activities, she has good activities and stuff, but like, to teach us how to teach, that is where I feel like there was a disconnection between what she was trying to do...I felt like she wanted to teach us and wanted to help us, and like give us all these experiences and stuff, but it just wasn't something that she, I felt, she was comfortable doing or she wasn't used to it, I guess.

Jenn also discussed how her relationship with the Science Methods teacher was different from her other teachers,

I talked to her, but I'm a talkative 'I'm going to make you talk to me' person, but I didn't really build a relationship to get to know her really, I just knew basically who she was, got a feel for what she is from observing her... but a personal connection? Not really. It wasn't the same as it would be with one of my teachers on campus.

Relationships with the elementary students. According to most participants, relationships formed with the elementary students were extremely limited. Beth (high efficacy) stated "We really didn't have time to develop relationships with the students. Similarly, Amy (low efficacy) felt that student relationships were limited due to a lack of opportunities to interact with these students,

We never really interacted with them [students] too much. And when she was teaching we weren't really participating, we were just watching. So, it wasn't like you were interacting with the students more than when you taught just that one time. Relationships with peers. Although relationships with the teacher and the elementary students were limited, most of the participants in this course developed a mutual interdependence on one another while conducting their lessons and utilized one another as a support-system throughout the experience. Sara (low efficacy) stated, “...when one of us has a weakness...we 
work well together, the four of us...I guess we...in ways that she has weaknesses, I have the strengths and in ways that I have the weaknesses she has the strengths." Cara (low efficacy) had similar feelings about her peers, stating "we are all pretty close, especially with my group that I taught with, it was...we all kind of took on our own role in preparing for our lesson. We got along really well, so that worked out.” Jamie (high efficacy) stated,

It was really good. I have worked with most of the same people on a lot of other projects this semester, so we've definitely gotten really close and we work well together and everyone, in all of my group projects this semester, everyone works so well, contributes, they don't just slack off and let everyone else do all of the work..., it's been really positive.

It is evident in Jamie's statement that these close bonds formed with peers were formed in other courses as well as this one. Jenn's (high efficacy) relationship with her peers extended to a reliance on them to help her through the class. She stated,

I would have died without the people in my class with semester. Everybody worked together super well and we all collaborated through the whole semester, and with her [the teacher], in that class, it was more like...she wasn't very up-to-date on like ...I relied more on my class to tell me what was due...

The group mentality. The deep peer bonds that developed as a result of participating in this course, and possibly other courses in the "Block" semester, resulted in the high efficacy participants speaking for one another and exhibiting a "group mentality" as they answered interview questions. Beth stated, "We just don't listen because she never gets our attention..." and "the class has had discussions ... as a whole...We will sit there and even during class... it is just those looks that you exchange...why are we even here?" Beth further commented, "We 
weren't getting what we needed. It needs to be more geared towards teachers, how to teach science, what strategies to use with your students." Jamie stated, "Even though everyone did feel bored and they didn't really want to go to class, everyone...I think she got along with all of us really good, there were no issues there." Jenn was more definitive in her opinion that the class, as a whole, disliked the course, as she stated, "I know a lot of people really, really, really hated that class."

Assessments and feedback as meaningful work. Effective forms of assessment and feedback are essential for students participating in teacher preparation programs, as they help students to understand their level of competence at a particular task. Bandura (1997) suggested that verbal persuasion, in which "People are led, through suggestion, into believing they can cope successfully with what has overwhelmed them in the past" can affect efficacy beliefs; however, depending on the types of comments received after a performed task, those beliefs can either be influenced in a positive manner or a negative manner. Feedback from teachers and/or peers after completing an assessment, such as a lesson, presentation, paper or reflection, would qualify as verbal persuasion. There were various forms of assessments in the Science Methods course, including the group lesson, readings and reflections from two books, and a presentation on the use of technology in the classroom. For the group lesson, the participants were graded both by their peers and the teacher of the course. Many participants, regardless of efficacy classification, commented on the teachers' absence from all or just a portion of their group lesson. Amy, (low efficacy) stated, "I mean there was one point where we sat and watched our peers teach for 20 minutes and she was not in the room, so how can she judge whether that was good or not?" Similarly, Cara (low efficacy) stated, "She is really not seeing everyone's [lesson]...you know...she doesn't get to spend the entire time with them and watching them 
teach their lessons." Beth (high efficacy) stated, "She was not in ours for very long. She was there for five or ten minutes that I saw her in there, and she was the one to grade us." Kate (high efficacy) expressed her desire for meaningful feedback when she stated, "She wasn't even there to watch ours [lesson]. If I am doing something wrong I want to know, so I can improve and that didn't happen so..."

Participants also commented on the nature of the feedback from the teacher regarding their group lesson. Amy (low efficacy) commented on the lack of depth in the grading and the ineffective feedback, stating “she doesn't grade any of those hard, she just says 'Thanks for the effort." Similarly, Cara (low efficacy) stated,

She kind of says everyone did a great job and the whole class puts in their two cents at the end and tells them what they could've done better to improve their lesson...I would want her feedback, but her feedback is...I mean we all...I got a $96 \%$ on mine, my entire group did, so...

In addition, Amy felt that she could not give meaningful feedback to her peers during their group lessons, stating "I didn't feel like I could grade them really what I thought they should get ...I'm not judging my peers poorly when they are going to judge me.”

Cara (low efficacy) also commented on the lack of clarity in the assignments and the lack of effective feedback from the short papers they had to write concerning the assigned readings. She stated,

She grades them and she'll give us not much feedback. She just says 'Good job, your paper was great' and that is it. So, I feel like I talk to other people in the class and we weren't sure exactly what we were supposed to be writing on, because the directions weren't very clear. 
Cara did not just want to know that her paper was great, but why her paper was great. Beth (high efficacy) expressed a lack of engagement with the assigned books and the ineffective assessment following the readings, stating,

It [assignment to read book] didn't capture my attention in any way, shape or form. That book, I felt like was a waste of my time than anything else, because all we did was write a paper about it, we didn't discuss it in class or anything or use it or apply it."

Beth felt that the writing assignments “didn't really affect me, so I don't really remember them even." Both Beth and Jamie (high efficacy) commented on the lack of meaning or purpose to the assignments. Jamie felt that the assignment objectives should have been clarified by the teacher, stating, "I think that they don't have a purpose. Maybe if she had explained her intentions with the assignment, I would have understood that more." In comparing this course with the other block semester methods courses, Beth stated, “This one [Science Methods course], I don't think had near as much work [as the other block courses] and I don't think it was as meaningful work." Jamie also discussed the nature of the entire course, stating, "I don't think it had a really huge effect on me just because I didn't get a whole lot out of it."

\section{Textural and Structural Descriptions}

The following is a textural and structural description of each participant's experience with the Science Methods course. The textual descriptions include participants' perceptions of what happened during the experience; whereas, the structural descriptions provide the context of the experience, which is, essentially, how the participant came to perceive what they did during this experience (Moerer-Urdahl \& Creswell, 2004). Life history data from the first interview, including descriptions of previous experiences with science education, reasons for choosing the profession, and PSTE beliefs, were used to generate these structural descriptions. An 
examination of the textural and structural descriptions from the different perspectives of each of the participants allowed for the creation of an overall textural and structural description for those with low and high efficacy.

\section{The Experience for Low Efficacy Participants}

Amy, textural description. When Amy was asked to describe the experience of the Science Methods course, she used the word, "boring," and when she initially described the teacher of the course and her teaching style, she explained, "As far as her teaching the kids, that was better for me than her teaching us, because she doesn't really know what to say to us and her PowerPoints are off-key." During the teachers' lectures, Amy would wonder, "what are you telling us this for?" Amy said that during the course, she observed the teacher conducting a lesson with elementary students, which she described only as "okay," but she conceded that it was "beneficial" to be able to evaluate the lesson and determine what she would have done differently. However, her experience of being taught by the teacher was "not good." Amy explained that she didn't really see the teacher relate what she did with the elementary students to those students in the methods course. Amy felt that "a lot of the things we do for her is us helping her," rather than being helped by the teacher. She used these terms again when she described the homework for the course, which she found to be "all busy work... or to help her out."

Amy described another aspect of the course, which was to both teach a lesson to elementary students and to watch her peers teach a lesson. While Amy thought it was helpful to watch her peers teach in order to observe different teaching styles, she did not feel like she could properly evaluate her peers or "throw them under the bus" based on their teaching, due to fear of reprisal during her own lesson. She stated, 
I didn't feel like I could grade them really what I thought they should get, because she told us half our grade was coming from that, and I'm not judging my peers poorly when they are going to judge me.

Amy also commented on the amount of time the teacher observed the lessons taught by students, specifically with regard to her teacher's ability to properly assess the teaching of the lesson, when she stated, "I mean there was one point where we sat and watched our peers teach for 20 minutes and she was not in the room, so how can she judge whether that was good or not?" Amy's own feedback from her lesson included a comment by that teacher that she "take[s] no prisoners," with regard to Amy's ability to manage a classroom. Amy felt that this comment was made because the teacher lacked good classroom management skills, as "there are kids in her class who do not pay attention, because she doesn't make them pay attention."

Amy's feelings regarding this course were that she "dreaded going down there, because it was boring or unproductive or unorganized." She described the beginning of a typical day in the methods course as, "We wait for 15-20 minutes for her students to show up. We do nothing in those 15-20 minutes; nothing productive...we sit and stare at each other. She usually tries to get ready because she is unorganized." Amy thought that the reason for this lack of productivity and disorganization was because the teacher "has hit her wall and she is kind of over it... and maybe she just doesn't know how to relate her stuff back to us." Amy also expressed concerns with how the class was taught. She discussed what she thought would be appropriate times to learn from the student perspective, in which she and her classmates would participate in activities as elementary students, and when she should be taught as a teacher, learning more teaching strategies. Amy stated, 
...there are times when it is ok if you want to do 'ok, you are the student now,' but then teach to us like you are teachers. Like, if she would have given me a bunch of methods and said 'when I teach oil spills, I teach this; when I teach gas, this is how I teach.' So, it is great to see how my peers teach, but then maybe she could take it and say, 'When I do this, here is what I do.' I think that is what I would benefit from.

One aspect of the course that Amy had mixed feelings about was the informal field experiences. She felt the outdoor experiences at the nature center were "alright...It just wasn't for me, I'm sure your students would enjoy it, so it was ok." However, the "Challenger" experience, in which she and her classmates went on a fictitious mission to mars, she found to be "great... that was a good experience and I remember doing that when I was in elementary school and think that is still good."

Amy said that if she were to describe this course to a friend she would say that "it stunk," and that the course would have been more "beneficial" if it had been designed like her Math Methods course. During the Math course, she was able to observe "each and every teacher teach," and she received "strategies" and "hand-outs" from the teachers she observed.

The context of Amy's experience: Structural description. Amy, an outspoken 21 yearold, was living with her fiancée during her Science Methods course. Amy had the lowest PSTE score of all of the participants in this study. While Amy took 4-7 science courses, she claimed to have had mainly negative experiences with science. She remembered having science experiences in all of her grades, but she didn't necessarily learn from them, as she claimed that there was "too much repetition," and "If [she] didn't understand the content the first time, [she] probably didn't understand it the second time." She felt that her courses had too many lectures and they lacked differentiated instructional strategies, specifically with regard to kinesthetic learning. While Amy 
did not remember anything "outstanding” from elementary school, she found her middle school science experiences to be "horrible." She specifically remembered "dissections" and "dead things in jars." She found her college experiences with science teachers to be mainly negative, describing one teacher as un-invested or "not really on-point," and another teacher created a fearful and uneasy learning environment, in which she "sat there on pins and needles, because I was scared of what he was going to say to me next." Amy claimed that the science content of this course was not the problem, but that she thought the uncomfortable environment distracted from the learning of that content. Ultimately, she did not feel she received what she needed from that course.

Amy always wanted to be a teacher from the time she was little, receiving workbooks and a chalkboard from family members. She jokingly commented that her "stuffed animals should be really intelligent" after posing as her "students." In high school, she developed a love of broadcasting and hoped to eventually become a broadcast educator; however, the lack of such a program in college led her to explore elementary education. Amy claimed that she loved all aspects of broadcasting; whereas, the science and math disciplines had many aspects that she did not like. This led her to think that broadcasting was what she was "supposed" to do, as it was "easy" for her. Amy believed that her broadcasting experiences in high school helped her to become extremely comfortable speaking in front of others; however, in college there were not enough presentation opportunities to continue this level of comfort.

Amy's perceptions of her ability to teach science, prior to the beginning of the methods course, were that she would need to learn content, but that she could put her "teaching strategies to work" and "...pull things from other things." At the end of the methods course, she described her confidence in her ability to teacher science as: 
...a little bit more than when I started, so I guess that's good. Because, with what I did see, even just with my peers, there was a lot of interactive stuff, there was a lot of inquiry-type things and I guess when I was doing inquiry up here [in college] I was like, I don’t remember ever doing that in my science classes. Well, I did that [when I was younger]...So I guess I never made the connection to the activities that I was doing when I was younger.

Amy's negative experiences with science education, and particularly science educators, influenced the way she perceived her science experiences in this course. The lack of investment and the fearful learning environment created in some of her previous science courses affected her perceptions of the actions of the Science Methods teacher, so that Amy saw her teacher as someone who was not giving her the teaching strategies she felt she needed to become an effective teacher. As a child and as an adult student, Amy was never truly engaged in the scientific process in a way that would connect her to the content. In addition, Amy's disappointment at not being able to combine her two loves, broadcasting and teaching, may also have affected her attitude regarding this experience. Regardless of these negative experiences, Amy's personal science teaching efficacy beliefs improved over the course of the semester, because she was able learn teaching strategies by watching her peers model teaching.

Jane: Textural description. When Jane was asked to describe the experience of the Science Methods course, she commented, “Truthfully, I felt like I didn't learn what I wanted to learn," and that the course was "a waste of time." However, she felt that the informal field experiences "were the best experiences of the whole class," because they were "like a real situation...it was fun...more useful than what we have done in the classes." She thought that those experiences had the most impact, because she was "getting to actually do it, instead of just 
talking about it and experiencing what the kids would experience.” Aside from these informal education experiences, she claimed that the rest of the course was "repetitive," stating, .... a lot of it was just we would watch her teach her fifth grade or fourth grade class and then she might talk about one or two things that we have already heard of, so it was just like... it wasn't a lot of new information.

When asked to describe a typical day in the course, she simply said "You watch a lesson." Upon further prompting, she explained, Sometimes one of us would do it [the lesson], but if none of us were teaching, it would be her showing us. So it was that and then we would talk about how that lesson went and then she would go over maybe one other thing.

Jane described the lesson she taught with peers as "fine," but then elaborated on the difficulties her group faced the day of the lesson, as she stated, “...we went to class and we set it all up and she had used it the day before, so we had to hurry up and find something to use. She had forgotten that she told us to use it." Jane's group had to improvise and use their "back-up" activity with the students. Jane's concerns for the lesson were having effective time management, inexperience conducting a lesson of that length, and a lack of experience conducting a lesson with an upper elementary grade. In spite of these concerns, however, Jane said, "Overall, it went better than I thought." She even found the last- minute activity changes to be a "good experience," because she was able to realize her ability to improvise.

When Jane discussed her experiences with watching her peers model lessons, she commented on how she only had the opportunity to observe grades four and five, and that while observing these upper grades was "helpful," she felt that "there could have been more" to the class, such as, 
More instruction from her about what we could do. Like more strategies and things to use. I feel like we just watched her do a lesson and that was it. You know, different strategies that we could use and things to do.

Jane thought that the course only had a "little bit" of an effect on her confidence to teach science, stating, "I said I just feel like we didn't learn enough strategies and enough about how to teach science to feel more comfortable with it." She believed that the slight increase in confidence she felt was due to the knowledge gained from the informal learning experiences, as she learned that there are "things out there to go to as well, outside the classroom."

The context of Jane's experience: Structural description. Jane was 21 years old and lived on campus during the Science Methods course. She had a job taking care of a child with special needs during her four years of college. This position helped cultivate Jane's interest in working with those with disabilities, as her experiences with this child and her family imbued in her the need to not only help severely disabled children, but also their families. In college, Jane decided to attempt to earn a specialization in special education along with her degree in elementary education. She described how she hoped to someday earn a Master's Degree in Special Education, specifically, those with severe disabilities. Jane claimed to have "just always known that she wanted to be a teacher," and she "... fell in love with school" due to the influence of a "wonderful kindergarten teacher." Jane has "always worked with kids," teaching dance, Sunday school, and Bible school; however, she has had no previous "formal" teaching experiences.

While Jane took 4-7 science courses, she claimed to have had mainly negative experiences with science education, as these courses did not include many hands-on, inquirybased or problem-based learning experiences. Instead, she participated in what she calls, "book- 
work science," which, she claimed, "turned me off to science." While Jane did not remember many science education experiences with elementary, middle, or high school, with the exception of some informal field experiences at a science center where she enjoyed the "whole hands-on thing, connecting with real world situations," she did remember her interactions with some of her science teachers. She claimed that she remembered her science teachers from middle and high school because they were strict. An experience that particularly influenced Jane's feelings toward science education involved an altercation with an Earth Science teacher in high school. Jane said that she told her teacher that she felt it was unfair that her classmates were achieving the same grade in the class as she was, but they were not turning in their work on time. Jane claimed that the teacher, "got kind of snippy with me, and said 'life's not fair,' and was really mean about it and made me cry," which led her to think, "okay, these are science teachers." Jane also felt that because many of her science teachers were older, they "weren't really open to change."

Jane commented that she had to rely on her peers to achieve differentiated instruction, as she claimed that when a science teacher "...teaches one way with the book, it is nice to have your peers around that can maybe explain it to you in a different way." This reliance on peers was also seen in the Science Methods course in college, as the participants bonded with one another, but did not form a close relationship with the teacher of the course.

This lack of a connection with her previous science teachers and her feelings that she had “never had a science teacher where we really experienced anything," influenced Jane's perceptions of her Science Methods teacher and her experiences with the course as a whole. Jane's main concern in this course was that she was not getting the strategies she needed for effective science education. This is analogous to her previous experiences of also not getting 
what she needed in science courses. With regard to her desires as a future teacher, Jane wanted to be able to gain the skills necessary to provide an effective science experience using strategies such as informal, but realistic, learning situations.

Cara: Textural description. When asked to describe her experience with the Science Methods course, Cara used the word, "random.” She explained, “... some days we'd watch her teach and then other days we would evaluate her and she would ask us for feedback on certain things." Cara claimed that it was helpful to watch her peers teach lessons, as she was able to "see what they come up with" and, because "some of their lessons have been really awesome." However, Cara found the assessments to be repetitive, as she was, "doing the same thing, week in and week out," and she found the teacher's feedback to be ineffectual, as the teacher ...really doesn't say much about it [the student lessons] after they are done. She kind of says everyone did a great job and the whole class puts in their two cents at the end and tells them what they could've done better to improve their lesson.

Cara received similar feedback from her teacher on a paper she wrote, as she commented, "She just says good job, your paper was great, and that is it." Cara claimed that the directions for this assignment were unclear and that “we [the students] weren't sure exactly what we were supposed to be writing on...Some people were doing something completely different. I did something completely different and everyone got an okay grade on it." Cara felt that the ineffective feedback also extended to her peers, as she stated, "I feel like everyone... since it is just our whole class and we want everyone to do well, then everyone says 'Okay, you did a good job' and we just continue on to the next thing."

Cara has "always been little weak with the science background" and she "wants to learn how to teach it better," but she did not feel that she could achieve this goal with her Science 
Methods teacher. Cara explained that she was depending on her placement teacher for student teaching to gain ideas for teaching science. She stated,

My teacher that I'm with for student teaching, she is awesome with science...she is just really into science. I've kind of been going through her more than I have been for my science at [the University], so I've learned a lot... she just has all these ideas.

Cara claimed that the teaching experience in the Science Methods course "definitely" increased her confidence "a little bit" in science teaching, because she had "never really done anything with science, like a science lesson like that before, with kids involved, it's normally been with my peers..." However, Cara felt like she "could have gotten a lot more [information]," from the course and that it lacked structure and was "too easy." Cara felt that to make the course better, the teacher could "grade a little harder and give us more material and more things to do ...give us more strategies," and the course could be "more challenging." Cara claimed that she wants to be challenged, and she felt like science "should be pretty challenging... I should be getting a lot from it."

Overall, Cara dreaded going to the elementary school each Thursday, because she said "we are going to do the same thing... and it is pointless." Cara's expectations for this course were not fulfilled, as she explained,

I thought, in that class, that I was going to get certain techniques on how to better prepare myself on how to teach to children, and, to me, it was just a regular science class. There was no benefit to me... There was no lesson plan, there was nothing like that. To me, that didn’t benefit [me] what-so-ever.

The context of Cara's experience: Structural description. Cara was 21 years old and lived with her parents during the Science Methods course. She has had 4-7 previous science 
courses and she classified her previous experiences with science as "negative." Cara claimed that she did not "like science," but, rather, she enjoyed "Reading and English." Her father was an English teacher and was a strong influence on Cara's propensity for these subjects, as she claimed that her father was very strict with grammar and writing as she was growing up. Cara explained that she always wanted to be a teacher ever since she and her sister used to play "teacher" with a chalkboard in her attic. Cara did not have many clear memories from elementary school with regard to science education, although she felt like “...we never really covered a lot of science. We either ran out of time or, if we did have time, it was like a quick cram session," and she did not recall any hands-on activities until middle and high school. Cara claimed that she "never really had an okay experience with my [science] courses." Cara described herself as a visual learner who needs hands-on learning, but her previous science experiences did not provide enough of this form of learning, which, in-turn, affected her learning of science content and her attitude toward science education. Cara claimed that her middle school science teacher made her "nervous and you didn't feel comfortable to ask her questions," and her high school science teachers were "nice," but concerning science content, she had a “negative-like outlook on the whole... Science doesn't come easy to me, I'm a visual learner, a lot of hands on would help me, but it has been lecture, lecture, lecture.” This desire for hands-on learning experiences explains why Cara found the informal field experiences to be "beneficial" and "interesting." She claimed that she enjoyed "doing that kind of stuff instead of just sitting in the classroom."

Cara felt that during all of her previous school experiences, she learned best from teachers who were "pushing" students to learn. She claimed that one of her reasons for performing so well in her AP English class in high school was due to the encouragement she 
received from her teacher to "not give up" just because the information was challenging.

However, with science teachers, this type of encouragement was not forthcoming. She stated, ...I feel like with Science it was always just kind of like, the teachers weren't really...if they saw you struggling or having problems they wouldn't be like 'hey, we can do this or this,' they'd just push you to the side.

These experiences shaped Cara's perception toward science teachers as individuals who were not invested in their students learning, and explains Cara's negative attitude toward both the Science Methods teacher and the course as a whole.

Prior to the beginning of the course, Cara described her ability to teach science as "not great... because I don't have confidence in myself when it comes to teaching science... it doesn't come easy to me." The experience of teaching a lesson with her peers slightly increased her confidence, although she felt that it would have been better for her if she had had to teach a lesson by herself, even though she would have felt "nervous teaching in front of [her] peers."

Cara's needs for this course were not met, regarding her desire for teaching strategies, the opportunity for lesson plan development, and the individual implementation of a science lesson with elementary students. Cara's need to be encouraged and also challenged was not fulfilled, because she felt the assessments were ineffective and too easy. If these needs had been met, and she had had the opportunity to rise the challenges that faced her, her belief in her capability to teach science may have increased, just as her writing ability had in her high school English class.

\section{The Experience for High Efficacy Participants}

Kate: textural description. When asked to describe the Science Methods course, Kate described the informal field experiences to be "fun," and she went into detail about the activities in which she and her peers participated, such as making transects in the forest, measuring the 
circumference of trees, and using a robotic arm to pick up "moon" rocks. She explained how, for each of these activities, she behaved like an elementary student and was "like a little kid." Kate was also able to see these activities from a teacher's perspective, as she thought it would be useful for her future students because the activities were "... more realistic and I think they could get a better understanding" of the content being taught.

The rest of the course, however, Kate found less useful. Kate explained how she and her peers would spend the first hour of the class observing the methods teacher, or another teacher at the school, conduct a lesson with students, or they would watch their peers teach. Kate was able to observe first, second, and fifth grades being taught, and she and her group taught a lesson to pre-school. After this first hour, the methods teacher would teach a "quick" lesson using PowerPoint, which Kate did not find useful, because "It was stuff that was common sense that we've learned in my other block classes." She felt that she would have gained a "better understanding" of how to teach science if she was "taught how elementary students are taught" through hands-on activities, rather than the lecturing. The teacher would also use this "lecture" time to review homework assignments, which were mainly papers based on readings. Kate did not find these forms of assessment useful or effective, as she thought it would have been better to “actually make a lesson." Kate found the lesson plan development assignments from her other block courses to be beneficial, because "when we have to make lessons, and it is just like a light bulb goes off in your head, and it is just like 'oh, well this will work." Kate did enjoy the group teaching assignment and felt that her group lesson with the students "went really well" and she was "surprised by how much the kids knew already and they were inquisitive."

Kate found her relationship with the teacher of the course to be "frustrating," as "she forgot our names every week." Kate explained that when the teacher would call on a student to 
answer a question, she would be too busy trying to look up a student's name to listen to the answer. Kate felt that the teacher's age and the "overwhelming" experience of having to teach both college students and elementary students at the same time impeded the relationship development between her and the methods students. With regard to the relationships formed with her peers in the course, Kate said that initially they were "if-y," however, after working with one another throughout the semester she got to know her peers "pretty well."

Due to her experiences within this course, Kate does not think that the course improved her confidence in her ability to teach science. Kate explained how science and social studies are not her "favorite" subjects, but in the Social Studies methods course, she was able to become comfortable teaching this subject matter; however, this did not happen with the Science Methods course. Overall, Kate felt that the teacher "didn't flow well," in transitioning between the different topics in the course and Kate identified a lack of a "connection" between these topics. She also felt that the topics covered in the course were ones that she had already learned about in previous courses. Kate said, 'I didn't want to be there...I really didn't. I sat there and thought that I could be sitting in my dorm room doing homework that I need to get done for other classes" Kate also confessed that she did not "keep up with the readings in the course," but that if she had she "would have been able to teach [her]self and get a better understanding.

The context of Kate's experience: Structural description. Kate was 21 years old during the Science Methods course, and has had 4-7 science courses as part of her education. Kate has also had previous experience teaching in a volunteer capacity. Kate always wanted to be a teacher from the time she was four years old when she used to play "school" with her mother. Kate claimed that her mother wanted to become a teacher, but due to family circumstances, could not follow this career path. Her mother's love of teaching and other 
teachers who "cared about how they taught us" further influenced Kate to enter into the teacher preparation program.

Kate's experiences with science education were mainly positive. She claimed to love math, and chemistry is her "favorite part of science," because she can "relate" to this subject. Kate enjoyed performing experiments, because it involved "putting things together to figure it out." While Kate did not remember many science experiences in elementary or middle school, she believed her love of chemistry was influenced by her high school chemistry teacher. Kate described how this teacher's passion for chemistry was evident in the learning environment he created. Her teacher incorporated media into his course by performing experiments on his own television show and he would video-tape students performing experiments, which Kate found beneficial, as she said she was able to "look back and see what you did, because right when you are doing it, you think 'Oh, I want to do this."' Kate thought that his passion for chemistry, his love of students, and his ability to "make [high school students] not have an attitude," helped the students to "get it." Kate's experience with this teacher influenced her beliefs about the characteristics of an effective science teacher. She felt that if more teachers provided these types of unique learning experiences, they would be able to more fully engage students. Kate felt that in order for her to learn to be an effective teacher, she required the opportunity to watch another educator model an engaging learning experience from the perspective of a preservice teacher, rather than as a student as she did in high school. Unfortunately, Kate was not engaged through much of the Science Methods course and, based on her descriptions of the Science Methods teacher, she did not feel the teacher's passion for science as she did with her high school chemistry teacher. 
Prior to the beginning of the Science Methods course, with regard to her capability to teach science, Kate felt that she was "not confident enough yet...I don't think I've been given enough experience with science." Kate thought that it would be helpful to see a science lesson modeled, and then study-up on the specific science content necessary for the lesson. Kate feared not knowing science content well enough to answer "random questions" posed by students, as she stated, "I don't want to stand there and be like, 'um, I'll get back to you on that one." Kate felt that more science teaching experiences, which would require her to develop lessons each week, would help to increase her confidence. She felt these types of teaching experiences would give her more "practice" and help her to think about the best way to teach a lesson using handson strategies. Kate was also hoping to gain "a better understanding of how to implement science to a kids level" in the Science Methods course. Unfortunately, in the Science Methods course, while Kate had the opportunity to observe different teachers and her peers modeling science lessons, she only had one teaching experience, which she felt was not enough. Overall, Kate felt that her confidence increased "a teeny bit" from that one teaching experience, but not due to the other activities in the course.

Beth: Textural description. Beth described the Science Methods course as "very repetitive." With regard to the informal field experiences, Beth had already experienced the environmental center activities, "more than once" in elementary school and had been to the Challenger Center, "like four times," although Beth conceded that these experiences were "very cool for the people that hadn't done it." Beth described how the field experiences were taught from the student perspective, in which she and her peers experienced learning "as elementary students." Beth thought it would have been "more beneficial" to "take the teacher role... since that's what we are going to do." Beth understood that she and her peers were "always going to be 
students," however, she felt that, as a preservice teacher in this course, she should not be treated as a student, as she was "no longer in that [student] role..."

Beth enjoyed her group teaching experience utilizing tablets to help students learn about tree classification, and she was surprised that "the students understood how you use the technology more than I did." However, Beth claims that there "was a little bit of confusion about what we were actually supposed to be teaching the students" because there was a lack of communication between the Science Methods teacher and the teacher of Beth's elementary class.

For Beth, a typical day in the Science Methods course involved observing her peers model a lesson or teaching a lesson with her peers. This would be followed by a critique of how the lesson was conducted, with the class making suggestions for improvements. Beth did not remember many lessons conducted by the teacher of the course, as she claimed, "they didn't impact me, so I don't really remember them.” Beth would have preferred that the course incorporate professional development workshops that would allow students to learn about different types of science curriculum and how to integrate science into other subjects. She said that the class "could have been better geared for ways to teach science." Beth felt that the students in her class weren't "getting what we needed" because the teacher failed to engage them and she lacked effective classroom management skills. Beth said "we [Science Methods students] just don't listen, because she never gets our attention and there is no management involved." She felt that the teacher also lacked "good communication skills," which resulted in "no relationships were getting formed with the professor." Beth did enjoy working with her classmates in her group lesson and she benefited from observing other students model teaching, as she felt it was a "great opportunity to learn how to work with others that have different teaching styles from yourself." 
Beth did not feel that this course increased her confidence to teach science, because she was already confident in her abilities and because she was forced to play the "student-role" in the class. She stated,

I felt more of the time that I was the student, rather than going into the teacher role, if that makes sense. I still felt like that student, rather than learning to teach it. I needed more teaching strategies rather than to sit and [learn] how to be a student.

Beth also felt that the assessment activities were less time-consuming for her, because of her comfort with the subject matter. Beth claimed that the assessments were "not meaningful work," as they did not "capture my attention in any way, shape or form." She commented that since the assessments did not "affect" her, she did not really remember them.

Overall, Beth claimed that the Science Methods course made her feel frustrated, and she would ask herself, "Why are we even here? We could be doing something else... why are we sitting in this class?" She wanted the teacher to "make it worth our time," but she did not learn teaching strategies or gain knowledge about science curriculum as she had hoped.

The context of Beth's experience: Structural description. Beth, at 21 years old, has had mainly positive science experiences, and while she didn't remember many specific details about elementary school, she did recall completing "too many worksheets." In middle school, she remembered more experimentation, but she claimed that there were "issues with the teachers not knowing how to bring it down to the level that the students needed it to learn." During high school, she recalled performing experiments in biology and physics class, and while she did not particularly like physics, she remembered how her teacher "made [her] learn." Although she claimed that this teacher went "above their head[s]" and taught content "too fast," he made Beth repeat experiments that she did not understand, which helped her to learn the material better. 
Beth participated in science fairs in both middle and high school, which she claimed, "opened [her] up to exploring." She thought that she remembered these science fairs, because she conducted the experiments on her own, with very little outside help. Beth also thought that these experiences would help her with her future students, in that she will "be more open to letting kids just explore rather than giving them something and say[ing] 'go do it this way,"” and she "would prefer to give them something and say 'go find a way to do it."”

Beth had extensive tutoring experience with physical science in college. She believed that this experience allowed her to learn different teaching "techniques" and how to "differentiate more," as she had to tutor "a lot of students who [were] at completely different levels." Because Beth often tutored large groups of students at a time, she claimed that she, "[felt] more like a teacher than a tutor."

Beth was strongly influenced by her father, an auto-mechanics teacher at a vocational school, and she believed that she inherited from him her curiosity with how things work. Beth remembered, “...helping him with cars when [she] was 2 or 3 and yelling at him for doing things wrong." Her favorite thing to do when she was little was "taking apart the coffee table and putting it back together." Beth's intelligence was obvious to others, as she remembered how "everyone told me not to teach," because she was “too smart." Beth's response to that was "Isn't that who you want teaching your children?"

Prior to beginning the Science Methods course, Beth described herself as, ...the kind of a person that, if you give me something, I can learn it whether I want to or not, I will learn it. Whether I like it or I'm interested, I'll figure out how to do it and figure out how to teach it... 
Beth thought that her ability to teach science was "Not perfect, of course, because I'm still learning." She claimed that classroom management is her "biggest fear," rather than science content, and she "enjoy[s] finding different activities to teach [students] with and making up [her] own games and stuff." Beth felt most comfortable with the Physical Sciences, "because that is what I've done my science fair projects in and that is what I have the stronger background in." Beth was not as strong in Biology, but she felt, "I could learn it as I'm teaching it and figure it out. I think as the years go I'll get better, because I'll know it better myself...” Beth believed that her previous experiences in school, the science fairs, and the tutoring, increased her confidence in science teaching. The tutoring experiences, in particular, Beth claimed, helped her to develop her

...own ways of [teaching], how to break it down for people... so it has made me more comfortable even if I'm not the best in those [subjects] to begin with, I'll get better and I'll figure out ways to do it.

Beth's feelings that the course was repetitive was not surprising, as she already had a number of informal experiences in her primary and secondary schooling, and her tutoring experiences helped her to gain valuable science teaching experience. Beth's frustration at being treated like a student was caused by her perception that she is ready to transition into the role of a teacher. Beth's criticism of the Science Methods teacher's lack of classroom management skills is a reflection of Beth's own fears of losing control of a classroom. Beth was hoping to learn management strategies, because she knew that that was her area of weakness.

Jaime: Textural description. When asked to describe the Science Methods course, Jamie initially talked about her experience with her group lesson. She stated, "My group went the second class we had ever had of the semester, so we were very...we felt very unprepared." 
She felt that conducting the lesson was "uncomfortable" and "intimidating," and she was concerned she would not say the right thing. While preparing for the lesson she felt "extremely rushed," and it was "difficult," because she had had little experience with the teacher and the class. Jamie said she "felt like we were kind of just out there by ourselves with no one there to help us or direct us" and she "just did not like that." Jamie would have liked to be able to "tailor [her] instruction" to "fit" the class. Jamie felt that she and her group would have been "more comfortable" if they had conducted their lesson at the end of the semester, after they had gotten to know the students and the expectations of the teacher. Jamie did have a "positive" experience working with her peers in her group, as each member contributed equally to the development and implementation of the lesson.

Jamie further described how each week she would "watch one or two groups teach a lesson for an hour...then basically she [the teacher] would have some kind of PowerPoint or some kind of little thing to kind of talk about, just random science-y stuff." The random "science-y stuff" did not include a discussion of science content, which Jamie felt would have benefited her. Jamie thought that she did not "get a lot from the class" and she did not think it "really prepared [her] to teach science very well." She thought that the teacher did not have effective classroom management skills, as the students were "just kind of were wild the whole time," which made Jamie question, "Why is this person telling us how to teach?” Jamie felt that the teacher's inability to manage the classroom made her "more nervous about teaching science," because if [the teacher] can't have control over her classroom and she has been a teacher for that long... what kind of troubles am I going to have?"

Jamie enjoyed the informal field experiences, as she found them "really cool" and "awesome." She was able to see how elementary age students would "love" these realistic 
learning experiences and "definitely learn" from them, because "there is so much science packed into those fieldtrips." She figured that if someone her age could enjoy them, so would students.

Jamie felt that the teacher of the course did not give her "a lot of useful information," and she felt that "this class was a waste of time." Jamie used the word "frustrating" to describe the teacher's inability to communicate new teaching strategies to the class, and Jamie claimed that the strategies she did communicate were a review of what she had already learned in other classes. Overall, she found the class "boring," and she struggled "so hard to pay attention." Jaime found the assignments too easy and felt they did not "have a purpose." She was unable to "see the connection" between the teacher's "intentions" for the assignments and her developing the skills necessary to become a better science teacher. Jaime felt that, by the end of the Science Methods course, her confidence in science teaching was "probably about the same" as it was when she began the course, and she was left with a "feeling of like not being satisfied by what [she] got."

The context of Jamie's experience: Structural description: Jamie described her previous experiences with science education to be mainly positive, although she claimed that nothing "really sticks out" from elementary school, and the only experience she recalled from middle school was building a bridge in a physical science class. Most of her memories from her secondary education were from chemistry courses in her sophomore and junior years. She claimed that the teacher of these courses "forced" her to think, as he "made us actually form the knowledge in our own head..." through problem-based learning experiences, and "he didn't just give us the answers." Jamie felt that because she remembered the content she learned in those classes, the challenges associated with the class were worth it, and she felt that, as a preservice teacher, she gained an understanding that "those [teaching] strategies actually work." 
Jaime always wanted to become a teacher, as it was "never really a question in [her]

mind." Her first grade teacher was a strong influence on her love of school, as Jamie claimed she ...was just like the kind of teacher that made me want to come to school every day...I mean I can't say I remember a lot of things that I learned in first grade but I do remember how she made me feel.

Jamie was 21 years old during the Science Methods course and was raised in a very small town. She was initially concerned about attending college far from home and claimed that her parents "pushed [her] to go away to school just for the experience of being on [her] own and being independent."

Prior to the start of the Science Methods course, Jaime felt confident in her knowledge of scientific content, but she voiced concerns over her ability to "make [science] interesting for kids." She believed that "just because you have the knowledge to teach it doesn't mean you can do a good job." She felt that she would need more experiences teaching science in order to increase her confidence. However, in the Science Methods course, she only had one experience. In addition, Jamie's experiences with science education helped her to realize the importance of providing hands-on experiences for students. She stated,

I guess I feel like from my past experiences I have learned that if I want my students to learn from me, than I need to have them doing real things, relating my lessons to real life situations and kind of like tying those things together so they can apply it to real life. The one "real life" teaching experience in the Science Methods course was useful, but Jamie would have benefited from more of these experiences throughout the course.

Jamie's perceptions of the Science Methods course were the opposite of those she had as a child in her first grade class. Her descriptions of her first grade teacher imply that her needs, at 
that time, were being met. Her expectations of how a teacher is supposed to make a student feel were developed in those early grades. The teacher of the Science Methods course did not make Jamie want to "come to school every day," and did not meet her needs as a student, leaving Jamie feeling unsatisfied in the course.

Jenn: Textural description. When asked to describe her experiences with the Science Methods course, Jenn first commented on the informal field experiences, as she stated, "We were participating like the students would." Jenn remembered taking part in these field experiences as a child, and while she found it less engaging as an adult, she felt that "If that had been my first time at either of those, I probably would have really enjoyed it." In the Science Methods course, Jenn would have preferred to approach these informal learning experiences from the 'educator's perspective," so that she could have learned "how that would be worked into my classes."

A typical day for Jenn, in this course, was to arrive at the school and wait for 30 minutes, talking with her classmates. Then Jenn "observed [the teacher's] lesson" or she "would go to another grade and [she] would watch their lesson and then come back and talk about it." This would be followed by the Science Methods student's participating in elementary activities as a means of learning teaching strategies. Jenn participated in one group teaching experience in which she and her group had to develop a science lesson and implement it with the elementary students. When Jenn described her group lesson, she claimed that she was "surprised by a lot of the things," particularly with regard to the students' knowledge and enthusiasm. She stated, "they [elementary students] enjoyed being outside... they had all kinds of good answers ...the way that they had answered questions was shocking to me... they knew a lot." Jenn believed that the teaching experience was beneficial in that "now I know that I've actually done a lesson and it is not like super stressful for me to have to find material or help or resources." However, Jenn felt 
that more teaching experiences, as she had in her Math Methods course, would have been more helpful. She claimed that the teacher and peer modeling that she experienced in the Science Methods course made her feel like she was "still seeing... taking what someone else is doing, more observing, more second-hand." This second-hand learning did not improve her confidence in her ability to teach science throughout the semester. Jenn would have preferred to develop a small lesson for each grade, each week of the semester, as she stated, "that [would have] made it more real-life, more first-hand and beneficial to our actual teaching."

Jenn did not feel that she developed a "personal connection" with the teacher of the course, as she would have with her other teachers on-campus; although she "knew basically who she was, got a feel for what she is from observing her." While Jenn did not have the opportunity to develop relationships with the elementary students in the class, because she "just sat there and watched lessons go on," she claimed that those observations helped her to understand student behavior. Jenn did develop close relationships with her peers in the class, as she stated that she would have "died without the people in my class," and that because the teacher was not "very up-to-date" she "relied more on [her] class to tell [her] what was due."

Overall, Jenn thought that the Science Methods course was beneficial in that it "allowed [her] to be in an actual classroom, with actual students, seeing science done instead of a silly little activity here and there." In addition, she appreciated a "designated time" for science for the elementary students to "give them the opportunity to get more ahead in that subject," compared to what she has seen in her other placements as a preservice teacher.

The context of Jenn's experience: Structural description. When asked to describe her previous experience with science education, she first recalled going on field trips and then participating in hands on learning experiences during both her elementary and middle school 
education. Jenn enjoyed the field trips in which she was able to observe "real people" doing their job. Jenn claimed to have liked science until high school, because she was able to perform experiments, which were "easy to take in;" however, once she was in high school, she felt that her science courses were based on facts that she had to memorize. One positive aspect of her high school experiences with science was that Jenn became an excellent note-taker, which helped her in college. Her early science experiences in college were similar to those in high school, where she was told, "These are the facts, memorize them, and take the test." Jenn felt that this type of teaching and assessment were "not the best way that I learn[ed] it... I can get an A on a test, but that doesn't mean that I know the stuff." Jenn claimed that she had not had many chances to actually do science, rather, she learned about doing science. Jenn had mostly good experiences with her previous science teachers, as they were usually her "favorite teachers," but it was because she liked them as "people" and not due to "how they taught..." She felt that many of her teachers "knew the content," but they lacked the skills to "communicate it in the best way."

As a child, Jenn did not aspire to become a teacher, as she wanted to go into the medical field as a doctor or nurse. However, during high school, she had the opportunity to take a course in childcare, and she enjoyed working with the children. Jenn claimed that she "didn't want to be in school forever" and was "good at school," so she began to consider teaching as a profession. She thought it is better to "learn from someone who likes to learn and likes to be here and is excited about learning, instead of someone else who isn't..." Jenn did not receive complete support for her change in career plans, as "some people" told her she was "wasting being smart." Her response to this lack of support was, "You want your kids to learn from smart people, not dumb people," so she entered into the teacher preparation program. 
Prior to beginning the Science Methods course, Jenn described her ability to teach science as her "weakest area of what [she] would be confident in." She felt that she had the science content knowledge and the skills to research how to teach concepts, but lacked actual knowledge of science teaching strategies. Jenn felt that her teacher preparation program did not provide her with sufficient exposure as to how to teach science, as she has received in other content areas. Jenn believed that a person's comfort level with science directly influences the ability to teach science, as she commented, "Most people feel the least comfortable with science because their teachers felt the least comfortable with science." She felt that there were many science teachers who entered the field because they could "get a job" and they were "not bad at science," rather than those who became science teachers because they love science. Jenn felt that engagement is important when it comes to teaching science and that students need to see how science can be "fun."

Jenn hoped that the Science Methods course would provide her with the opportunity to observe students engaged in "hands-on, minds-on" learning activities, but that did not occur. Although Jenn described herself as "not a shy person," she claimed that the environment in the methods course made her feel "overwhelmed, like I'm going to be judged by what I say," and that the teacher of the course was not "ready" to help her. Her previous experiences with science teachers and their inability to communicate content in a meaningful way influenced her perception of the Science Methods teacher. Jenn's outgoing personality was stifled in this course due to her lack of self-assurance in her ability to teach science.

The special case: Sara, a textural description. Sara is considered a special case in this study, because her perceptions of her experiences are relatively different from both the high and low efficacy participants. While Sara's score on the PSTE survey placed her in the low efficacy 
group, her experiences within the Science Methods course were generally positive, as opposed to those of the other participants. When asked to describe the course, Sara thought that "a lot of the experience was good, some of it not as much." The "good" experiences Sara described were the informal field trips to the environmental center and to the Challenger Center. Sara did not think she would like the environmental center experience because she is "not an outdoors-y girl," but when describing it, she exclaimed, "Oh my gosh, I loved that!” During her walk through the forest, Sara was responsible for collecting the different types of maple leaves for the class. Sara enjoyed this activity so much that after the class ended, she decided to keep the leaves and press them into her class journal. During this experience, Sara was the only one in her group who would "play in the creek," which she says was "not in my comfort zone," but she was happy to jump in the creek up to her knees. Sara claimed that she loved the experience, because prior to her explorations, she had been unaware that "there was so much stuff in the creeks." Also, she thought it was "good to see that teaching doesn't have to take place in a classroom," which was different from many of Sara's previous experiences in elementary school, as they took place primarily indoors. Sara also enjoyed the outdoor component of the Science Methods course, because it was a "nice break-up of all day, every-day classroom," and, as Sara described herself as someone who cannot sit through long lectures, "getting up and moving and doing everything," was "fun..."

Sara also had positive comments about the Science Methods teacher's lessons with her elementary class. Whereas, most of the other participants were critical of the teacher, Sara claimed that she thought that the teacher "did do a lot of activities that [she] thought were really cool" and she was "really impressed with it." Sara also liked that the teacher of the course was open to feedback regarding her lessons with students. However, Sara agreed with many of the 
other participants that the teacher had issues with classroom management, and she felt the time spent disciplining students limited the coverage of science curriculum. Sara claimed that the "fifth grade class especially, they basically knew what they could get away with, they pushed her buttons..."

Sara thought that her group lesson conducted with her peers "went really well," even though she was "really nervous about it." Sara's lesson for first graders, whom she refers to as the "itty-bitties," were not her preferred age group, as Sara hoped to work with older elementary or middle school-aged students. As she conducted the lesson, Sara was "shocked at how much first graders know," and she contributed this knowledge to a private school education where "they [teachers] can kind of teach a little bit differently than they can in the public school." After the lesson, Sara received positive feedback from one of the students in the class who attended Sara's church. She claimed that this response from a student made her "feel really good." Sara also appreciated learning from her peers, as she claimed that she "got a lot from" watching them teach, because she was able to observe different teaching strategies. She said she felt that "the way I would teach something and the way someone else would teach something is so different."

Sara's perceptions of her experiences within the course evolved from annoyance at unfulfilled expectations at what she thought she should be doing to guarded optimism about what she was able to experience. Sara claimed that when she started the course she was "one of those people that bitched and moaned about having to go [to the class]," however, once she really reflected on her experiences within the course, she thought,

...we did do a lot of things that I think are beneficial, maybe not so much on the lower elementary level, we didn't see that as much as the upper elementary, but for me it is beneficial because I want to do upper elementary. 
The context of Sara's experience: Structural description. At 24 years old, Sara was the only "non-traditional" student in the study. While she claimed to have had mainly negative experiences with science education, she was able to view the Science Methods course in a positive light, unlike all of the other participants. Sara has few fond memories of her school experiences from both elementary and high school. Sara's county did not have an official "middle school," as her elementary school ran from kindergarten through $8^{\text {th }}$ grade and high school included grades $9-12$. She claimed that the "school system down there is horrible" and she would never consider a teaching position within that county. Sara had few memories of what she calls "little kid science," with the exception of an experiment with chicken bones for a science fair project. She claimed that the experiment was her mother's idea and she "[didn't] even know what it was for," but got "third place" in the science fair. Another science experience that she remembered was an inquiry-based project involving the building of a "remote control car that could move a ball to an X." While this activity involved hands-on learning, which Sara preferred, she considered this a negative experience, because she was placed in a group of students who were not "dumb," but they were "lazy, and they were slackers." Sara described herself as someone who has "never been 'science' at all" and she did not "even know where to start" with this project. Sara purposely missed school on the day the project was due, because she "didn't want to be there to be present for [her] first 'F' ever." Sara felt that the experience would have been better if she had been given more guidance as to how to complete the task.

Sara only remembered a "few details" of dissecting "everything under the sun" in a high school science class, and while she claimed that she enjoyed the hands-on nature of the activities, she was unable to connect the activities to the content she was supposed to learn. She claimed, "I remember it was fun and that I enjoyed it, but I don't think I learned anything from it, I don't 
think I got anything out of it." Sara felt that many of her high school science teachers were judgmental, and would "look down on you if you were wrong." These feelings of judgment deterred Sara from participating in class as she considered herself a "perfectionist," and she did not want her teachers "to think that [she was] the stupid kid in class," so she was less likely to try to answer questions. Sara had a positive experience with two college level science classes, in which her teacher made the courses "exciting" and "interactive," and the teacher created an atmosphere in the classroom that allowed Sara to feel comfortable answering questions. She claimed, "You could answer questions and it was ok if you didn't answer right." Unfortunately, this positive environment was not created in all of Sara's college science courses. Sara described how one of her teachers did not like the way she answered a question in class and told her that if she "didn't work on her science speaking skills, she was going to be a horrible teacher." Sara was extremely upset by this and "broke out into tears," when telling another education professor about her experience. She was encouraged by this professor to confront her science teacher. Sara took this advice and confronted the teacher about his inappropriate comments, for which he apologized. After this experience, Sara claimed that she was driven to work harder on her assignments, as she stated that she wanted to "prove to him that I am not stupid," which, after receiving positive feedback from this teacher, "definitely boosted the self-esteem." Sara's high school concerns about being perceived as the "stupid kid in class" perpetuated in her college science classes; however, these concerns prompted her to work harder to achieve success.

Sara claimed that while she always wanted to be a teacher, this was not the major in which she began her college career. Sara began as an undecided major at a community college and then switched to small business management, and then to social work. Sara switched her major three more times before finally deciding upon education. Sara claimed that the reason she 
did not initially pursue education was due to her father's lack of support and his insistence that she would "never make a dime" and would "always be poor" in this field. In addition, Sara "fought the idea" of teaching for a "long time," as she thought she wanted to "do something glamorous." Sara finally got the support from her family that she needed to enter the teacher preparation program at the University, after her mother witnessed her teaching children during a mission trip for her church.

Prior to the beginning of the Science Methods course, Sara claimed that, of the four content specialization areas, she was "dreading science" the most, and that she would make a "pitiful science teacher." She was also "dreading” teaching her group lesson that was scheduled for the end of the semester. Sara felt that part of the reason for her feelings of dread was because she "didn't have a lot of good teachers that modeled" effective science teaching, and she thought that her previous teachers were not necessarily "bad" teachers in general, but that they may not have "been strong in science." Sara believed that her teachers' weaknesses in science teaching were the reason she has few memories of science in the classroom. This made Sara want to "want to try and work really hard" to be a "good a science teacher" if she "has to teach it." Sara may not have to teach science at all at the elementary level, as her specialization is social studies and she hopes to obtain a job teaching middle school social studies. Sara believed that she can "rock social studies," but science is "always going to kind of intimidate me." Sara felt that it was the "idea of teaching" science that intimidated her the most and she was fearful of "being a failure" to students. Sara felt very strongly that if she becomes an ineffective teacher, she should not be teaching. Sara vehemently stated, 
If I'm a bad teacher, if I'm a crappy teacher, I hope I get fired, not because I don't want to do it, but because I care enough about little kids or middle school kids that if I'm not a good teacher, I hope they fire me and I hope they get someone better.

Sara believed that in order for her to become an effective science teacher, her education should involve more than just reading or listening to science content in a lecture. She felt that she needs someone to "explain [science content] and make the connection," and many of her previous science teachers did not help her make these connections. She felt that teachers need to “make students want to learn" about science by making classes exciting and by making connections between science and the students' lives.

Overall, Sara believed her previous negative experiences impacted her feelings toward science education; however, she conceded that it is easier "to remember the bad than the good." Sara hoped that her Science Methods teacher and peers would give her constructive criticism on her group lesson. Sara's feedback on her lesson was overwhelmingly positive; however, the nature of this feedback was shallow, and Sara wished she would've had the opportunity to teach a second lesson in order to show progress over time.

\section{Composite Textural Description: What did Low Efficacy Participants Experience in the}

\section{Course?}

When low efficacy participants talked about the Science Methods course, they used words such as "boring," and "repetitive." Specific aspects of the course were described differently, however. When participants described the informal field experiences, they used terms such as "beneficial," "fun," and "useful." One participant said it was the "best experience in the whole class," and another said that she "loved" that part of the course. One individual liked "doing that kind of stuff instead of just sitting in the classroom," and another thought that it 
was "good to see that teaching doesn't have to take place in a classroom." Several participants commented on the realistic nature of these experiences, as they stated how it was helpful to experience "what the kids would experience," and how it was "like a real situation" with students.

When describing the experience of being taught by the teacher of the course, one participant said that it was "not good," and that she would wonder "what are you telling us this for" during the teachers' lessons. Another participant thought that the lessons were "not very useful," and another said that she felt that she "didn't learn what [she] wanted to learn." One individual commented on the repetitive nature of the teachers' lessons, as she claimed that the teacher would spend her time "talk[ing] about one or two things that we have already heard of." Another participant discussed how students in the class "just watched her do a lesson and that was it."

The nature of the relationships developed during the course varied depending on the individuals involved. Several of the participants described the lack of a relationship between the teacher of the course and the students of the Science Methods course. One individual claimed that the teacher "was like a separate entity," and another student felt that the "class was too big and she was too all over the place." There were also limited opportunities to develop relationships with the elementary students in the class. One participant stated, "We never really interacted with them too much," and another said that the methods students "really didn't have time to develop relationships with the [elementary] students." All of the participants developed close relationships with their peers, as one individual stated, "We are all pretty close, especially with my group that I taught with, it was...we all kind of took on our own role in preparing for our lesson. We got along really well so that worked out." Another participant commented on the 
dependence on one another's strengths while teaching, as she stated, "we work well together, the four of us...I guess we...in ways that she has weaknesses I have the strengths and in ways that I have the weaknesses she has the strengths." One participant commented on the rapport which developed with her peers during this course and other "Block semester" courses, as she stated that her group "get[s] along really well," as they have been "working together all year."

Most of the low efficacy participants had positive comments regarding their teaching experience in the course, particularly with regard to their performance. Participants used phrases such as, "I thought it went really well," and "it went better than I thought." However, several participants claimed that they were "nervous" about conducting the lesson, and one participant was particularly concerned about "teaching in front of [her] peers." One participant enjoyed the group aspect of the lesson, as she was "glad we did it in a group, because you didn't have to teach the whole time;" however, another felt that it was difficult for everyone in the group to have a "voice" during the lesson, and would have preferred a teaching experience in which she was the only teacher. Concerns that arose during the lesson included the ability to manage their "time" and uncertainties about a lack of experience teaching certain grades, as one participant stated "I've never really had experience above second grade, so I was nervous about that." The low efficacy participants had mixed feelings regarding the "modeling" aspect of the course, in which they observed the teacher of the methods course as she taught the elementary students, and as they watched their peers teach lessons to the elementary students. One individual thought that the teacher "did do a lot of activities that ... were really cool," and another said that "Some of the things that she did with the kids was good... When she was interacting with the students it was okay." Several students expressed concern over the teachers' inability to manage the students of the Science Methods course, as one student commented, "the lesson would have 
went a lot better if she had had more classroom management." Participants described peer modeling as a means to "see their [peers'] ideas and what they would come up with," and commented that they "got a lot from it, because you learn...the way I would teach something and the way someone else would teach something is so different."

Low efficacy participants described the assessments and the feedback from the assessments as ineffectual. One individual thought that the course as a whole was not "challenging," and stated that the "course was a breeze compared to everything else I've had to do this semester." Other participants commented on the teacher's absence during the lessons and their concern over not receiving honest feedback on their performance, as they used phrases such as "she was not in the room, so how can she judge," and "she doesn't get to spend the entire time" observing students during the lessons. Other participants were concerned about both the quality and quantity of the feedback. One student felt that that the teachers' feedback was not honest, as the teacher "says everyone did a great job," on the lesson. Another participant felt that the teacher did not "give us not much feedback" on her performance. One individual also commented on the peer feedback for which she both gave and received during the group lessons. She felt that she could not give her peers effective feedback and she "didn't feel like I could grade them really what I thought they should get" due to her concern for reprisal during her lesson. Other participants were concerned that they did not have the opportunity to observe or teach to all of the elementary grades, and questioned, "How do I go to my kindergarten class and teach science when I didn't see it?" 


\section{Composite Structural Description: How did Low Efficacy Participants Experience the}

\section{Course?}

All low efficacy participants had taken 4-7 previous science courses prior to entering the Science Methods course, had few previous teaching experiences, and claimed to have had mostly negative experiences with science education. These individuals had "too much repetition" in their primary and secondary schools, and their courses often lacked hands-on, inquiry, or problem-based learning experiences. They claimed that their courses had "too many lectures," and consisted mainly of "book-work science." The low efficacy participants who had the opportunity to experience science in an informal environment during their early education enjoyed the hands-on, realistic learning experiences and, because of their engagement, seemed to remember these events with the most clarity. However, most of these individuals did not remember science experiences in their elementary classrooms, and they described a poor learning environment in their middle and high school classes. Several individuals described their feelings of "anxiety" and "fear," and they claimed that they were "nervous" and "not comfortable" due to the environment created by the teachers in these courses. One student claimed that she "sat on pins and needles" because she was unsure of what her science teacher was going to say to her. These negative experiences with science teachers left the participants feeling fearful, sad, or frustrated with science education. Several participants claimed that they lacked a connection with their previous science teachers, which continued into the Science Methods course; therefore, they relied on one another for support both emotionally and with their learning of teaching strategies. In the Science Methods course, the students' lack of a relationship and emotional connection with their teacher prevented them from receiving what they needed, which, for most the low efficacy participants, was a connection to the content and 
strategies for teaching science content. During their previous science experiences and in the Science Methods course, they never felt truly engaged in the scientific process and they were not challenged in their science classrooms, which most low efficacy participants felt was needed in order to connect with the content. Poor experiences with science teachers and the lack of engagement with science content throughout their education affected their perceptions of what it means to be a science teacher and their perceptions of science in general. Despite their negative experiences with science education, and specifically with the Science Methods course, all low efficacy participants experienced an increase in their science teaching efficacy beliefs as a result of this class; however, this increase was mainly due to the single teaching experience.

Low efficacy participants entered the field experience with the enthusiasm of a child, ready and willing to participate in the discovery process. They could appreciate the informal nature of these experiences as they lacked the confines of a classroom and provided the realism they felt was necessary for their learning of science content. Their previous traditional science education experiences had been so unfulfilling as to not be remembered, or absent completely from the curriculum in their schools. The notion of "being like children" while participating in science experiences, particularly to those found in the field experiences of the Science Methods course, opened them to learning though the eyes and minds of a child and helped them to enjoy science content and the scientific process. However, the rest of the Science Methods course seemed to further reinforce the low efficacy participants' feelings of "not liking science," as the experiences with the teacher and the lack of "connection" with science content perpetuated. These individuals entered this course with a fear and dislike of both science content and the idea of teaching science. Their lack of relationship with both their teacher and the elementary students in the class hindered their learning process. The need to develop a trusting relationship with their 
teacher and their desire to have the opportunity to develop a trusting relationship with the elementary students were essential components that were left unfulfilled in this course. While they enjoyed both watching their peers teach, and they could appreciate the experience of teaching a science lesson to elementary students, they did not feel that the quantity and quality of these experiences were sufficient to make them more effective science teachers.

\section{Composite Textural Description: What did High Efficacy Participants Experience in the}

\section{Course?}

When high efficacy participants talked about the Science Methods course, they used words such as "boring," "frustrating," "random," and "pointless." Specifically, several of these participants found the informal field experiences to be repetitive, because they had already participated in these experiences in their primary and secondary education. One individual had “...participated in it when I was in school, both of those field trips...so they weren't as exciting for me as they could have been," and had "done that probably four times before," while another stated that she "had done [the informal experience] in grade-school more than once." Several of the participants stated that they would have preferred that these experiences were taught from the teacher's perspective, in which the participants would have been taught how to utilize the informal field experience with their own students; however, these experiences were taught from the student perspective, and the teaching strategies for these types of learning environments still eluded the students. One participant said that she would have preferred that the field experiences were "taught from the educator's perspective and how that would be worked into my classes." Other participants commented on the realistic nature of the informal experiences, as one individual stated, "These [field] experiences were more...I would say...I don't know, more realistic, because you are actually out there in nature," and another felt that children would "get a 
better understanding" of science content, because the experiences "felt real... and kids would love that."

The nature of the relationships that developed between the teacher, the Science Methods course students, and the elementary students varied during the course, as they had with the low efficacy group. One student commented that "no relationships were getting formed with the professor," and another said that she "didn't really build a relationship to get to know [the teacher]." Others added that there was no "personal connection" with the teacher, as there would have been with a professor on-campus. They felt "frustrated" that "she forgot our names every week," and that the teacher would only "listen half of the time," because she was "trying to look for our names." This forgetfulness made the high efficacy participants question the teacher's investment in their course. In addition, participants said that they felt that the teacher "wasn't very up-to-date," which, one participant suspected, was due to her age. The teacher was further described as "a very sweet person," and one participant felt "a good relationship there," but she "didn't necessarily learn from her." Descriptions of the relationships that formed between the Science Methods students and the elementary students included comments such as "we didn't really get to interact with the kids very much," "we just sat there and watched lessons go on," and "we really didn't have time to develop relationships with the students." Several participants thought that it "would've been helpful" to interact with students, but they "really didn't have the opportunity." One participant felt that developing these relationships is important, because students "need to have that trust with you and they need to know that you care." The relationships formed between students in the Science Methods course were described as "really good," and that the experience of working with one another was "really positive." One participant said that "it was a really good collaborative effort on how do we work with each of 
our personalities," and it was "a great opportunity to learn how to work with others that have different teaching styles." Another participant described how she grew to depend on her peers, as she said she would have "died without the people" in her class. Participants in this class grew to know one another "pretty well," and were "really close" during the projects they have worked on together, both in this course and other "Block" courses.

As with the low efficacy participants, the high efficacy group generally found the teaching experience to be a positive one, as most said that their lesson went "well." One participant thought that "it was good for me to actually teach children strictly a science lesson," and another found it "helpful to do it for that experience." Several students commented that they were surprised at the elementary student's depth of knowledge and found their answers to questions to be "shocking." Not all comments regarding the teaching experience were positive, however. One student claimed that she felt confused about "what we were actually supposed to be teaching the students," and others felt "really rushed" and "very unprepared." Several participants would have preferred to have the opportunity to conduct lessons throughout the semester, as they had done in their Math Methods Block course.

The high efficacy participants described the teacher "modeling" as a "second-hand" experience, in which they were "taking what someone else is doing...observing...more than like actually doing." This made them feel they "were not as involved," as they just "sat there and watched lessons go on." They did not feel that merely watching the teacher conduct lessons with her elementary class was very "helpful," as that they did not receive "useful information." Several felt that the teacher's inability to manage the classroom detracted from the experience, which led one participant to question, "Why is this person telling us how to teach?" In addition, these participants found the teacher's lessons to their own class to be lacking in both science 
content coverage and teaching strategies, and they felt the information covered "was common sense" and had already been covered in other courses. One participant added that the teacher may "have a lot of really good strategies and ideas," however, she did not think that the teacher "communicated them those to us very well." Participants felt "frustrated" "not satisfied" and "bored" in the course. They were not learning the information they felt they needed, which was "how to teach science, [and] what strategies to use with...students."

The high efficacy participants did not find the assessments in the course to be effective and described them as a "waste" of time, as they did not "have a purpose." Several participants claimed that the assessments were not engaging and "didn't capture my attention in any way, shape or form," which made them less "affected" by the assessments, causing them to not "get a whole lot out of it." Several even commented that their lack of engagement in the assessments caused them to have limited memories of their experiences, as, when asked, they could not remember what they were supposed to accomplish in this course. One participant felt that the teacher should have "explained her intentions" in order to help her understand the assessments. Another individual claimed to be frustrated that the teacher was not present for most of her group's lesson and would not be able to give her effective feedback. She commented, "If I am doing something wrong I want to know, so I can improve." Several participants felt that the assessments were not challenging enough, as the work was not "meaningful" and they found the course, as a whole, to be "easier" than the other Block courses. One participant commented that the assessments "didn't take a lot of my time," because the content "was stuff I was already comfortable [with]." Overall, the participants "weren't getting what [they] needed" and they felt that the course "needs to be more geared towards teachers," rather than students. 


\section{Composite Structural Description: How did High Efficacy Participants Experience the}

\section{Course?}

All high efficacy participants had taken 4-7 previous science courses prior to entering the Science Methods course, had a least one previous teaching experience, and claimed to have had mostly positive experiences with science education. As with the low efficacy group, several of the high efficacy participants did not remember much about their elementary and middle school science experiences; however, all of them remembered at least one positive experience with a science educator or science content. Several of these participants commented about being taught by teachers who "cared about how they taught" and were "passionate" about the content. Most of these individuals described inquiry-based high school science experiences, in which their teachers created a challenging learning environment that "forced" students to think and "made students learn," because the teacher "didn't just give us the answers."

Most of the high efficacy participants wanted to pursue a career in teaching since childhood, and claimed to, at the very least, "like science," because, as one individual stated, she could "relate to the content." Several of these individuals did not have support from their families for their career choice, as they were told that they were "too smart" to be a teacher. Their previous experiences with science, either through informal science experiences or through actual teaching experiences, helped these individuals to gain more confidence in both their knowledge of science content and in their ability to teach science. One individual claimed that her previous experiences in science fairs "opened [her] up to the idea of exploring," and her experiences as a tutor in college helped her to "develop [her] own ways of teaching." The high efficacy participants were less concerned with learning content in their Science Methods course, as, for the most part, they were already comfortable in this area; however, they hoped to gain 
knowledge of strategies for teaching science content in an engaging manner that was "at the kids level," as well as both knowledge of classroom management techniques and the opportunity to practice these strategies. Due to their hopes for having these specific needs met in the course, they struggled with being treated as "students," in which they had to "behave" like elementary students or college students during most of the different experiences, and they would have preferred to be taught as teachers. These individuals seemed to equate being treated as a student to being taught content (which they did not need), and being treated as a teacher to learning about teaching strategies (which they did need). See Table 4 for a summary of the similarities and differences between the textural and structural descriptions of low and high efficacy participants.

Table 4

Similarities and Differences between Textural and Structural Descriptions for Low and High Efficacy Participants. $\underline{\text { Similarities - Low and high efficacy groups: } \quad \text { Differences: Low efficacy } \quad \text { Differences: High efficacy }}$

found Science Methods class boring

liked realistic nature of field experience

did not like being taught by teacher

found aspects of the course repetitive

formed limited relationship with teacher and elementary students

teacher feedback limited and poor quality

developed dependency on peers

benefited from group lesson

wanted be become teacher since childhood felt Science Methods course lacked challenge

enjoyed watching peers teach

fearful, sad, or frustrated with science education

lacked connection with previous science teachers

lacked connection with science content

previous science education lacked progressive learning strategies preferred to be taught from teacher perspective

felt peer modeling was secondhand experience

positive experiences with science

challenged by teachers

enjoyed science content

experienced progressive learning strategies 


\section{Chapter 5: Discussion}

\section{The Essence of the Experience}

The experience of being an individual with low efficacy or high efficacy in the Science Methods course is surrounded by the idea of connectedness. This refers to both the connection between the individuals and the science content, whether this content is learned in an informal field experience or in a traditional classroom, as well as the connection to the other individuals involved in the course, including the teacher, peers, and the elementary students. The low efficacy participants enjoyed the informal field experiences because they could make connections between the realistic activities and the science content they were supposed to be learning. They appreciated the level of engagement these activities provided for students, and because they were able to see through the eyes of a child as they participated in these activities, they gained an understanding as to how effective these types of experiences could be for elementary students' learning of science. The high efficacy participants could also see how effective these experiences could be for learning, but they failed to make the connection between how they, as teachers, could apply the knowledge learned from the experience with students. These individuals did not want to experience the activities as a child would, as they had already done this during their own childhood. They desired much more specific information, such as how they should utilize these activities with students and connect the field experiences to national and state content standards and objectives.

Both high and low efficacy participants also struggled to make a connection between the purpose of the assessments and the intentions of the teacher. The content of the course was described as both boring and repetitive, and questions of "why am I doing this?" and "why are we here?" permeated the course, because there was no clear purpose for the assessments. Perhaps 
if the teacher had formed more of a relationship with each of the individuals in the course, her intentions would have been more transparent. This lack of a connection between the teacher and her students was a stumbling block throughout the entire course. The low efficacy students felt there was a lack of investment in their learning from the teacher, and high efficacy participants felt condescension, as they wanted to be treated as colleagues, rather than merely students. The lack of a connection with the elementary students amplified their feelings of nervousness and imbued in them a general sense of unpreparedness to teach these students. All of the individuals seemed to understand that the relationships formed with students is essential to the learning of content, as they realized that in order to teach content effectively, a teacher must understand the needs of students. If this understanding is lacking, then the teacher is essentially teaching "blind" and making assumptions of student needs. The students of the course experienced this form of "blindness" from their teacher, as she was unaware of their needs throughout the semester. The connections that were lacking with both the teacher and the elementary students caused a stronger bond to form between all of the individuals in the course, as they relied upon one another for content knowledge, strategies, and emotional support.

Self-efficacy changes and connectedness. Low efficacy individuals lacked knowledge of science content and had ineffective science teachers throughout their entire education, which, most of them seemed to understand, affected their perceptions of science education and influenced their dislike of science content. Their poor interactions with science teachers, which included experiences of being ignored, or in some instances, actually fearful in the classroom, caused these individuals to be mistrustful of science teachers and experience anxiety in a science classroom. Upon entering the Science Methods course, they understood why they were nervous to teach science, but this awareness did not make teaching lessons any less challenging. They 
also seemed to understand the correlation between actually teaching science to elementary students and their level of anxiety when it came to implementing science lessons. While they were nervous to teach a science lesson, they were able to overcome this anxiety and successfully implement a lesson with elementary students, which helped them to experience an increase in their confidence in science teaching. They believed that additional science teaching experiences would have further increased their confidence, but this did not occur in the course.

It is not surprising that the low efficacy participants experienced anxiety in the Science Methods course, particularly with regard to their group lesson, as studies have shown a relationship between science anxiety and previous negative experiences with science in a classroom setting (Mallow, et al., 2012), and that compared to other majors, education majors show much higher levels of science anxiety (Udo, Ramsey, \& Mallow, 2004). The low efficacy participants discussed how these negative experiences with science and science educators caused them to dislike science and become deficient in science content knowledge. These findings are supported by other studies which reported on elementary students' negative feelings toward science content and lack of content knowledge (Davis \& Smithey, 2009; Ramey-Gassert \& Schroyer, 1992; Rice, 2005; Tosun, 2000).

The low efficacy individuals were also receptive to the field experiences, in which they "acted" like young students, and they hoped to be equally engaged in the learning process in the non-field portion of the Science Methods course; however, this did not occur either. These individuals were able to make a connection between the positive aspects of the course, which helped their efficacy (the engaging field experiences, the authentic teaching experience, and close relationships they developed with their peers), and what was needed in their education to 
further increase their science teaching efficacy beliefs, which included additional science teaching experiences, teaching strategies, and hands-on, realistic learning experiences.

High efficacy individuals were not deficient in science content knowledge, so they did not express fear or anxiety in this respect, and their previous experiences with science education were generally positive, as most of the participants were able to remember an experience with a prior educator that influenced their "liking" of science; however, these individuals were plagued by a feeling of dissatisfaction throughout the course. They struggled with the dichotomy of desiring a deeper connection with their teacher and feeling that she was inadequate as an instructor. In addition, while they found the course to be easy, which decreased their stress level during an otherwise difficult semester, they hoped to be challenged in this course. For the most part, however, this did not occur. The high efficacy individuals continuously compared this experience to their previous experiences with science education and were extremely critical of the course overall, as most of them had had previous teachers who engaged them in the science content, challenged them to think, and instilled in them a desire to learn. During their time in the Science Methods course, they were unable to determine a connection between the intentions of the teacher, the content, and the assessments, which they felt was needed in order to be properly challenged and to experience a satisfying level of engagement in the content. They found the class "pointless" or a "waste of time," because they could not understand or see these connections being made. Perhaps this lack of understanding was due to their preconceived notions of what it means to learn to teach. They questioned the teacher's abilities, because they were not learning the teaching strategies they thought they should be learning. They were critical of the teaching strategies she was employing with her elementary students, but without prior knowledge of the needs of these students. The high efficacy individuals openly admitted a lack 
of a relationship with the elementary students, and a lack of knowledge as to how these students learned; however, this deficiency was not taken into account when they observed the teacher during her lessons or when they reflected upon her teaching strategies. Feelings of disappointment and frustration followed these individuals throughout the course; as they were not challenged by the assessments, and they did not gain the strategies they felt they needed in order to become better teachers. In spite of these perceived deficiencies, the science teaching efficacy beliefs of high efficacy individuals did not decrease, but remained constant. Most of these individuals relied upon having their needs met in their student teaching experience, which would follow the Science Methods course.

\section{Sources of Efficacy in the Science Methods Course}

According to Bandura (1977), "vicarious experiences," or the act of observing another performing a behavior with success, can be a positive or negative source of efficacy (p. 197), and the more an individual can identify with the person modeling the behavior, the higher the potential increase in efficacy (Bandura, 1977; Tschannen-Moran et al., 1998). When the students watched either their peers or the teacher of the course successfully implement a lesson with elementary students, they were encouraged that they would be able to emulate these behaviors. This was particularly true when the low efficacy participants observed others modeling teaching behaviors. The low efficacy participants' PSTE increased during these vicarious experiences, as they were able to envision themselves also being successful while performing similar teaching behaviors. High efficacy participants did not achieve this same increase in PSTE throughout the course, as their confidence was already high. These individuals were more critical of the behaviors of others and they also seemed to look for more faults in how lessons were conducted with students, particularly with regard to how the teacher of the course implemented lessons. The 
high efficacy participants seemed to be more affected when they observed the teacher making what they perceived as mistakes in her lessons, which caused them to question her ability to teach them anything that they did not already know from other education courses. While their PSTE did not decrease while observing her "failures" as a teacher, it did not increase either. It is also possible that the high efficacy participants did not feel they could identify with the teacher due to her age and their feelings of her not being "up to date" with teaching strategies.

The authentic teaching experience with elementary students seemed to have much more of a positive effect on PSTE than the experiences of watching others model behaviors, particularly for low efficacy participants. According to Bandura (1977), "personal mastery experiences," such as the task of developing and implementing a lesson with elementary students performed by the individuals in this study, help to "promote behavioral accomplishments" and ultimately alleviate fears associated with the behavior (p. 195). While the low efficacy participants claimed to have an increase in their confidence as a result of this authentic teaching experience, it did not completely eliminate their fears. Bandura (1977) suggests that completing a task with success multiple times may be necessary to develop "mastery expectations," in which these individuals would expect to be successful when teaching a science lesson in the future (p. 195). The opportunity for repeated successes in teaching was not available for the students in this Science Methods course, so the low efficacy individuals were unable to completely alleviate their fears, and their improved self-efficacy was not strongly established (Bandura, 1997). This lack of an established efficacy could potentially impede the transfer of new teaching behaviors to new situations, such as when they become inservice teachers (Bandura, 1997). Previous studies have shown that providing opportunities for teaching science in an authentic manner can promote a positive attitude toward science education in general and, specifically, science 
teaching (Cantrell et al., 2003; Huinker \& Madison, 1997; Kenny, 2010; Palmer, 2006). Such authentic teaching experiences have shown to be particularly effective in increasing science teaching efficacy beliefs (Carrier, 2009; Palmer, 2006). While both the low and high efficacy participants in this study claimed to have benefited from the group teaching experience, as was previously stated, only the low efficacy participants showed an increase PSTE as a result of the experience. This increase in PSTE for low efficacy individuals may be due to their limited opportunities for authentic teaching experiences, as all of these individuals stated that they had fewer previous teaching experiences to draw upon compared to the high efficacy groups. Bandura $(1977,1997)$ posits that the more an individual repeats a particular behavior in a successful manner, the stronger the efficacy expectations will become. The low efficacy participants' limited opportunities to teach would have made them both more anxious to teach and more influenced by successful teaching endeavors. The high efficacy participants generally found the opportunity to teach science to elementary students to be useful, but only performing this authentic experience one time during the course of the semester was not enough to further increase their PSTE.

Previous studies have shown that hands-on experiences using inquiry-based learning, such as those experiences provided by the two informal field trips, promote a positive attitude toward science education in general and, specifically, science teaching (Bleicher, 2006; Cox \& Carpenter, 1989; Ramey-Gassert \& Shroyer, 1992). While the field experiences in the Science Methods course did not involve authentic teaching, these experiences were realistic and allowed the participants to have similar experiences as their students would and were considered a source of efficacy in this study. The low efficacy participants were able to increase their PSTE as a result of participating in these experiences, because they could envision themselves in their 
conscious mind recreating these experiences with students. These field experiences allowed the low efficacy participants to see science as "fun" and engaging, which promoted a more positive attitude toward science. The high efficacy participants did not experience the same increase in PSTE, as they were less engaged by these experiences due to the fact that they had already had these experiences in their previous science courses. They seemed to lack the ability to make the connection between their role as a student during these field experiences, where they could become engaged in the content, and how they, as preservice teachers, could utilize these experiences with future students.

Another source of efficacy identified by Bandura (1977) is "verbal or social persuasion," in which an individual is persuaded that they possess the ability to successfully complete a task (p.198). While verbal persuasion is considered a weaker source of efficacy compared to mastery or vicarious experiences (Bandura, 1977, 1982), this source of efficacy played a role in affecting the PSTE of the participants in the Science Methods course. The participants in this course interacted with their teacher, their peers, and the elementary students; therefore, they had the opportunity to receive both encouragement and feedback regarding their teaching behaviors from these individuals. Both the high and low efficacy participants commented on their lack of effective feedback from the teacher after they performed their lesson, which limited the potential effects on their PSTE. Constructive criticism provided by the teacher would have helped them to know how they could improve their science teaching abilities in future lessons. Constructive criticism from their peers after their lesson was also limited. As one participant mentioned, the participants in the course all told one another that they did a "good job," even if this critique was inaccurate. In addition, both high and low efficacy groups had limited opportunities to interact with and receive feedback from the elementary students in the class; therefore, they did not 
receive verbal persuasion from these individuals either. Due to this lack of quality feedback from the teacher, their peers, and the elementary students, this source of efficacy was largely absent from this course.

The final source of efficacy posited by Bandura $(1977,1997)$ is “emotional arousal," or the "physiological state" of an individual, which refers to the level of stress or anxiety an individual experiences during a particular endeavor (p.198). As it was previously mentioned, both efficacy groups in this study experienced nervousness prior to teaching their group lesson; however, the level of anxiety varied between the groups. Low efficacy participants reported higher levels of anxiety with regard to their teaching abilities and their knowledge of science content; whereas, high efficacy individuals reported anxiety, although not as heightened as the low efficacy participants, with regard to their level of preparedness, their ability to manage a classroom, and their lack of experience with different elementary grades. According to Bandura (1977, 1997), high levels of anxiety can impede performance, because individuals tend to expect to fail when they are under tremendous stress, which may result in avoidance of the particular behavior. The successful completion of a task when an individual is under stress can lead to increased efficacy, if the individual perceives that their success was due to their skills (Bandura, 1977). Both low and high efficacy participants in this study claimed to have had a successful implementation of their lesson, and while they acknowledged their anxiety prior to and during the lesson, they felt that the experience was useful. However, only the low efficacy group increased their PSTE, indicating that the act of successfully implementing a science lesson while experiencing high levels of anxiety had much more of an impact on their perceptions of their ability to teach science, compared to the high efficacy participants who experienced lower levels of anxiety. 


\section{Expectations and Learning}

In the current study, high efficacy individuals placed high expectations on the teacher of the course, and they were extremely critical when she did not meet their expectations. These individuals expected to be engaged in science content using hands-on, inquiry-based learning activities, they expected to be challenged during the assessments while possessing a clear understanding of the purpose of these assessments, they expected to be taught effective science teaching strategies and to be provided with ample opportunities to practice utilizing these strategies, all while learning in an environment that was supportive. They expected this supportive learning environment to be created through both a close relationship with their teacher and with their peers in the course. Because many of these expectations were not met, these individuals were less receptive to what they could have learned in this course, as their strong expectations actually impaired their learning process. This was supported by the lack of an increase in their science teaching efficacy beliefs during the Science Methods course as shown in their STEBI-B scores and interview answers.

Low efficacy individuals held less concrete expectations of their teacher and were less critical of her performance. Their previous negative experiences with science education led them to have low expectations of both the Science Methods teacher and the course, as these individuals held hopes rather than expectations; exhibiting an attitude that said "anything has to be better than how I was taught before." Because of these lower expectations, these individuals seemed to be more receptive to the learning in this course. Although they claimed that they did not receive enough teaching strategies, opportunities for science teaching, or close relationships, their STEBI-B scores and answers to interview questions regarding their confidence in teaching science indicated that they were able to learn enough to increase their science teaching efficacy 
beliefs throughout the course. This was particularly evident with Sara, the "special" case in this study. As a non-traditional student, Sara held different expectations for the Science Methods course. While she held less concrete expectations, like the other low efficacy individuals, Sara's positive attitude and extremely strong work ethic throughout the course helped her to have a much more positive experience. This positive attitude was possibly due to her level of maturity and her keen observation and analysis skills, as she seemed to be able to make the connections between the intentions of the teacher with regard to both the assessments and the field experiences, and her role as a learner in this course. Sara's attitude was one of readiness, as she was receptive to all of the experiences and the education she could receive from these experiences. Similarly, in a study examining individuals with differing levels of PSTE, Ramirez Sangueza (2010) found that the disposition of an individual can affect their confidence in science teaching, and specifically, a positive attitude in the face of challenges can improve efficacy beliefs.

\section{Previous Experiences and the Conscious Mind}

According to Bandura's Social cognitive theory (1997), an individual's nature is determined by interactions between environmental, cognitive, and behavioral factors. Individuals use symbols to "process and transform transient experience into internal models that serve as guides for future action" (Bandura, 1997, pg. 18). The previous experiences of individuals within the Science Methods course developed in them a strong notion of what it meant to be a teacher early in their lives. For high efficacy individuals, positive teaching role models, both when these individuals were children, as well as in their secondary and post-secondary education, suggested to them that the role of a teacher was to provide an engaging, challenging, and safe environment for learning. While low efficacy individuals had positive influences for teaching in general, they 
lacked a positive experience with secondary and post-secondary science educators, which influenced their perceptions of science educators. The positive or negative representations of a teacher in their conscious mind influenced their expectations for their teacher preparation courses, specifically with regard to how they expected to be taught in the Science Methods course, and influenced the characteristics they would like to develop as preservice teachers in order to teach their own students. Previous studies of the effects of prior science education experiences on efficacy beliefs indicate that individuals with lower efficacy who describe their experiences using descriptors such as "indifferent, distain, and avoidance" and "monotonous, lacking, and uninspiring," (Ramirez Sangueza, 2010, p. 198) indicate that their understanding of science content is weak (David, Pettish, \& Smithey, 2006). According to Ramirez Sangueza (2010), individuals with a poor understanding of science face struggles when teaching science.

High efficacy students' symbolic representations of a science teacher and science teaching were different than those with low efficacy. The high efficacy students wanted to learn the strategies necessary for effective teaching and envisioned their teacher for this endeavor as one who possessed similar qualities as those of the teachers' with whom they felt influenced by the most; whereas, the low efficacy individuals hoped to learn how to avoid creating the same boring or fear-ridden environment created by their ineffective science teachers, which caused them to dislike both science and science teachers early in their education. Bandura (1997) posits that "cognitive representations" of an individual's past experiences can influence their behavior, suggesting that a positive representation could lead to positive action in the future and a negative representation could lead to negative action in the future (p. 19). With regard to teacher education, this suggests that a positive experience with a science teacher could lead to a positive cognitive representation of the characteristics of an effective science teacher, which could then 
influence the behavior of this individual, causing them to exhibit these effective teaching behaviors in the future. However, a negative experience with a science teacher could lead to a negative cognitive representation of the characteristics of a science teacher, which could then cause this individual to exhibit ineffective teaching practices.

\section{Contributions of the Current Study to Teacher Preparation Programs}

As previously mentioned in Chapter 2, while there have been many studies which examined Science Methods courses in a general fashion and, more specifically, the science teaching efficacy beliefs of individuals in a Science Methods course, there were virtually no studies on the nature of the experience of those with differing levels of PSTE. The purpose of this study was to determine the level of PSTE in students entering into a Science Methods course during their final year of teacher preparation, determine changes in PSTE after participating in a Science Methods course, and, ultimately, determine the essence of this experience for individuals with high and low efficacy. The data collected in this study provides valuable insight into the lives of preservice teachers as they navigate the challenges of this final year, particularly with regard to experiences designed to improve teaching ability, such as those found in a Science Methods course. The data also provides an understanding as to how previous experiences with science education can impact current perceptions of capabilities to teach science. The education an individual receives is dependent on a complex web of factors, many of which are out of the hands of those offering the educational experience, including previous experiences with science

educators and science content, support by students' family members, and content preferences of students. Educators in teacher preparation programs have no control over the previous experiences of their students, as they cannot erase the harm done to students by ineffective teachers, and they do not have insight into the behaviors of previous teachers who have 
positively impacted the perceptions of their students. However, teachers can attempt to form close relationships with students in order to gain awareness as to how their previous experiences have impacted their students' current perceptions and then provide experiences that have been shown to positively impact efficacy.

Studies have shown that providing increased mastery experiences, such as authentic teaching experiences, and vicarious experiences, such as observations of those modeling successful teaching behaviors, as well as encouraging verbal persuasion, and promoting an environment which helps to decrease anxiety prior to and during teaching experiences, will increase teaching efficacy beliefs (Bandura, 1986; Brand \& Wilkins, 2007; Howitt, 2007). Additionally, encouraging students to engage in reflective behaviors and ownership of teaching practices can help improve efficacy (Ramirez Sangueza, 2010). Ramirez Sangueza (2010) found that regardless of the level of efficacy, those with "ownership of practices toward student learning" were better able to reflect upon how authentic teaching experiences and the act of observing others teaching could affect their practice, and they were able to adjust their teaching behaviors and their thinking of that teaching practice (p. 221). The current study adds to this knowledge by examining the meaning of the experiences of those with differing levels of efficacy and how understanding this meaning provides a window into why students perform the behaviors that they do.

Limitations of the study. Performing a successful phenomenological study, which seeks to discern the meaning of an experience, depends on the willingness of participants to divulge to the researcher their thoughts, feelings and perceptions regarding a particular event. In the current study, I found several of the participants to be quite reserved when answering questions regarding their experiences within the course. This reticent behavior made determining the true 
essence of the experience rather challenging, as answers to open-ended questions were too succinct and did not contain the details and depth of feeling necessary for a rich description of the experience. While a researcher should not coerce answers out of participants who are unwilling or unable to answer questions regarding an experience, perhaps different, more probing questions which addressed impressions and perceptions of the experience would have stimulated a deeper conversation about the experience. In addition, a phenomenological study of an experience generally examines one event, rather than a series of events that make up an experience; therefore, the current study could be deemed too general for a phenomenological investigation. Perhaps, it would have been more appropriate to examine one experience within the Science Methods course, such as the informal field experience or the group teaching experience.

Additional limitations involve the structure of the course. The Science Methods course was conducted in a private institution with small class sizes of approximately 15 students. This school had a designated science classroom with additional outdoor learning space, and a designated elementary science teacher. Such an environment does not necessarily reflect the actual teaching environment in which the Science Methods students will eventually begin their teaching practice as inservice teachers, and the majority of these students will be teaching at public institutions. Given that this was a private school, and several of the participants commented on their expectations of the school and of the elementary students, student expectations for the Science Methods teacher (the elementary teacher for the private school) and the course were not realistic. The Science Methods students expected to observe and learn strategies for teaching inquiry-based learning both inside and outside the classroom, they expected the teacher to effectively utilize various forms of technology available in the classroom, 
and they expected the students to be more engaged in the learning process, because they were "private school kids." When they did not observe all of these behaviors, many attributed this to the deficiencies of the teacher, or to the poor attitudes of the elementary students. This inconsistency with what they observed and what they expected to see in the private institution may inhibit the generalization of the findings of this study. However, given that experiences within the course were similar to those of other Science Methods courses which took place in public institutions, the essence of this experience may be generalizable for those with low or high efficacy.

Implications of the study. The implications of this study extend from general teacher education and, more specifically, to science teacher education. When individuals in this study were asked to describe their thoughts and feelings regarding the Science Methods course, they often commented on their experiences within all of their "Methods Block" courses, using these experiences as a comparison of what they considered effective or useful learning experiences. The current study allowed these students the opportunity to explore their feelings about their time in the teacher preparation program. The intertwining of the learning experiences within their "Block" semester provides insight as to how students perceive this time- as one large experience with many facets. Each facet of their overall experience within this semester can affect their general teaching efficacy, and possibly their science teaching efficacy beliefs. Several participants commented on their initial anxiety about teaching in the "Math Methods Block." However, after successfully teaching several math lessons, their teaching efficacy increased, and this potentially increased their science teaching efficacy beliefs, as science content was equally daunting to teach. These students seemed to think, "If I can teach Math, than I can teach 
Science." Teacher educators should be aware of the impacts of one methods course on all of the other courses in this final semester before student teaching. A successful model for a methods course, as was described by individuals in this study, could be replicated in other methods courses. Providing students with the opportunity to describe their experiences within these courses would enable teacher educators to understand the types of experiences that are working, and the types of experiences that are ineffective for preservice teacher learning. Science teacher educators should be concerned about the perceptions of preservice teachers, as these perceptions affect their teaching behaviors (Ramirez Sangueza, 2010). Preservice teachers who are deficient (or feel they are deficient) in their preparation for science teaching generally have a poor attitude concerning teaching and are less likely to teach science in an elementary school (Brand \& Wilkins, 2007; Levitt, 2001; Palmer, 2001; Wenner, 1993). This deficiency in science teacher preparation will perpetuate from generation to generation, as the students being taught by unprepared teachers could potentially develop a dislike or disinterest in the sciences, and, should they become teachers themselves, their poor experiences could further affect their perceptions of science and their science teaching efficacy. Providing effective learning experiences in both science content courses and Science Methods courses would confront the major issues in preservice elementary teacher education: pedagogy, content knowledge, and efficacy. Teacher educators could also benefit from an examination of individual experiences within teacher preparation courses, as it would allow for better curriculum mapping. Participants in the current study often commented on the repetition of content and teaching strategies within the Science Methods course, and knowledge of this and communication between teachers within teacher preparation programs could help to reduce the redundancy within the curriculum. 
The overall essence of the experience of the Science Methods course for both efficacy groups was a need for connectedness with the science content, the assessments, the elementary students, and the teacher of the course. Suggestions for creating this connectedness can be found in the following section.

\section{Creating Connectedness in Teacher Preparation Programs}

Studies of connectedness with regard to education have focused on science curriculum, specifically concerning conceptual connections in science texts (Eichinger \& Roth, 1991) and the environment of the school (Blum, 2005). School connectedness has been described by Blum (2005) as "an academic environment in which students believe that adults in the school care about their learning and about them as individuals" (p. 16). In addition, factors that have shown to threaten school connectedness include "social isolation, lack of safety in school, and poor classroom management" (Blum, 2005, p. 2). While the previous study did not focus on connectedness in higher education classrooms, the factors that contribute to and detract from connectedness can be extended to higher education institutions, specifically to the environment created in a science education course. The participants in the current study did not necessarily suffer from social isolation; however, several of the lower efficacy participants claimed that they had experienced fear or intimidation from a teacher in a previous science classroom, and several expressed concern over the Science Methods teacher's ability to manage a classroom and felt that this chaotic atmosphere detracted from student learning. Feelings of fear and a lack of stability in a learning environment lessen the likelihood of "meaningful” learning (Blum, 2005, p. 2). Creating connectedness, within an entire school or within a classroom, is essential for student learning, as studies have shown that students who feel more connected to school will 
have an increased likelihood of succeeding in their studies and are more likely to graduate (Connell, Halpern-Felsher, Clifford, Crichlow, \& Usinger, 1995; Wentzel, 1998).

How can teachers help to create a feeling of connectedness? Blum (2005) suggests offering smaller class sizes, and making learning "relevant and meaningful" (p. 2) by providing students with clear guidelines for the behavioral and academic expectations of the teacher. Transparency of teacher expectations was missing in the Science Methods course and the participants complained about the large class size, as it made it difficult for the teacher to properly assess their group lessons and it made their groups too large for significant individual contributions to the lessons. Additionally, smaller class sizes would allow for a closer relationship to form between the teacher and students, which would help to provide the academic and emotional support necessary for learning. Previous studies have shown that creating a supportive environment can impact efficacy beliefs, teaching behaviors, and student success in the classroom (Ashton \& Webb, 1986; Gibson \& Dembo, 1984).

When attempting to create connectedness in a science content or Science Methods course for preservice elementary teachers, it is important to also monitor student PSTE beliefs in order to determine how students' perceptions of capabilities for teaching science are changing. Determining the PSTE of students is significant, because individuals with differing levels of efficacy will respond differently to various learning experiences, as was determined by the current study and previous studies. These studies have shown that individuals with high efficacy are more likely to use reform strategies in teaching science, such as inquiry-based learning, create more supportive learning environments for students, and are less likely to allow challenges to affect their efficacy beliefs (Parjares \& Schunk, 2001; Ramirez Sangueza, 2010). In addition, monitoring student attitudes along with PSTE during teacher preparation courses can help to 
provide insight as to their potential teaching behaviors and their response to challenges. Ramirez Sangueza (2010) found that the disposition of those with either low or high efficacy can affect teaching practice, as those with higher efficacy viewed challenges as an opportunity to learn new information and that such challenges did not negatively impact efficacy beliefs; whereas, those with lower efficacy tended to blame outside sources for their shortcomings while teaching and were more threatened when faced with challenges. With regard to teaching practice, individuals with low efficacy were unable to connect their teaching behaviors to student learning; whereas, those with high efficacy were able to identify a relationship between teaching practice and student learning, and they were able to adjust their teaching practice according to the needs of the learner (Ramirez Sangueza, 2010).

Understanding the science teaching efficacy beliefs of students as they progress through a teacher preparation program can be an indicator of students' potential as science educators. Previous studies have shown a relationship between the level of efficacy a teacher possesses and the effort expended in the classroom (Gibson \& Dembo, 1984), the likelihood of perseverance in the face of teaching challenges (Gibson \& Dembo, 1984), the degree to which an individual will commit to the teaching profession (Coladarci, 1992), and their inclination and preparedness to try different and innovative teaching strategies (Allinder, 1994). As a high level of effort, commitment, and perseverance are all essential characteristics of an effective teacher, assessing students' PSTE and evaluating the thought processes of individuals as they experience teacher education programs can aide in the development of these characteristics.

Finally, a feeling of connectedness in preservice elementary teachers can be established if educators attempt to gain a deeper understanding of their students' perceptions of science and science teaching throughout their entire course of study in higher education. This could be 
accomplished through both quantitative STEBI-B surveys and qualitative interviews at different time points in a teacher education program. Both quantitative and qualitative assessments are necessary, because the STEBI-B survey alone will not provide the richness of data necessary to understand student perceptions of their capabilities and the factors that are shaping these perceptions. According to Ramirez Sangueza (2010), previous efficacy studies have been too limited in scope, as they have focused primarily on the sources of efficacy beliefs and, specifically, teacher behaviors, rather than focusing on "how they think about what they do," which limits how teaching practices develop during a teacher preparation program (p. 217). Analyzing the experiences of students as they progress through a teacher education program will also help educators to understand the meaning of the experiences for students, which can help shape the direction of a particular course or a program of study for teacher preparation. The current study not only examined levels of efficacy and changes in efficacy beliefs during a Science Methods course, it also focused on the experiences and the meaning of the experiences of participants with differing levels of efficacy. In essence, this study went beyond merely examining how preservice elementary students are performing teaching behaviors, but allowed for a glimpse into the conscious mind of those with differing levels of efficacy as they experience a Science Methods course and provided an understanding of the meaning of the experience for these individuals. 


\section{References}

Fact Sheet. (no date). Retrieved from Wheeling Country Day School: http://www.wcdsedu.com/201108-04-23-47-02.html

Student teaching and certification. (no date). Retrieved March 22, 2012 from West Liberty University College of Education : http://go.westliberty.edu/professional-education/files/2012/02/updatedElem-curr-sheet-Fall-2011.pdf

Abell, S. K., Park Rogers, M. A., Hanuscin, D. L., Lee, M. H., \& Gagnon, M. J. (2009). Preparing the next generation of science teacher educators: A model for developing PCK for teaching science teachers. Journal of Science Teacher Education, 20, 77-93.

Allinder, R. M. (1994). The relationship between efficacy and the instructional practices of special education teachers and consultants. Teacher Education and Special Education, 17, 86-95.

American Association for the Advancement of Science. (1993). Benchmarks for Science Literacy. New York: Oxford University Press.

Anderson, C. W., \& Smith, E. L. (1987). Teaching Science. In V. Richardson-Koehler (Ed.), Educators' Handbook: A research perspective (pp. 84-111). New York: Longman.

Anderson, R. D. (1994). Issues of curriculum reform in science, mathematics and higher order thinking across the disciplines. Washington DC: US Government Printing Office.

Anderson, R. D. (1995). Curriculum reform: Dilemmas and promise. Phi Delta Kappan, 77(1), 33-36.

Anderson, R. D. (1996). Study of curriculum reform. Washington DC: US Government Printing Office.

Anderson, R. D. (1997). The science methods course in the context of the total teacher education experience. Journal of Science Teacher Education, 269-282.

Appleton, K. (2003). how do beginning primary school teachers cope with science? Toward an understanding of science teacher practice. Research in Science Education, 33, 1-25.

Ashton, P. T., \& Webb, R. B. (1986). Making a difference: Teachers' sense of efficacy and student achievement. New York: Longman.

Ball, D. (1988). Unlearning to teach mathematics. For the Learning of Mathematics, 8, 40-48.

Bandura, A. (1977). Self-efficacy. Psychological Review, 191-215.

Bandura, A. (1982). Self-efficacy mechanism in human agency. American Psychologist, 37, 122-147.

Bandura, A. (1986). Soucial foundations of thought and action: a social cognitive theory. Englewood Cliffs: Prentice-Hall, Inc.

Bandura, A. (1989). Human agency in social cognitive theory. American Psychologist, 44, 1175-1184.

Bandura, A. (1995). Self-efficacy in changing societies. New York: Cambridge University Press.

Bandura, A. (1997). Self Efficacy: The exercise of control. New York: W. H. Freeman and Company.

Bayraktar, S. (2009). Pre-service primary teachers' science teaching efficacy beliefs and attitudes toward science: The effect of a science methods course. The International Journal of Learning, 16(7), 383-396.

Berger, P., \& Luckmann, T. (1966). The Social Construction of Reality: A Treatise in the Sociology of Knowledge. Garden City, NY: Doubleday.

Berman, P., McLaughlin, M., Bass, G., Pauly, E., \& Zellman, G. (1977). Federal prgrams supporting educational change. Vol VII Factors affecting implementation and continuation. The Rand Corporation, Santa Monica, CA. 
Bhattacharyya, S., Volk, T., \& Lumpe, A. (2009). The influence of an extensive inquiry-based field experience on pre-service elementary student teachers' science teaching beliefs. Journal of Science Teacher Education, 20, 199-218.

Blank, R. K., \& Dalkilic, M. (1992). State politics on science and mathematics education. Washington DC: Council of Chief State School Officers, State Education Assessment Center.

Bleicher, R. E. (2004). Revisiting the STEBI-B: Measuring Self Efficacy in Preservice Elementary Teachers. School Science and Mathematics, 383-391.

Blum, R. W. (2005). A case for school connectedness. The adolescent learner, 62(7), 16-20.

Brand, B. R., \& Wilkins, J. (2007). Using self-efficacy as a construct for evaluationing science and and mathematics courses. Journal of Science Teacher Education, 23(1), 44/55.

Burley, W. W., Hall, B. W., Villeme, M. G., \& Brockmeier, L. L. (1991, April). A path analysis of the mediating role of efficacy in first-year teachers' experiences, reactions, and plans. American Educational Research Association. Chicago.

Bursal, M. (2012). Chages in american preservice elementary teachers' efficacy beliefs and anxieties during a science methods course. Science Educaiton International, 23(1), 40-55.

Cannon, J. R., \& Scharmann, L. C. (1996). Influence of a cooperative early field experience on preservice elementary teachers science self-efficacy. Science Education, 80(4), 419-436.

Cantrell, P. (2003). Traditional vs. retrospective pretests for measuring science teaching efficacy beliefs in preservice teachers. School Science and Mathematics, 177-185.

Cantrell, P., Young, S., \& Moore, A. (2003). Factors Affecting Science Teaching Efficacy of Preservice Elementary Teachers. Journal of Science Teacher Education, 177-192.

Carrier, S. J. 2009. The effects of outdoor science lessons with elementary school students on preservice teachers' self-efficacy. Journal of Elementary Science Education, 21(2), 35-48.

Coladarci, T. (1992). Teachers' sense of efficacy and commitment to teaching. Journal of Experimental Education, 60, 323-337.

Connell, J. P., Halpern-Felsher, B., Clifford, E., Crichlow, W., \& Usinger, P. (1995). Hanging in there: Behavioral, psychological, and contextual factors affecting whether African-American adolescents stay in school. Journal of Adolescent Research, 10(1), 41-63.

Cox, C. A., \& Carpenter, J. R. (1989). Improving attitudes toward teaching science and reducing science anxiety through increasing confidence in science ability in inservice elementary school teachers. Journal of Elementary Science Education, 1(2), 14-34.

Creswell, J. (2007). Qualitative inquiry and research design: Choosing among five traditions. Thousand Oaks, CA: Sage Publications.

Creswell, J. W., Plano Clark, V. L., Gutmann, M. L., \& Hanson, W. E. (2008). Advanced Mixed Methods Reserach Designs. In V. L. Plano Clark, \& J. W. Creswell, The Mixed Methods Reader (pp. 161196). Los Angeles: Sage Publications.

Cronbach, L., \& Furby , L. (1970). How should we measure "change" - Or should we? . Psychological Bulletin, 68-80.

Davis, E. A., Petish, D. \& Smithey, J. (2006). Challenges new science teachers face. Review of Educational Research, 76(4), 607-651.

Davis, E. A., \& Smithey, J. (2009). Beginning teachers moving toward effective elementary science teaching. Science Education, 93, 745-770. 
Denzin, N. (1989). Interpretive Interactionism. Newbury Park, CA: Sage .

Denzin, N. K., \& Lincoln, Y. S. (1994). Introduction: Entering the field of qualitative research. In N. K. Denzin, \& Y. S. Lincoln, Hanbook of Qualitative Research (pp. 1-17). Thousand Oaks, CA: Sage Publications.

Descartes, R. (1977). The essential writings. New York: Harper and Row.

Eichinger, D., \& Roth, K. J. (1991). Critical analysis of an elementary science curriculum: Bouncing around or connectedness? Institute for Research on Teaching, Michigan State University, Center for Learning and Teaching. East Lansing: Michigan State University.

Enochs, L. G., \& Riggs, I. M. (1990). Further Development of an Elementary Science Teaching Efficacy Belief Instrument: A Preservice Elementary Scale. School Science and Mathematics, 694-706.

Gee, C. J. (1996). Preservice elementary teachers: Their science content knowledge, pedagogical knowledge, and pedagogical content knowledge. National Association for Research in Science Teaching. St. Louis, Missouri.

Gibbs, C. (2002). Effective teaching: Exercising self-efficacy an thought control of action. British Educational Research Association, (pp. 1-11). Exeter, England. Retrieved April 2, 2012, from www.leeds.ac.uk/educol/documents/00002390.htm

Gibson, S., \& Dembo, M. H. (1984). Teacher efficacy: A construct validation. Journal of Educational Psychology, 76, 569-582.

Ginns, I. S., \& Watters, J. J. . (1990). A longitudinal study of preservice elementary teachers' personal and science teaching efficacy. (Reports - Research/Technical ED 404 127).

Greene, J. C., Caracelli, V. J., \& Graham, W. F. (2008). Toward a Conceptual Framework for Mixed Method Evaluation Designs. In V. L. Clark, \& J. W. Creswell, The Mixed Methods Reader (pp. 121148). Los Angeles: Sage Publications.

Guba, E. G., \& Lincoln, Y. S. . (1994). Competing paradigmsin qualitative research. In N. K. Denzin, \& Y. S. Lincoln, Handbook of Qualitative Research (pp. 105-117). Thousand Oaks, CA: Sage Publications.

Gunning, A. M., \& Mensah, F. M. (2011). Preservice elementary teachers' development of self-efficacy and confidence to teach science: A case study. Journal of Science Teacher Education, 22, 171185.

Hall, B., Burley, W., Villeme, M., \& Brockmeier, L. (1992). An attempt to explicate teacher efficacy beliefs among first year teachers. American Educational Research Association. San Francisco.

Harker, R., Gibbs, C. J., Ryan, H., Weir, K., \& Adams, D. (2000). The impact of change on teacher satisfaction, motivation, and health. New Zealand Journal of Educational Studies.

Hechter, R. 2011. Changes in preservice elementary teachers' personal science teaching efficacy and science teaching outcome expectancies: The influence of context. Journal of Science Teacher Education,22 , 187-202.

Housego, B. (1992). Monitoring student teachers' feelings of preparedness to teach, personal teaching efficacy, and teaching efficcacy in a new secondary teacher education program. Alberta Journal of Educational Research, 38(1), 49-64.

Howitt, C. (2007). Pre-service elementary teachers' perceptions of factors in an holistic methods course influencing their confidence in teaching science. Research in Science Education, 37, 41-58.

Hoy, W. K., \& Woolfolk, A. E. (1990). Socialization of student teachers. American Educational Research Journal, 27, 279-300. 
Hoy, W. K., \& Woolfolk, A. E. (1993). Teachers' sense of efficacy and the organizational health of schools. The Elementary School Journal, 93, 356-372.

Huinker, D., \& Madison, S. K. (1997). Preparing efficacious elementary teachers in science and mathematics: The influence of methods courses. Journal of Science Teacher Education, 8(2), 107-126.

Humphrey, E. (1991). Searching for life's meaning: A phenomenological and heuristic exploration of the experience of searching for meaning in life. (Doctoral dissertation). Retrieved from Dissertation Abstracts International. (51, 4051B)

Hurd, P. D. (1986). Perspectives for the reform of science education. Phi Delta Kappan, 85, 281-285.

Husserl, E. (1931). Ideas: General introduction to pure phenomenology. (W. R. Gibson, Trans.) London: George Allen and Unwin.

Husserl, E. (1967). The Thesis of the Natural Standpoint and Its Suspension. In J. Kockelmans, Phenomenology (pp. 68-79). Garden City, NY: Doubleday.

Husserl, E. (1977). Cartesian meditations: An infroduction to metaphysics . The Hague: Martinus Nijhoff.

Jang, S. (2004). Establishing the field of science education policy: In analysis of math and science initiative. Science Education International, 16(4), 345-361.

Joet, G., Usher, E. L., \& Bressoux, P. (2011). Sources of self-efficacy: An investigation of elementary school students in France. Journal of Educational Psychology, 103(3), 649-663.

Kelly, J. (2000). Rethinking the elementary science methods course: a case for content pedagogy, and informal science education. International Journal of Science Education, 22(7), 755-777.

Kelly, J., \& Ponder, G. (1997). Evolution chaos, or perpetual motion?: A retrospective trend analysis of secondary science curriculum advocacy. Journal of Curriculum and Supervision, 12, 222-245.

Kenny, J. (2010). Preparing primary teachers to teach primary science: a partnership based approach. International Journal of Science Education, 32(10), 1267-1288.

Kockelmans, J. (1967). Phenomenology: The philosophy of Edmund Husserl and its interpretation. Garden City, NY: Anchor Books.

Levitt, K. E. (2001). An analysis of elementary teachers' beliefs regarding the teaching and learning of science. Science Education, 86(1), 1-22.

Lortie, D. (1975). Schoolteacher. Chicago: University of Chicago Press.

Mallow, J., Kastrup, H., Bryant, F. B., Hislop, N., Shefner, R., \& Udo, M. (2012). Science anxiety, science attitudes, and gender: Interviews from a binational study. Journal of Science Education and Educational Technology, 19, 356-369.

Martin, K. and Reynolds, S. (1991). The learning laboratory: An ongoing conversation. The Constructivist, $11,15-20$.

Maslach, C., Jackson, S. E., \& Leiter, M. P. (1996). Maslach burnout inventory manual (3rd ed.). Mountainview, California: CPP, Inc.

McDonnough, J. T., \& Matkins, J. J. (2010). The role of field experience in elementary preservice teachers' self-efficacy and ability to connect research to practice. School Science and Mathematics, 110(1), 13-23.

McDonnough, J. T., \& Matkins, J. J. (n.d.). The role of field experience in elementary preservice teachers' self-efficacy and ability to connect research to practice. School Science and Mathematics, 110(1), 13-23. 
Moerer-Urdahl, T., \& Creswell, J. (2004). Using transcendental phenomenology to explore the "Ripple Effect" in a leadership mentoring program. International Journal of Qualitative Methods, 3(2), 28.

Morgan, D. L. (2008). Paradigms Lost ane Pragmatism Regained: Metodological Implications of Combining Qualitative and Quantitative Methods. In V. L. Plano Clark, \& J. W. Creswell, The Mixed Methods Reader (pp. 29-67). Thousand Oaks: Sage Publications.

Moustakas, C. (1990). Heuristic research: Design, methodology, and Applications. Newbury Park, CA: Sage Publications.

Moustakas, C. (1994). Phenomenological research methods. Thousand Oaks, CA: Sage Publications.

Mulholland, J., Dorman, J. P., \& Odgers, B. M. (2004). Assessent of science teaching efficacy of preservice teachers in an Australian University. Journal of Science Teacher Education, 15, 313331.

National Research Council. (1996). National Science Education Standards. Washington DC: National Academy Press.

National Research Council. (2011). National A Framework for K-12 science education: Practices, crosscutting concepts, and core ideas. Washington DC: National Academies Press.

National Science Teachers Association. (1992). The Content Core. Washington DC: National Science Teachers Association.

Pajares, F., \& Schunk, D. (2001). Self-beliefs and school success: Self-efficacy, selfconcept, and school achievement. London: Ablex.

Palmer, D. (2006). Durability of changes in self-efficacy of preservie primary teachers. International Journal of Science Education, 28, 655-671.

Palmer, D. H. (2001). Factors contributing to attitude exchange amongst preservice elementary teachers. Science Education, 86(1), 122-138.

Patton, M. Q. (2002). Qualitative Research and Evaluation Methods. Thousand Oaks, CA: Sage Publications.

Phillips, J. R. (1988). Research Blenders. Nursing Science Quarterly, 4-5.

Pines, A. M., \& Aronson , E. (1988). Career burnout: Causes and cures. New York: Free Press.

Plano-Clark, V. L., \& Creswell, J. W. (2008). The Mixed Methods Reader. Los Angeles: Sage Publications.

Plourde, L. A. (2002). The influence of student teaching on preservice elementary teachers' science selfefficacy and outcome expectancy beliefs. Journal of Instructional Psychology, 29(4), 245-253.

Raizen, S., \& Michelsohn, A. (Eds.). (1994). The future of science in elementary schools: Educating perspective teachers. San Francisco: Jossey-Bass.

Ramey-Gassert, L., \& Shroyer, M.G. . (1992). Enhancing science teaching self-efficacy in pre-service elementary teachers. Journal of Elementary Science Education, 26-34.

Ramirez Sangueza, C. (2010). Preservice teacher elementary science teaching self-efficacy and teaching practices: A mixed methods, dual phase, embedded case study. (Doctoral dissertation). Retrieved from Digital Scholarship @UNLV. (844)

Rice, D. C. (2005). I didn't know oxygen could boil! What preservice and inservice elementary teachers' answers to 'simple' science qustions reveals about their subject matter knowledge. International Journal of Science Education, 27(9), 1059-1082. 
Riggs, I. M. (1991, April). Gender differences in elementary science teacher self-efficacy. American Educational Research Association. Chicago, IL.

Ross, J. A. (1994, June). Beliefs that make a difference: The origins and impacts of teacher efficacy. Canadian Association for Curriculum Studies, (pp. 1-45). Alberta, Canada.

Rotter, J. B. (1966). Generalized expectancies for internal versus external control of reinforcement. Psychological Monographs, 80, 1-28.

Saklofske, D., Michaluk, B., \& Randhawa, B. (1988). Teacher's efficacy and teaching behaviors. Psychological Reports, 63, 407-414.

Sale, J. E., Lohfeld, L. H., \& Brazil, K. (2008). Revisiting the quantitative and qualitative debate. In V. L. Plano Clark, \& J. W. Creswell, The Mixed Method Reader (pp. 363-374). Thousand Oaks: Sage Publications, Inc.

Schoeneberger, M. (1986). Elementary science as a little added frill: A report of two case studies. Science Education, 70, 519-538.

Seidman, I. (1998). Interviewing as Qualitative Research. New York: Teachers College Press.

Shulman, L. (1986). Those who understand: Knowledge growth in teaching. Educational Researcher, 15, 4-14.

Skaalvik, E. M., \& Skaalvik, S. . (2010). Teacher self-efficacy and teacher burnout: A study of relations. Teaching and Teacher Education, 26, 1059-1069.

Skaalvik, E. M., \& Skaalvik, S. (2007). Dimensions of teacher self-efficacy and relations with strain factors, perceived collective teacher efficacy, and teacher. Journal of Educational Psychology, 99, 611625.

Smith, Q. (1981). Husserl's early conception of the triadic structure of the intentional act. Philosophy Today, 81-89.

Spiegelberg, H. (1982). The phenomenological movement. Dordrecht: The Netherlands: Martinus Nijhoff. Stepans, J. I., McClung, P. A., \& Beiswenger, R. E. (1995). A teacher education program in elementary science that connects content, methods, practicum, and student teaching. Journal of Science Teacher Education, 6, 158-163.

Stewart, D., \& Mickunas, A. . (1990). Exploring phenomenology: a guide to the field and its texts. Athens, $\mathrm{OH}$ : Ohio University Press.

Swars, S. L., \& McMunn Dooley, C. (2010). Changes in teaching efficacy during a professional development school-based science methods course. School Science and Mathematics, 110(4), 193-202.

Teddlie, C., \& Yu, F. (2008). Mixed Methods Sampling: A typology with examples. In V. L. Plano Clark, \& J. W. Creswell, The Mixed Methods Reader (pp. 199-228). Los Angeles: Sage Publications.

Thompson, A. G. (1992). Teachers' beliefs and conceptions: A synthesis of the research. In D. A. Grouws (Ed.), Handbook of research on mathematics teaching and learning (pp. 127-146). New York: Macmillan.

Thompson, A. G. (1992). Teachers' beliefs and conceptions: A synthesis of the research. In D. S. Grouws (Ed.), Handbook of research on mathematics teaching and learning (pp. 127-146). New York: Macmillan.

Tilgner, P. J. (1990). Avoiding science in the elemntary school. Science Edcation, 74(4), 421-431. 
Tobin, K., Tippins, D. J., \& Gallard, A. J. (1994). Research on instructional strategies for teaching science. In D. L. Gabel (Ed.), Handbook of research on science teaching and learning (pp. 45-93). New York: Macmillan.

Tosun, T. (2000). The beliefs of preservice elementary teachers towards science and science teaching. School Science and Mathematics, 100, 374-379.

Tschannen-Moran, M., \& Woolfolk Hoy, A. (2007). The differetal antecedents of self-efficacy beliefs of novic eand moreperientia. Teaching and teacher education, 23, 944-956.

Tschannen-Moran, M., Woolfolk Hoy, A., \& Hoy, W. K. (1998). Teacher efficacy: Its meaning and measure. Review of Educational Research, 68, 202-248.

Tuchman, E., \& Isaacs, J. (2011). The influence of formal and informal formative preservice experiences on teacher self-efficacy. Educational Psychology, 31(4), 413-433

Udo, M. K., Ramsey, G. P., \& Mallow, J. V. (2004). Science anxiety and gender in students taking general edcuation science courses. Journal of Science Education and Technology, 13(4), 436-446.

van Kaam, A. (1966). Existential foundations of psychology. Pittsburgh: Duquesne University Press.

Van Manen, M. (1990). Researching lived experience: Human science for an action sensitive pedagogy. Albany, NY: State University of New York Press.

Watters, J. J., \& Ginns, I. S. (1995, April). Origins of and changes in preservice teachers' science teaching efficacy. National Association of Research in Science Teaching. San Francisco, CA.

Wenner, G. (1993). Relationship between science knowledge levels and beliefs toward science instruction held by pre-service elementary teachers. Jouranl of Science Education and Technology, 2(3), 461-468.

Wentzel, K. R. (1998). Social relationships and motivation in middle school. Journal of Educational Psychology, 90(2), 202-209.

Windschitl, M. (2003). Inquiry projects in science teacher education: What can investigative experiences reveal about teacher thinking and eventual classroom practice? Science Education, 87(1), 112143.

Woolfolk, A. E., \& Hoy, W. K. (1990). Prospective teacher' sense of efficacy and beliefs about control. Journal of Educational Psychology, 82, 81-91.

Yilmaz, H., \& Huyuguzel Cavas, P. (2008). The effect of the teaching practice on pre-service elementary teachers science teaching efficacy and classroom management beliefs. Eurasia Journal of Mathematics, Science, and Technology Education, 4(1), 45-54. 
Appendix A

Participant Cover Letter

July 12,2012

Dear Participant,

This letter is a request for you to take part in a research project to assess science teaching efficacy beliefs and the lived experience of preservice elementary teachers. This project is being conducted by me, Karen A. Kettler, M.S. in the Department of Curriculum and Instruction at WVU, with supervision of Dr. Jeffrey S. Carver, an assistant professor in the Department of Curriculum and Instruction, for a Doctoral Degree in Curriculum and Instruction.

If you should decide to participate in this research project, you will complete four Science Teaching Efficacy Belief online surveys that should last no longer than 23 minutes. The first survey will be administered in late August, 2012 at the beginning of the Science Methods course. There will be two surveys administered at the end of your Science Methods Course in December, 2012. The fourth survey will be administered at the end of your student teaching experience in May, 2013. If you feel uncomfortable answering any of the survey questions, you are not required to answer. In addition, if you agree to participate, you may be interviewed by me, Karen A. Kettler, at approximately three time points during the course of the school year: at the beginning of the Science Methods course, at the end of the Science Methods Course, and again at the end of your student teaching experience. These interviews should last between 60-90 minutes each. The surveys and interviews will not hinder your ability to complete the course or student teaching experience, or interfere with your interactions with your peers in the class or the elementary students with whom you will be working.

As part of the course requirements for the Science Methods course and student teaching experience you will keep a reflective journal documenting your experiences. In addition, as part of your requirements in the Department of Professional Education at West Liberty University, you are required to take the Praxis II exam. If you decide to participate in my study, and you are chosen to be interviewed, would you mind if I used the information in the reflective journal and your Praxis II score as part of my research on science teaching efficacy beliefs and the lived experience of preservice elementary teachers? If you are agreeable to this, please state so in your acceptance email.

Your involvement in this project will be kept as confidential as legally possible. All data will be reported in the aggregate. You must be 18 years of age or older to participate. I will not ask any information that should lead back to your identity as a participant. Your participation is completely voluntary. You may skip any question that you do not wish to answer and you may discontinue at any time. Your class standing will not be affected if you decide either not to participate or to withdraw. West Virginia University and West Liberty University's Institutional Review Board acknowledgement of this project is on file. 
I hope that you will participate in this research project, as it could be beneficial in understanding how science teaching efficacy beliefs affect the experiences of preservice teachers, and it could help in the development of future programs that would enhance efficacy and, potentially, teaching practice. Thank you very much for your time. Should you have any questions about this letter or the research project, please feel free to contact me, Karen A. Kettler at (***)***_**** or by e-mail at kkettler@westliberty.edu or Dr. Jeffrey S. Carver at $(* * *) * * *$ ***** or by email at jeffrey.carver@mail.wvu.edu.

If you would like to take part in this research, please email me at kkettler@westliberty.edu by August 27, 2012.

Thank you for your time and help with this research.

Sincerely,

Karen A. Kettler, M.S. Assistant Professor of Biology
Jeffrey Carver, Ed.D.

Assistant Professor of Science Education 


\section{Appendix B}

Demographic survey

Participant number

Name (in full):

Gender (circle one):

Female

Male

Ethnicity (circle one):

Caucasian (non-hispanic)

Hispanic

African American

Other (Asian, Native American)

Number of previous science courses taken (circle one):

0-3 courses

4-7 courses

$8+$ courses

Previous experiences teaching (circle one):

None

Substitute / Volunteer

1-2 Teaching

Prior experience with science:

Positive Experience

Negative Experience 


\section{Appendix C}

STEBI-B survey

Please indicate the degree to which you agree or disagree with each statement below by circling the appropriate letters to the right of each statement.

$$
\begin{aligned}
\mathrm{SA} & =\text { STRONGLY AGREE } \\
\mathrm{A} & =\text { AGREE } \\
\mathrm{UN} & =\text { UNCERTAIN } \\
\mathrm{D} & =\text { DISAGREE } \\
\mathrm{SD} & =\text { STRONGLY DISAGREE }
\end{aligned}
$$

1. When a student does better than usual in science, it is often because the teacher exerted

SA A UN D SD a little extra effort.

2. I will continually find better ways to teach science.

3. Even if I try very hard, I will not teach science as well as I will most subjects.

SA A UN D SD

4. When the science grades of students improve, it is often due to their teacher having found a

SA A UN D SD more effective teaching approach.

5. I know the steps necessary to teach science concepts effectively.

SA A UN D SD

6. I will not be very effective in monitoring science experiments.

SA A UN D SD

7. If students are underachieving in science, it is most likely due to ineffective science teaching.

8. I will generally teach science ineffectively.

SA A UN D SD

SA A UN D SD

9. The inadequacy of a student's science background can be overcome by good teaching.

SA A UN D SD

10. The low achievement of some students cannot generally be blamed on their teachers.

SA A UN D SD 
11. When a low-achieving child progresses in science, it is usually due to extra attention

SA A UN D SD given by the teacher.

12. I understand science concepts well enough to be effective in teaching science.

SA A UN D SD

13. Increased effort in science teaching produces little change in some students' science

SA A UN D SD achievement.

14. The teacher is generally responsible for the achievement of students in science.

SA A UN D SD

15. Students' achievement in science is directly related to their teacher's effectiveness in

SA A UN D SD science teaching.

16. If parents comment that their child is showing more interest in science at school, it is

SA A UN D SD probably due to the performance of the child's teacher.

17. I will find it difficult to explain to students why science experiments work.

SA A UN D SD

18. I will typically be able to answer students' science questions.

SA A UN D SD

19. I wonder if I will have necessary skills to teach $\quad$ SA A UN D SD science.

20. Given a choice, I will not invite the principal to SA A UN D SD evaluate my science teaching.

21. When a student has difficulty understanding a $\quad$ SA A $\quad$ UN D SD science concept, I will usually be at a loss as to how to help the student understand it better.

22. When teaching science, I will usually welcome student questions.

SA A UN D SD

23. I do not know what to do to turn students on to science. 


\section{Appendix D}

\section{Focused Life History Interview Questions}

Purpose of interview: Create a context for the study, as I had each participant provide a detailed description of their previous experiences with science education and preservice teacher preparation.

Timeline: Late August 2012-early September 2012; beginning of Science Methods Course Potential duration: $40-60$ minutes

\section{Questions:}

1. Take a moment to think about your past experiences with science education. Please describe your past experiences with science, focusing on past experiences in school and in any other extracurricular science events, such as tutoring and participation in science fairs, as well as your past experiences with informal science education.

2. Describe your past experiences with science teachers and your peers in science classes.

3. Describe how you came to want to participate in the teacher preparation program.

4. How would you describe your ability to teach science at this time?

5. How do you believe these experiences have impacted your beliefs about science education and teacher effectiveness? 


\section{Appendix E}

\section{Post-Science Methods Course Interview Questions}

Purpose: To gain a comprehensive account of the participants' experiences with the Science Methods course; to put the experience within the context of a social setting.

Timeline: December 2012, after the completion of the Science Methods Course

Potential Duration: 60-90 minutes

\section{Questions:}

1. Take a moment to think about your experiences with the Science Methods course. Please describe your experiences within the course.

2. What incidences or people connected with the Science Methods course stand-out for you?

3. Please talk about your relationships with your teacher of the course, peers within the course, as well as students you directly worked with during your field experiences.

4. Please construct a typical day in the Science Methods course from beginning to end.

5. How did the experience of the Science Methods course affect you? What changes do you associate with this experience?

6. How did the experience affect significant others in your life?

7. What feelings were generated by the experience?

8. What thoughts stood out for you as you went through the course?

9. If you could change the Science Methods course... what would you do?

10. How do you feel about beginning student teaching in the Spring?

11. Have you shared all that is significant with reference to your experience with the Science Methods course? 


\section{Appendix F}

Epoche

My role as a researcher in this study was one of "an outsider looking in," as I was not the teacher of the Science Methods course. I recognized that I entered into this role with preconceived notions concerning some of the participants in the study and some preconceptions about elementary majors as a whole, particularly concerning the sciences. I will first address the former preconceptions.

I teach the Life Sciences for Elementary Majors course at a small state higher education institution. This course focuses mainly on life science content for preservice teachers; however, I model different science teaching techniques in order to aide in the development of pedagogical content knowledge. There are several individuals in this study who attended my Life Sciences class the year prior to the beginning of this study, so I am aware of their personalities and I have a general sense of their abilities. I am also aware that my previous interactions with these students could have influenced my interactions with them in this study. For example, there are several individuals in the study with whom I have had all positive interactions, and, at the beginning of the study, I looked forward to interviewing them. I viewed these individuals as potentially "good" students and future teachers, and I suspected that these individuals would have higher efficacy and would be more receptive to participating in my research (after the "pre" STEBI-B survey, only two of these individuals qualified for the interview portion of the study). My preconceptions regarding these individuals may not have been accurate, but I was aware of the potential influence of my perceptions on my interactions with them during the interview process. Conversely, there were several individuals in the study who struggled in my class, so I already had an idea (correct or not) of their opinions toward science and science teaching, and I 
recognized that it was possible that I, as one of their previous science teachers, contributed to some of their negative conceptions toward science and, potentially, their lower efficacy.

My more general preconceptions about elementary education majors with regard to science is that many of them do not like this field and do not want to teach science. This is based on both educational research I have conducted, as well as my own interactions with preservice elementary students throughout the nine years I have been teaching. I have noticed many students struggle with science content and find it difficult to teach science concepts using progressive strategies. I am aware that I may not have properly prepared them to do this, and have expected too much from them in my course. I have wondered if other teachers have experienced this as well, assuming student content knowledge where it was lacking.

Prior to the beginning of the study, I had concerns that students would not want to participate in my study, but would do so in order to placate me, possibly due to my role as an authority figure at the University. In addition, I was also feeling apprehensive about the interview process, because I wanted to be successful in this endeavor. Specifically, I was concerned that I would forget to ask an important question or ignore a prompt that would have led to richer data. I was also worried that the students would think the questions were irrelevant, which would cause then to give flippant answers, which would, ultimately, result in data that lacked depth.

Continued epoche during the study. I have wondered how my previous interactions with three of the interview participants affected my interviewing. After reflection, I do not think my previous knowledge of these individuals directly affected the manner in which I conducted the interviews themselves; however, I think I felt more at ease with individuals with whom I already had, at most, a superficial relationship. With one of the participants, I already knew she had a good attitude and would probably be open to answering my questions, so I felt more confident in 
conducting this interview. Since she was one of my earliest interviews, I think that help set the tone in which I conducted the other interviews. Interviewing her first helped me to think, "Okay, this will not be so bad." With the other two participants I had previously had in class, I had had less personal interactions with them, so it was almost as if they were strangers. However, I think their knowledge of me may have helped them to be more at ease, although this is just a supposition based on our interactions during the interviews. 


\section{Appendix G}

\section{Significant Statement Tables}

Table G1

Significant Statements of Participants with Low and High Efficacy Regarding the Field Experiences of the Science Methods Course.

Field experiences: low efficacy

Field Experiences: high efficacy
Significant Statements:

- When we went to the [Environmental] Center, oh my gosh, I loved that. I didn't think I would because I'm not an outdoorsy girl (Sara)

- Yeah, I loved it. I mean, I didn’t know there was so much stuff in the creeks, like animals. (Sara)

- I think it is good to see that teaching doesn't have to take place in a classroom. I think that is one of the biggest things that you see. (Sara)

- I guess it was a good experience to go out there and see the things, but to me it was just like... I've been out in the woods before...(Amy)

- I like doing that kind of stuff instead of just sitting in the classroom. I liked it, it was pretty beneficial I thought. (Cara)

- I felt like those were the best experiences in the whole class. (Jane)

- When we went to the Schrader Center we actually did what he would do with the students. (Jane)

- It [Schrader field experience was a lot of fun. And I feel like that was more useful than what we have done in the classes. (Jane)

- It [Challenger field experience] was like a real situation...It was fun. (Jane)

- Going to the Schrader Center and the Challenger Center and realizing that there's things out there to go to as well, outside the classroom; that was beneficial. (Jane)

- $\quad$ Like... us getting to actually do it, instead of just talking about it and experiencing what the kids would experience, that kind of thing. (Jane)

- We were like kids doing it, it was so much fun. (Jane)

Significant Statements:

- $\quad$ Because we had fieldtrips, and they were fieldtrips I had in grade school.... I had done in grade schoolmore than once. So, it was kind of boring in that aspect (Beth)

- It [Schrader field experience] was supposed to be very inquiry based, however, I did not find it to be because he gave us step by step directions of what to do, so we weren't really exploring on our own. (Beth)

- We went to the Challenger center-which is really cool, but I had done that probably four times before (Beth)

- [In the field experiences] we were being students, instead of taking the teacher role-which I thought would have been more beneficial since that's what we are going to do. (Beth)

- Go to the centers for teacher workshops...Do those kind of workshops rather than "you are a student and 
Table G2

Significant Statements Made by Participants with Low and High Efficacy Regarding Relationships Formed during the Science Methods Course.

- $\quad$ She [teacher] knows who we are, she kind of knows, our interests and ability level when it comes to science. (Sara)

- $\quad$ She [teacher] was like a separate entity. I guess because of that I could say that not really a close relationship. (Sara)

- So I mean I know them [peers] I guess on a personal level and a professional and when one of us has a weakness... we work well together, the four of us...I guess we...in ways that she has weaknesses I have the strengths and in ways that I have the weaknesses she has the strengths. (Sara)

- Really, unless you know the student outside you really didn't [build relationships with students], just because you would be with them and you would watch them, their class one week and then the next week you would be in the group that you would watch your peers teach and then you don't see them again except in passing. (Sara)

- The class was too big and she [teacher] was too all over the place. (Amy) 
- We never really interacted with them [students] too much. And when she [teacher] was teaching we weren't really participating, we were just watching. So, it wasn't like you were interacting with the students more than when you taught just that one time. (Amy)

- I mean I spoke to her a couple times before my lesson just to ask her, to touch base just on what they were doing, because I didn't know if we were going to follow up on what they were doing in the classroom or...she kind of just told us we could pick whatever we wanted to (Cara)

- Yeah, we are all pretty close, especially with my group that I taught with, it was... we all kind of took on our own role in preparing for our lesson. We got along really well so that worked out. (Cara)

- We all get along really well. We have been working together all year. We kind of keep our own same little groups. (Jane)

- I felt that no relationships were getting formed with the professor. (Beth)

- We formed really good relationships, especially with the group I was with-one of them was my roommate, so we already have a good relationship in that aspect. (Beth)

- But, with other classmates, it was a great opportunity to learn how to work with others that have different teaching styles from yourself because not everyone is going to teach things the same way, so it was a really good collaborative effort on how do we work with each of our personalities, yet teach one activity to a group of students, so that was really nice. (Beth)

- We really didn't have time to develop relationships with the students. (Beth)

- The class has had discussions on that as a whole. The whole class has discussed it. We will sit there and even during class...it is just those looks that you exchange.... why are we even here? (Beth)

- $\quad$...she forgot our names every week and it would get really frustrating, because apparently she gives you bonus points if you have a comment about something. So everybody would be raising their hand and she would call on you and I don't even think she would listen half of the time, because she was trying to look for our names and try to remember and then she was just like "a-huh, a-huh" and then when we were done she would go "what's your name again?" (Kate)

- I worked with same girls that I worked with for my other classes... when we started at first in block we were kind of if-y with each other. We'd had classes with each other, but it wasn't like...oh, I know you so well, but now I'd say we know each other pretty well. (Kate)

- $\quad$ TThinks relationship is necessary with students] because they need to have that trust with you and they need to know that you care and that you are not just here to work, to get your job done with and 
move on to the next day. They just need to know that you are there for them to learn and that is your number one goal. (Kate)

- She is older and I don't think she...I think she wants to be there, but I think it is a little overwhelming have her own elementary students plus us come, and, having to worry about what to do, you know? (Kate)

- I talked to her, but I'm a talkative, I'm going to make you talk to me person, but I didn't really build a relationship to get to know her really, I just knew basic who she was, got a feel for what she is from observing her, but a personal connection, not really. It wasn't the same as it would be with one of my teachers on campus. (Jenn)

- As far as like their behavior [the students] and the things that they liked and didn't like, yeah you can tell what they...but, we just sat there and watched lessons go on. (Jenn)

- I would have died without the people in my class this semester. Everybody worked together super well and we all collaborated through the whole semester. (Jenn)

- ...she [teacher] wasn't very up-to-date on like...oh, well, I'm going to put this up...I relied more on my class to tell me what was due, that kind of stuff. (Jenn)

- I know a lot of people really, really, really hated that class. (Jenn)

- I don't think that teacher is a bad teacher or that she didn't try or didn't care, I just feel like she is one of those people that is better with younger students. (Jenn)

- For me, I feel like it was harder for her to take what she does and what she knows and show us how to do that rather than show us her doing it. (Jenn)

- The kids liked her activities, she has good activities and stuff, but like, to teach us how to teach, that is where I feel like there was a disconnection between what she was trying to do. (Jenn)

- I felt like she wanted to teach us and wanted to help us, and like give us all these experiences and stuff, but it just wasn't something that she, I felt, she was comfortable doing or she wasn't used to it, I guess. (Jenn)

- Even though everyone did feel bored and they didn't really want to go to class, everyone...I think she got along with all of us really good, there were no issues there. She learned all of our names, I think that is nice. That means that she is trying to have a relationship; that she wants to know us by name. She is a very sweet person and there is a good relationship there, but I didn't necessarily learn from her. (Jamie)

- It was really good. I have worked with most of the same people on a lot of other projects this semester, so we've definitely gotten really close and we work well together and everyone, all of my group projects this semester, everyone works so well, contributes, they don't just slack off and let everyone else do all of the work..., it's been really positive. (Jamie)

- If we weren't the ones teaching, we didn't really get 
to interact [with students], we just had to sit along the wall and observe her teaching or the college students teaching. So, we didn't really get to interact with the kids very much. I wish we could have, I think that would have been really nice. (Jamie)

- If you know your students, you know how they think and what they like, than you can tailor your instruction to fit. So, that would've been helpful, but we really didn't have that opportunity. (Jamie)

Table G3

Significant Statements Made by Participants with Low and High Efficacy Regarding the Teaching Experience.

The teaching experience: low efficacy

The teaching experience: high efficacy
Significant Statements:

- I thought it went really well. I was really nervous about it... I was like oh my gosh, that's like the most boring topic ever. (Sara)

- I think if there was a way to maybe do instead of the group teaching like that...because sometimes there was like five and six people in a group and I feel like that was hard to let everyone voice certain...I think maybe an individual teach... I think I would benefit from that and plus it would help me too, because I always get nervous teaching in front of my peers, but I feel like that would have helped me better. (Cara)

- I was glad we did it in a group, because you didn't have to teach the whole time. (Amy)

- I was glad that I got to teach in the fifth grade, because some of the people that taught in other grades didn't even know their kids, didn't know what the skill level was, didn't know what they had done, didn't know what they hadn't done... how do you design a lesson for that? (Amy)

- It [the teaching experience] was fine. (Jane)

- Overall it went better than I thought, like we were concerned about time, because we had 60 minutes to do it and we've never really taught a lesson that long before. I've never really had experience above second grade, so I was nervous about that, but it did go well. (Jane)

- I feel like we don't get to pick a lot. It is her telling us what we should do...(Jane)

- The two times we did something we had to improvise. (Jane)

Significant Statements:

- I taught a lesson using the Ipads. That was really cool! It went well. (Beth)

- It was a little bit of confusion about what we were actually supposed to be teaching the students (Beth)

- My group went the second class we had ever had of the semester, so we were very...we felt very unprepared...We felt really rushed into it and everything (Jamie)

- It was the second week of classes that we had to do that, so we had the first class...ever... and the next week she told us that we were teaching. So, we had one week to get everything ready. We had absolutely no experience with those kids and really none with our professor either. We didn't really know what she expected and everything. And, I don't know... that 
made it so difficult. (Jamie)

- I think it was good for me to actually teach children strictly a science lesson. Yeah, I'm glad that we had to do it, I just wish that we would've been better prepared. I think it was helpful to do it for that experience. (Jamie)

- We would've just done teachings throughout, like we are doing at West Liberty elementary with our math...every other week we are doing an activity with the students with math. So if we could've done that for science, it would've been awesome, I would've gotten a lot out of that. (Jamie)

- She was really good about taking our suggestions...she actually redid that lesson and said it went a lot better. (Beth)

- We just don't listen because she never gets our attention and there is no management involvedwhich is how I felt it went. (Beth)

- It went really well. I was surprised by how much the kids knew already and they were inquisitive. (Kate)

- It went well...they liked it, being outside, separating stuff, they had all kinds of good answers. (Jenn)

- I was really surprised by a lot of the things, the way that they had answered questions was shocking to me, because they knew a lot (Jenn)

Table G4

Significant Statements Made by Participants with Low and High Efficacy Regarding the Experience of Watching Teacher and Peers' Lessons (teaching models).

Significant Statements:

- Within the actual classroom component, the teacher did do a lot of activities that I thought were really cool. (Beth)

- I think the lesson would have went a lot better if she had had more classroom management. (Beth)

- When would watch our other classmates teach, I feel like we got a lot from it, because you learn...the way I would teach something and the way someone else would teach something is so different. (Beth)

- As far as her teaching the kids, that was better for me than her teaching us. (Amy)

- Some of the things that she did with the kids was good... When she was interacting with the students it was ok, but afterwards it was not good. (Amy)

- It is great to see how my peers teach, but then maybe she could take it and say, "When I do this, here is what I do." I think that is what I would benefit from. (Amy)

- $\quad$...to see their ideas and what they come up with and some of the lessons have been really awesome (Cara)

- A lot of it was just we would watch her teacher her fifth grade or fourth grade class (Jane)

- We just sat there and watched lessons go on. (Jenn)

- When we were in that [Science Methods] classroom, it was more like, still seeing...I'm taking what someone else is doing, more observing, more second-hand, more than like actually doing, like 
experiencing that stuff. (Jenn)

- In that [Science Methods] class, it made me feel like we were not as involved. (Jenn)

- I don't think that the teacher that we had even really had control over the classes that we saw her teaching, because we would actually watch her teach classes too, with her students, mainly the fourth and fifth graders. They just kind of were wild the whole time. I mean, I felt like, why is this person telling us how to teach? I didn't really get much from it. (Jamie)

- $\quad$ But, the class itself, just going and sitting and watching her teach or watching my fellow students teach, I didn't think that was helpful. (Jamie)

- Not to say that the teacher was not a nice person, she was very nice, very easy to get along with, very friendly; she just didn't really give us a lot of useful information. I know everybody in the class feels this way. (Jamie)

Table G5

Significant Statements Made by Participants with Low and High Efficacy Regarding the Experience of Being Taught by the Science Methods Course Teacher.

- I just think she has hit her wall and she is kind of over it and maybe she just doesn't know how to relate her stuff back to us, because there are times when it is ok if you want to do "ok you are the student now," but then teach to us like you are teachers. (Amy)

- $\quad$ She gave us those types of ideas and those were I thought kind of useful that I could use in the future (Cara)

- ...she will give us some sort of classroom activity, but they are not very useful...I don't even remember some of the things that we've done. (Cara)

- Truthfully, I feel like I didn't learn what I wanted to learn. (Jane)

- She might talk about one or two things that we have already heard of, so it was just like...it seemed really repetitive, it wasn't a lot of new information. (Jane)

- More instruction from her about what we could do. Like more strategies and things to use. I feel like we just watched her do a lesson and that was it. (Jane)

- $\quad[\mathrm{I}]$ just feel like we didn't learn enough strategies (Jane)

- The class could have been better geared for ways to teach science (Beth)

- We weren't getting what we needed. It needs to be more geared towards teachers, how to teach science, what strategies to use with your students. (Beth)

- We just don't listen because she never gets our attention and there is no management involvedwhich is how I felt it went. (Beth)

- I didn't feel like she had very good group communication. (Beth)

- It was stuff that was common sense that we've 
learned in my other block classes. (Kate)

- I feel that even though we are in college, we need to be taught how elementary students are taught, like the hands on stuff, because it is a better understanding. Like, if we do group work or something I can remember it, but if we are just sitting there and she is just lecturing, it just doesn't sink in. (Kate)

- A couple times we did different activities that she would have done with her students... We did as if we were students, so she had done that with her students before that. (Jenn)

- $\quad$ Each class then basically she would have some kind of PowerPoint or some kind of little thing to kind of talk about- just random science-y stuff. (Jamie)

- It is frustrating. It is very frustrating. I just feel like...maybe she does have a lot of really good strategies and ideas, but I don't think she communicated them those to us very well. (Jamie)

- Some of the things that she talked about were completely things we've already learned, a review of things we already know enough about, like learning centers and things like that. She didn't elaborate and give us any new information, so it was just boring. (Jamie)

- Mostly strategies, like the learning centers...I'm trying to remember... It was just one of those things where you are just so bored that you are trying so hard to pay attention. (Jamie)

- Because, I don't have any hard feelings toward the teacher or anything like that, just this feeling of like not being satisfied by what I got from that and just the boredom. (Jamie)

- I would've liked to have had a little more content coverage... along with strategies and maybe if she could've put the two together and say well these are some really good ideas for how to teach this certain topic and it works really well because I've done it a bunch of times, you know. If she could've given us more examples like that, I think that would've been so much more helpful, but there was really no connections like that at all. (Jamie)

Table G6

Significant Statements Made by Participants with Low and High Efficacy Regarding Experiences with Assessments.

Assessments: low efficacy
- $\quad$...if I was grading you [peers] for real, I would not have liked all of the things that you did, but I just said, good, good, good, checkmark, and I was done. (Amy)

- I mean there was one point where we sat and watched our peers teach for 20 minutes and she was not in the room, so how can she judge whether that was good or not? (Amy)

- But she doesn't grade any of those hard, she just says "Thanks for the effort," so it is fine. (Amy) 
- So how do I go to my kindergarten class and teach science when I didn't see it? I didn't get any strategies...I didn't...nothing (Amy)

- She kind of says everyone did a great job and the whole class puts in their two cents at the end and tells them what they could've done better to improve their lesson. (Cara)

- She grades them and she'll give us not much feedback. She just says good job your paper was great and that is it. So, I feel like I talk to other people in the class and we weren't sure exactly what we were supposed to be writing on because the directions weren't very clear. (Cara)

- She is really not seeing everyone's [lesson]...you know...she doesn't get to spend the entire time with them and watching them teach their lessons (Cara)

- I would want her feedback, but her feedback is...I mean we all...I got a $96 \%$ on mine, my entire group did so...(Cara)

- It was a very easy course. I don't feel like it was challenging... but this one has just been a breeze compared to everything else I've had to do this semester. I feel like it being science, it should be... it should be pretty challenging. (Cara)

- She was not in ours for very long. She was there for five or ten minutes that I saw her in there, and she was the one to grade us. (Beth)

- This one didn't take a lot of my time I didn't really feel like, because it was stuff I was already comfortable in, so I kind of flew through the activities. (Beth)

- This one I don't think had near as much work [as the other block courses] and I don't think it was as meaningful work (Beth)

- It [assignment to read book] didn't capture my attention in any way, shape or form. That book I felt like was a waste of my time than anything else, because all we did was write a paper about it, we didn't discuss it in class or anything or use it or apply it (Beth)

- We had to create our lesson plan, but other than that there haven't been a whole lot of out of class assignments. A couple writing assignments that didn't really affect me, so I don't really remember them even. (Beth)

- She wasn't even there to watch ours [lesson]. (Kate)

- If I am doing something wrong I want to know, so I can improve and that didn't happen so...(Kate)

- I got like a sentence [of feedback]. (Jenn)

- Compared to other courses I had this semester I felt that that class was probably one of the easier ones because we only had one lesson and then a couple easy assignments (Jenn)

- I think that they don't have a purpose. Maybe if she had explained her intentions with the assignment I would have understood that more (Jamie)

- I don't think it had a really huge effect on me just because I didn't get a whole lot out of it (Jamie) 
- I mean it wasn't like a stressful course. It wasn't something I was going home and freaking out about... we didn't really have lengthy assignments. (Jamie)

Table G7

Significant Statements Made by Participants with Low and High Efficacy Regarding Perceptions of Science Teaching Efficacy. Perceptions of efficacy: low efficacy Significant statements:

- I don't want to say I feel like I'm going to go out and blow up science and be amazing at it, but at the beginning of the semester, I felt like I was like "if I teach science I'm screwed." But now I feel like, "yeah, I'm going to have to work really hard at it,".. but I don't feel like I will be a complete failure at it anymore, I guess. (Sara)

- I feel like at the beginning of the semester, being very, very nervous, because science is not my thing. But I think that as time goes on, yeah, I think eventually you come to a point where you are reading, you are doing this, you are doing that. It all comes together and it is like relief when it is over...but you...it is relief, but $\mathrm{I}$ have a lot of pride that...I don't think I'm going to fail. (Sara)

- It is a little bit more than when I started, so I guess that's good. (Amy)

- I've always been a little weak with the science background and I do want to learn how to teach it better and she [placement teacher for student teaching] just has all these ideas...I am just depending on my student teacher that I am placed with to help me with my science. I am thankful that she is very into it, so that is where I am going to get most of my help from. (Cara)

- I think it did (increased her confidence), I definitely think it did. I mean, I've never really done anything with science. (Cara)

- I feel more confident about things, but it is still kind of like in between. I feel like I could have gotten a lot more from it. (Cara)

- I guess I wouldn't say I feel less confident. I wouldn't say I feel a ton more confident, but I feel a little bit more confident. (Jane)

- I don't know that it really changed it (her confidence in teaching science) all that much, because I'm pretty confident in my science abilities. (Beth)

- I don't think the class had all that great of an impact on it [confidence in teaching science], because I felt more of the time that I was the student, rather than going into the teacher role, if that makes sense. I still felt like that student rather than learning to teach it. I needed more teaching strategies rather than to sit and how to be a student. (Beth)

- Maybe a little better[confidence in teaching science], just because I got that experience to teach science that one time (Kate)

- About the same [confidence in teaching science]... It is not how well I think I would teach it, but now I know that I've actually done a lesson and it is not 
like super stressful for me to have to find material or help or resources, or things like that. (Jenn)

- I personally didn't get a lot from the class. I don't think it really prepared me to teach science very well. (Jamie)

- I feel like in a way it made me nervous about teaching science because I feel like if she can't even tell us how to teach science, and she has been doing this for I don't know how many years, she said like 30 years or something she has been teaching. (Jamie)

- [Confidence in teaching science] probably about the same. I still have the background knowledge from my other classes... A lot of content and teaching practice and that has helped me a lot more than this course. (Jamie)

- So, I still have that background knowledge and I mean...I'm not really strong in science, but I find it very interesting and I'm always interested in learning new things, so I feel like I can still teach science to elementary students. I know I can, but I just have a little bit of a nervousness about it, still, that hasn't gone away over the semester, which I was kind of hoping it would. (Jamie) 